\title{
PRINCIPALS' COLLECTIVE EFFICACY BELIEFS AND TEACHERS' PERCEIVED OPPORTUNITIES FOR INVOLVEMENT IN DECISION MAKING
}

\author{
A Dissertation \\ Presented to \\ The Faculty of the Curry School of Education \\ University of Virginia \\ In Partial Fulfillment \\ of the Requirements for the Degree \\ Doctor of Philosophy \\ by \\ Ilon Bryce Weeldreyer, B.M., M.M.
}

May 2014 
(C) Copyright by

Ilon Bryce Weeldreyer

All Rights Reserved

May 2014 


\section{PRINCIPALS' COLLECTIVE EFFICACY BELIEFS AND TEACHERS' PERCEIVED OPPORTUNITIES FOR INVOLVEMENT IN DECISION MAKING}

\section{WEELDREYER, Ilon B.}

The University of Virginia, May 2014

Chair: James P. Esposito

The purpose of this study was to determine the extent to which principals' beliefs (collective efficacy beliefs) about teachers contributes to the variability in teachers' perceived opportunities for involvement in decision making over and above that explained by school size, principal's years of experience, and teachers' years of experience. In order to achieve the purpose of the study, answers to the following research questions were sought:

1. To what extent do principals' total collective efficacy beliefs account for variability in teachers' opportunities for involvement in decision making over and above that explained by school size, principal's years of experience, and teachers' years of experience?

2. To what extent does group competence account for variability in teachers' opportunities for involvement in decision making over and above that explained by school size, principal's years of experience, and teachers' years of experience?

3. To what extent does task analysis account for variability in teachers' opportunities for involvement in decision making over and above that explained by school size, principal's years of experience, and teachers' years of experience? 
This was a descriptive-correlational study. Data was collected from 23 elementary schools in three contiguous districts of a Midwestern state. Quantitative data was collected using survey methodology. The independent variables of interest, principal's total collective efficacy beliefs about teachers and its constructs of group competence and task analysis, were measured using the Goddard Collective Efficacy Scale Short Form. The principal survey also collected data for the independent control variables of school size and principal's years of experience. The dependent variable, teachers' perceived opportunities for involvement in decision making, was measured by the Russell Teacher Involvement and Participation Scale. The teacher survey also collected data for the independent control variable of teachers' years of experience.

In order to answer the research questions, hierarchical multiple regression was used. The findings of the study suggested that principal's collective efficacy beliefs accounted for variability in teachers' perceived opportunities for involvement in decision making over and above that explained by school size, principal's years of experience, and teachers' years of experience. Overall collective efficacy beliefs accounted for the greatest amount of variability and had a statistical significance of $p=.01$. The construct of task analysis accounted for less variability and had a statistical significance of $\mathrm{p}=.06$. The construct of group competence accounted for the least amount of variability and had a statistical significance of $\mathrm{p}=.14$.

The findings of the study suggest that the direction of the relationship between principals' collective efficacy beliefs and teachers' perceived opportunities for involvement in decision making is a negative one. This is contrary to the study's 
conceptual framework. Future research may provide better understanding of this relationship before implications for practitioners are given. 


\author{
Leadership, Foundations, and Policy \\ Curry School of Education \\ University of Virginia \\ Charlottesville, Virginia
}

\title{
APPROVAL OF THE DISSERTATION
}

This dissertation, "Principals' Collective Efficacy Beliefs and Teachers' Perceived Opportunities for Involvement in Decision Making," has been approved by the Graduate Faculty of the Curry School of Education in partial fulfillment of the requirements for the degree of Doctor of Philosophy.

James Esposito, Chair

Daniel Duke, Committee Member

Daniel Player, Committee Member

Timothy Konold, Committee Member

Date 


\section{DEDICATION}

I dedicate this work to my parents, Jim and Sue, to my brothers and sisters, Dirk, Darrah, Seth, Tallis, Amity, Misten, and Kia, to Gaia, to Jeff, to Jimmy the owl, and to Mike the dog. All of you are what I think of when I think of happiness, and at the end of my degree, I am happy. 


\section{ACKNOWLEDGEMENTS}

Aaron Laushway, thank you for being a friend and collaborator during my time at the University.

Walt Heinecke, for being there when I needed you and for your openness and understanding.

Francis Huang, I looked forward to every class and found your instruction helpful to my research.

The late Don Ball, I appreciated how you cared to make your students feel intelligent, especially when they felt uncomfortable or confused.

Sheilah Sprouse, for your wonderful assistance not only to me but to all students who pass through the Curry School.

The members of my dissertation committee, Tim Konold, Dan Duke, and Dan Player for their thoughtful and helpful input.

The chair, Pam Tucker for her help through the entire process and for her interesting coursework.

My mate, Gaia Read.

My best friend, Jeff Schultz, who gave me encouragement.

My parents, Jim and Sue Weeldreyer, for raising me the way they did and for their support during my degree.

Finally, my advisor and dissertation chair, Jim Esposito. Your patience and guidance are what made the completion of my degree possible. 


\section{TABLE OF CONTENTS}

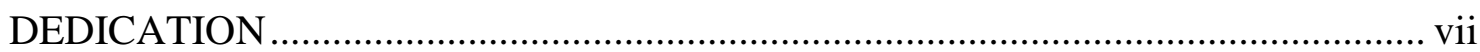

ACKNOWLEDGEMENTS ......................................................................... viii

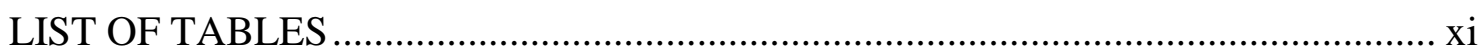

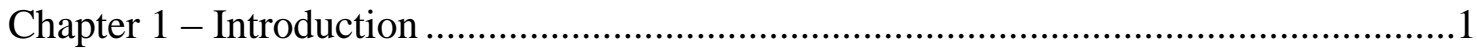

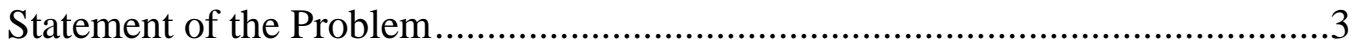

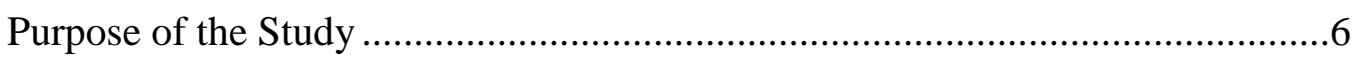

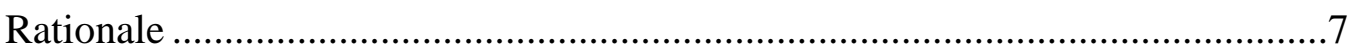

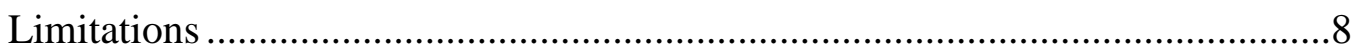

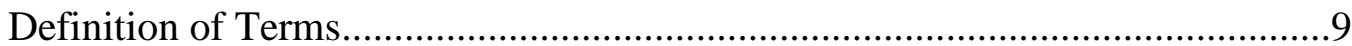

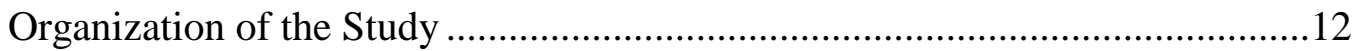

Chapter 2 - A Review of Literature ................................................................ 13

Involvement in Decision Making ...............................................................13

Leadership in Schools ..........................................................................22

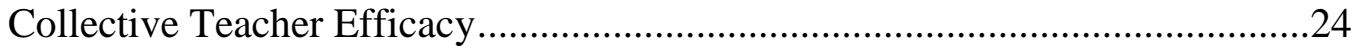

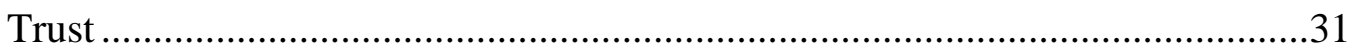

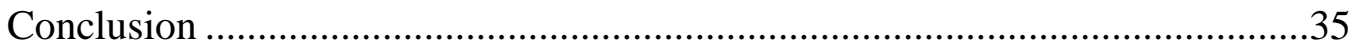

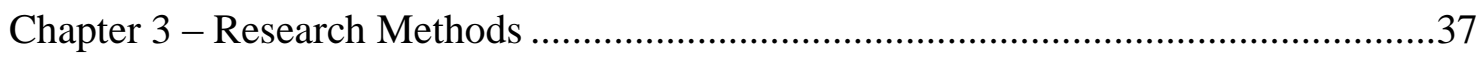

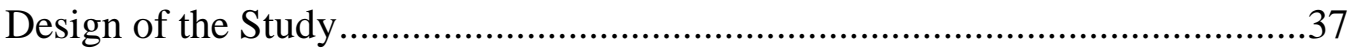

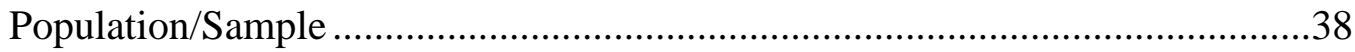




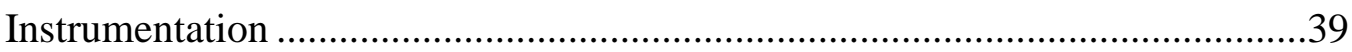

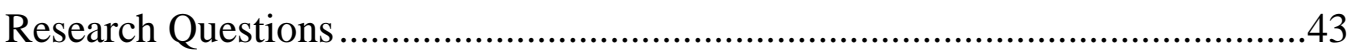

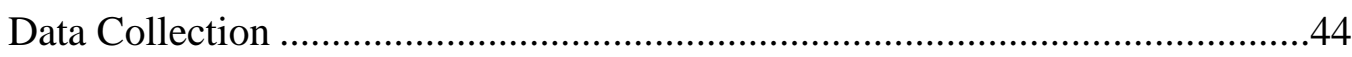

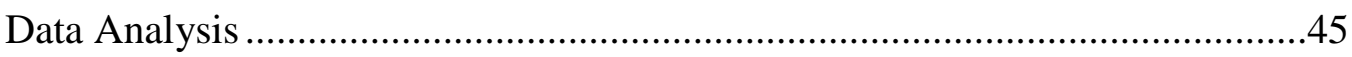

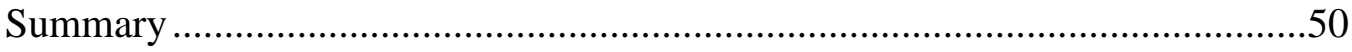

Chapter 4 - Presentation and Analysis of Data ………….........................................

Descriptive Statistics.........................................................................................

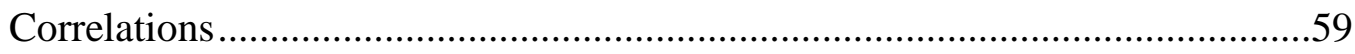

Regression Analyses …………………….....................................................61

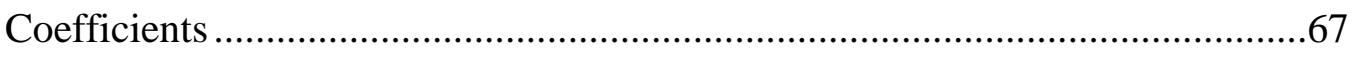

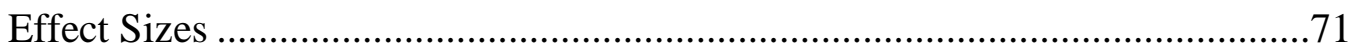

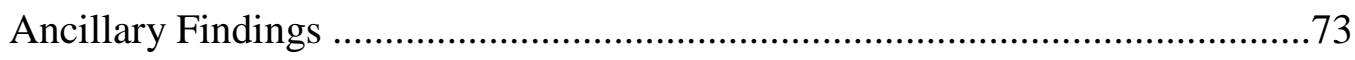

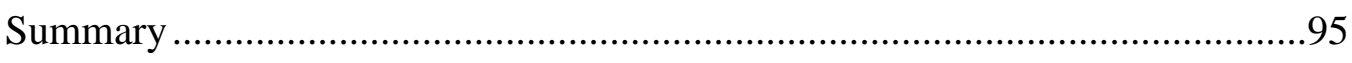

Chapter 5 - Summary and Conclusion …………………..........................................

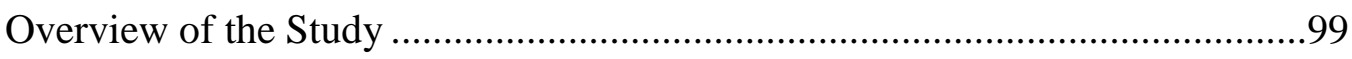

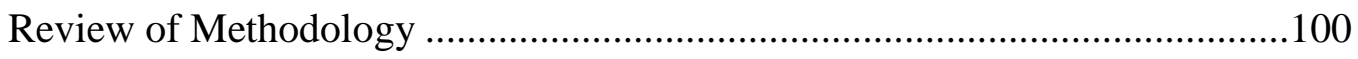

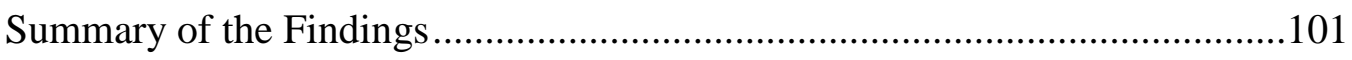

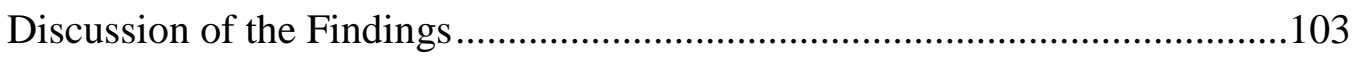

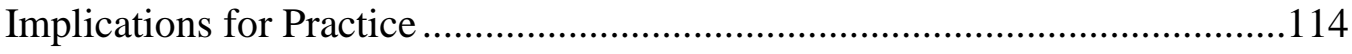

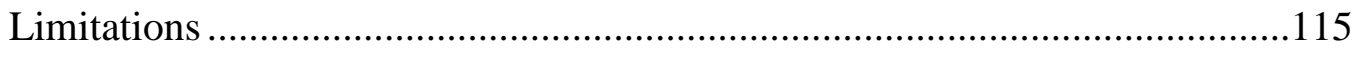

Recommendations for Future Research ........................................................117

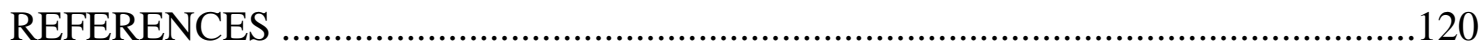

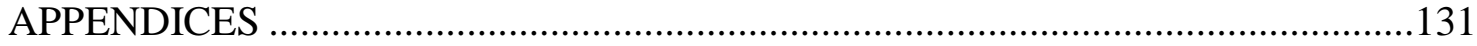




\section{LIST OF TABLES}

Table

Page

3.1 Participating Teacher Response Rates .......................................................46

3.2 Teacher Response Rates by School ................................................................46

4.1 Descriptive Statistics for the Dependent Variable ...........................................53

4.2 Descriptive Statistics by School for the Dependent Variable ................................54

4.3 Descriptive Statistics for the Independent Control Variables ...............................55

4.4 Descriptive Statistics by School for the Independent Control Variables ..................56

4.5 Descriptive Statistics for the Independent Variables of Interest...........................57

4.6 Scores by School for the Independent Variables of Interest................................58

4.7 Correlation Matrix for Dependent and Independent Variables.............................59

4.8 Regression - Variability in DM Explained by CEB.........................................62

4.9 Regression - Variability in DM Explained by GC ............................................64

4.10 Regression - Variability in DM Explained by TA .........................................66

4.11 Regression - Variability in DM Explained by GC and TA...............................67

4.12 Coefficients for the Full Prediction Model of CEB ...........................................68

4.13 Coefficients for the Full Prediction Model of GC .......................................69

4.14 Coefficients for the Full Prediction Model of TA ......................................... 70

4.15 Coefficients for the Full Prediction Model of GC+TA.....................................71

4.16 Effect Sizes for the Independent Variables of Interest ...................................72

4.17 Test of Statistical Power ........................................................................ 73

4.18 Correlation Coefficients with the Inclusion of DMSD ...................................74

4.19 Regression - Variability in DMSD Explained by GC ....................................76 
4.20 Coefficients for the Full Prediction Model of GC on DMSD .77

4.21 Descriptive Statistics for Areas of Decision Making..........................................78

4.22 Descriptive Statistics by School for Areas of Decision Making..........................79

4.23 ANOVA of the Seven Areas of Decision Making .......................................... 80

4.24 Tukey Post Hoc Test for the Seven Areas of Decision Making ..........................82

4.25 Correlation Coefficients with the Inclusion of DMSETA and DMSETB ............83

4.26 Regression - Variability in DMSETA Explained by CEB ...............................85

4.27 Coefficients for the Full Prediction Model of CEB on DMSETA .......................86

4.28 Regression - Variability in DMSETB Explained by CEB …...........................87

4.29 Coefficients for the Full Prediction Model of CEB on DMSETB .......................88

4.30 Regression - Variability in DMSETB Explained by TA .................................90

4.31 Coefficients for the Full Prediction Model of TA on DMSETB .........................91

4.32 Regression - Variability in DMSETA Explained by TA .................................92

4.33 Regression - Variability in DMSETA Explained by GC .................................94

4.34 Coefficients for the Full Prediction Model of GC on DMSETA.........................95 


\section{Chapter One}

Introduction

The National Commission on Excellence in Education drafted a Nation at Risk in 1983, calling for efforts to improve public schools' academic standards and accountability. A rationale was given to reform the nation's educational system in fundamental ways (Tyack \& Cuban, 1995). A more recent document, Goals 2000: Educate America Act (1994), established a set of eight goals ranging from "All children in America will start school ready to learn" and "The high school graduation rate will increase to at least 90 percent" to "United States students will be first in the world in mathematics and science achievement." In 2002, the No Child Left Behind Act of 2001 was enacted: "To close the achievement gap with accountability, flexibility, and choice, so that no child is left behind" (p. 1425). NCLB set regulations and guidelines for public schools to reach 100 percent proficiency in reading and mathematics by the year 2014 . While each of these legislative actions was taken with the hope that completion would be attained, the educational reform movement in the United States seems to be ever evolving.

There are many factors associated with school outcomes. Related student characteristics include socio-economic status, ethnicity, and race (Viadero, 2009). Factors such as teacher empowerment (Marks \& Louis, 1997), teacher efficacy (Ashton \& Webb, 1986; Bandura, 1997), and motivation (Ashton \& Webb, 1986) are related 
classroom factors. School-level factors include school leadership (Fullan, 2003) and collective teacher efficacy (Goddard, 2001).

Teacher morale, dissatisfaction, and motivation are factors associated with teacher performance and retention (Darling-Hammond, 2003; Sass, Seal, \& Martin, 2010). These factors are important for maintaining and improving the level of achievement in schools. Ways in which school leadership can hope to affect teacher morale, dissatisfaction, and motivation deserve attention. School reform revolving around school leadership and teacher involvement in decision making is one valuable approach (Taylor \& Bogotch, 1994). The amount to which teachers are offered opportunities to be involved in decision making is associated with school outcomes such as teacher retention, dissatisfaction, motivation, and morale (Darling-Hammond, 2003; Sass, Seal, \& Martin, 2010).

As an important aspect of teacher-related outcomes, the variability in teacher involvement and participation in decision making has continued to be researched (Conley, 1991; Rice \& Schneider, 1994; Conway \& Calzi, 1995, Marks \& Louis, 1997, 1999; Hoy \& Sweetland, 2000; Somech, 2002; Goldstein, 2004; Bogler \& Somech, 2004; Wahlstrom \& Louis, 2008; Weiner, 2011; Jackson \& Marriott, 2012). Research has suggested several factors relate to teacher involvement in decision making. School level proves to be a significant factor in predicting levels of teachers' involvement in decision making (Mohrman, Lawler, \& Mohrman, 1992). School size and principal's seniority have also been found to affect variability in teachers' participation in decision making (Rosenblatt \& Somech, 1998; Somech \& Drach-Zahavy, 2000; Somech, 2002). 
The principal's role is an important one, as principals are responsible for instructional and transformational leadership (Printy, 2010). Somech (2002) suggests that principals' leadership styles are based on their values and beliefs. Whether or not principals choose to involve teachers in decision making relies upon the principals' beliefs about teachers. Hallinger (2011) also states that the ways in which principals exercise their leadership is moderated by personal characteristics. Specifically, the author lists personal values, beliefs, knowledge, and experience of leaders as sources of variation in leadership practice (Hallinger 2011, p. 127). Part of principals' behavior is based on judgments of teachers' competence (Tschannen-Moran, 2004). One set of these beliefs about teachers' competence and skill is collective efficacy beliefs (Goddard, Hoy, \& Hoy, 2000).

Statement of the Problem

Across the nation educational organizations are looking for ways to improve school outcomes. School communities are under increasing pressure to meet expectations. The demand levied on schools was summarized by Smylie (2010):

Schools must change in fundamental ways in order to perform effectively in this future. They must become more flexible and adaptive, better able to deal with increasing complexity and ambiguity, more proactive than reactive, and reoriented toward different objectives. As change accelerates around them and as demands on them intensify, schools must begin to move and keep moving. They must improve and keep improving (Smylie, 2010, p. 2). 
It is a difficult time in education as teacher motivation, morale, and retention are ongoing significant problems facing schools as they try to meet expectations (Skaalvik \& Skaalvik, 2011). Teachers are leaving the profession at significant rates, leaving schools with setbacks such as vacancies and turn over. In the United States, twenty-five percent of teachers leave the profession by their third year, and forty percent of teachers leave within the first five years (Chang, 2009). Factors leading to teachers' exit from the profession include low morale, dissatisfaction, and burn out (Evans, 1998; Whitaker, Whitaker, \& Lumpa, 2009).

One of the approaches toward meeting these needs of teacher-related outcomes is based on involving teachers in decision making, which improves teacher retention, job satisfaction, motivation, and morale. Teachers with less empowerment have lower morale and higher levels of dissatisfaction. In order to reduce dissatisfaction and improve morale, administrators need to foster teacher participation in decision making and provide teachers with opportunities for professional growth (Darling-Hammond, 2003; Sass, Seal, \& Martin, 2010). Teachers are more likely to stay in schools and have greater satisfaction when they have opportunities for contribution to school-wide decision making. Examples of opportunities include decisions such as scheduling, selection of materials, and professional development (Boyd, Grossman, Ing, Lankford, Loeb, \& Wyckoff, 2011).

Variability continues in regard to the level of teachers' involvement in decision making (Conley, 1991; Rice \& Schneider, 1994; Marks \& Louis, 1999; Bogler \& Somech, 2004; Wahlstrom \& Louis, 2008). The variability is present in educational research foci such as shared decision making (Conway \& Calzi, 1995; Leech, 1999; 
Streck, 2009), participative decision making (Somech \& Wenderow, 2006; Somech, 2010), participative management (Somech, 2002; Benoliel \& Somech, 2010), distributed leadership (Goldstein, 2004; Heck \& Hallinger, 2010; Jackson \& Marriott, 2012), schoolbased decision making (Ferris 1992; Newcombe \& McCormick, 2001), empowerment (Marks \& Louis, 1997, 1999; Hoy \& Sweetland, 2000), collective leadership (Leithwood \& Mascall, 2008), and teacher-leaders (Gigante \& Firestone, 2008; Weiner 2011).

In some places there is high involvement of teachers in decision making, while in other places there is low involvement of teachers in decision making. Investigation is needed on potential factors associated with this disparity. While the dimensions and constructs of teacher involvement in decision making are well established, there is less known of the variables that could be considered antecedents to teachers' involvement in decision making. Based on a review of literature, some factors have been found as contributors to the variability such as school size, school level, and principal seniority. Another factor that may be associated with variability in teachers' involvement in decision making is principals' beliefs.

Leader behaviors affect group processes and in turn affect performance outcomes. Leaders decide whether to delegate responsibilities and offer opportunities for teachers to be involved in decision making based on judgments about teachers' skills and knowledge. This notion is supported by research on leaders showing that leaders' leadership styles and behaviors are based on their values and beliefs (Hackman, 2005).

There appears to be little research addressing the specifics of principals' beliefs in regard to delegating and involving teachers in decision making. There are many ways of defining principal beliefs, one of which is collective efficacy beliefs. After a review of 
literature, there appears to be little research evidence concerning the relationship between principals' collective efficacy beliefs about teachers and involvement of teachers in decision making.

\section{Purpose of the Study}

The purpose of this study was to determine the extent to which principals' beliefs (collective efficacy beliefs) about teachers contributes to the variability in teachers' perceived opportunities for involvement in decision making over and above that explained by school size, principal's years of experience, and teachers' years of experience. In order to achieve the purpose of the study, answers to the following questions were sought:

\section{Research Question 1}

To what extent do principals' total collective efficacy beliefs account for variability in teachers' opportunities for involvement in decision making over and above that explained by school size, principal's years of experience, and teachers' years of experience?

\section{Research Question 2}

To what extent does group competence account for variability in teachers' opportunities for involvement in decision making over and above that explained by school size, principal's years of experience, and teachers' years of experience? 


\section{Research Question 3}

To what extent does task analysis account for variability in teachers' opportunities for involvement in decision making over and above that explained by school size, principal's years of experience, and teachers' years of experience?

\section{Rationale}

This study was intended to contribute to the body of research regarding principals' collective efficacy beliefs about teachers and its relationship with teachers' perceived opportunities for involvement in decision making. It is hoped that the results of this study might expand the knowledge base and provide information for educators, administrators, and academia concerning the nature of leader-follower relationships in educational organizations. Findings of the study may have implications for further research regarding principals' leadership beliefs, principals' beliefs about teachers, or teachers' involvement in decision making. New areas of research not yet explored may find use of this study's findings.

The results of the study may be of help when trying to impact teacher-related outcomes related to teachers' involvement in decision making, such as motivation, morale, and retention. This may have implications for practicing educators. If the findings of this study can impact an antecedent of teachers' involvement in decision making, they may indirectly impact teachers' involvement itself. If principals' are ineffective when trying to improve teacher outcomes, this study's findings may be of 
help. Once more is understood about principals' collective efficacy beliefs about teachers, strategies could potentially be identified for changing principals' ineffective behaviors.

There are a number of ways in which the findings from this study may affect principals' beliefs and behaviors. Professional development can be enhanced through knowledge of principals' beliefs and associated behaviors. Pre-service training for principals and in-service workshops could make use of this study's findings. Preparation for administrators at the university level might include the details surrounding the relationship between principals' collective efficacy beliefs and opportunities for teachers to be involved in decision making.

As information is still sought on ways to impact teacher-related outcomes, research must continue to address the variability in teachers' perceived opportunities for decision making. The use of information from this study and the implementation of resultant strategies may help to impact the problem of variability in teachers' involvement in decision making. Impacting the problem of variability in teachers' involvement in decision making may in turn impact teacher-related outcomes.

\section{Limitations}

The limitations of this study are important to consider before attempting to generalize the results between populations. Limitations include in the following:

1. Findings are relevant to the population studied and should not be generalized to other populations. 
2. The findings of the study must be considered in regard to the validity and reliability of the measurements used: the Goddard (2002) Collective Efficacy Scale Short Form and The Russell (1992) Teacher Involvement and Participation and Scale (TIPS).

3. The definitions of terms limit the operational implications of the study.

4. The findings must take into account the lack of random selection and its limitation of generalizability.

5. There are many factors that may account for variability in teachers' perceived involvement in decision making. This study controlled for only 3 of those factors. The study was unable to control or account for all possible factors and this inability must be taken into consideration when examining the results.

6. The voluntary participation of respondents may not allow for a true reflection of principals' collective efficacy beliefs about teachers or teachers' perceived opportunities for involvement in decision making.

\section{Definition of Terms}

For the purpose of this study, the following definitions of terms were used for collective efficacy beliefs and its constructs, decision making and its areas, and control variables:

1. Principals' total collective efficacy beliefs (PCEB): was be defined by the total score on the Goddard (2002) Collective Efficacy Scale Short Form. 
2. Principals' collective efficacy beliefs of Task Analysis (TA): The task analysis construct was defined by the mean score derived from items $6,7,8,10,11, \& 12$ on the Goddard (2002) Collective Efficacy Scale Short Form.

3. Principals' collective efficacy beliefs of Group Competence (GC): The group competence construct was defined by the mean score derived from items $1,2,3$, 4, 5, \& 9 on the Goddard (2002) Collective Efficacy Scale Short Form.

4. Teacher involvement in decision making (DM): Total decision making was defined by the score from all items on the Russell (1992) Teacher Involvement and Participation Scale (TIPS).

5. Decision making subset A (DMSETA) was defined as the total mean score of decision-making areas goals/vision/mission (GVM), standards (STD), curriculum and instruction (CI), and staff development (SDEV).

6. Decision making subset B (DMSETB) was defined as the total mean score of decision making areas budget (BDGT), staffing (STFF), and operations (OPER).

7. Decision making standard deviation (DMSD) was defined as the standard deviation of teachers' overall mean scores within the school on the Russell (1992) Teacher Involvement and Participation Scale (TIPS).

8. Goals/Vision/Mission (GVM): Teachers' involvement in decision making with goals, vision, and mission was defined by the score derived from items 1-4 on the Russell (1992) Teacher Involvement and Participation Scale (TIPS).

9. Standards (STND): Teachers' involvement in decision making with standards was defined by the score derived from items 5-8 on the Russell (1992) Teacher Involvement and Participation Scale (TIPS). 
10. Curriculum/Instruction (CI): Teachers' involvement in decision making with curriculum and instruction was defined by the score derived from items 9-15 on the Russell (1992) Teacher Involvement and Participation Scale (TIPS).

11. Budget (BDGT): Teachers' involvement in decision making with budget was defined by the score derived from items 16-19 on the Russell (1992) Teacher Involvement and Participation Scale (TIPS).

12. Staffing (STFF): Teachers' involvement in decision making with staffing was defined by the score derived from items 20-23 on the Russell (1992) Teacher Involvement and Participation Scale (TIPS).

13. Operations (OPER): Teachers' involvement in decision making with operations was defined by the score derived from items 24-28 on the Russell (1992) Teacher Involvement and Participation Scale (TIPS).

14. Staff Development (SDEV): Teachers' involvement in decision making with staff development was defined by the score derived from items 29-32 on the Russell (1992) Teacher Involvement and Participation Scale (TIPS).

15. School size (SS): was defined as the total number of students enrolled at the school.

16. Principal's years of experience (PYE): was defined as the total number of years a principal served in the role of principal at the school.

17. Teachers' years of experience (TYE): was defined as the mean of the total number of years served at the school by participating teachers. 


\section{Organization of the Study}

The study is divided into five sections. The first chapter serves to introduce the study, give background information, a problem statement, purpose of the study, research questions, rationale, limitations, assumptions, definition of terms, and the organization of the study.

Chapter two serves as a review of literature. The review includes literature associated with involvement in decision making, teacher efficacy, trust, and a conceptual framework.

Chapter three serves as a presentation of methodology. It presents the study's purpose, research design, research questions, population, instrumentation, data collection, and statistical procedures for data analysis.

Chapter four presents an analysis of the data including: descriptive statistics, correlations, regression analysis, coefficients, effect size, and power analysis.

Chapter five contains a summary of the study, discussion of the findings, limitations, and implications for future research. 


\title{
Chapter Two
}

\begin{abstract}
A Review of Literature
Involvement in Decision Making

People working together to achieve outcomes has been a crucial element for social organization dating back to our ancient ancestors. "Human history is largely a story of people working together in groups to explore, achieve, and conquer (Kozlowski and Ilgen 2006, p. 77).”
\end{abstract}

Organizational leaders are expected to make decisions that will ultimately impact all levels of an organization and beyond. Eberlin and Tatum (2008) found that these decisions require leaders to aggregate and integrate multiple sources of inputs rapidly. They also must "assess potential impacts (good and bad), integrate their professional and personal experiences, evaluate bottom-line and financial data, and appraise the reactions and support of key stakeholders (p. 310).” Schwarber (2005) suggests that leaders need to involve others in decision making "in order to obtain needed information, come up with creative alternatives, gain commitment, and train future generations of decision makers in a sound process (p. 1088).”

Margulies and Black (1987) suggest that there are two rationales for participatory decision making drawn from ideas set forth by Dachler and Wilpert (1978) and Locke 
and Schweiger (1979). At the root of the first rationale, there is a "humanist" or "democratic" justification for participatory decision making. This idea revolves around the belief that people have the right to be involved in decisions that affect their lives, assuming they can participate intelligently. The second rationale is labeled "pragmatic" or "human relations" and supports the idea that "participatory decision-making is an instrumental way to achieve higher productivity, efficiency, profits, or other valued organizational results (Black and Gregersen 1997, p. 861)."

Kerr and Tindale (2004) suggest that with participatory decision making, organizations experience higher levels of cohesion, and that these more cohesive groups tend to be more productive. Beal, Cohen, Burke, and McLendon (2003) found that three components of cohesion were significant: interpersonal cohesion, group pride, and task commitment. Barrick, Bradley, Kristof-Brown, and Colbert (2007) also identified three similar elements of group cohesion: social cohesion, group pride, and team commitment.

Black and Gregersen (1997) found that participative involvement in decision making accounted for significant amounts of variability in job satisfaction and performance. The five participative decision making processes in their study were identifying problems, generating alternatives, selecting solutions, planning implementation, and evaluating results. In regard to identifying problems, Saunders and Miranda (1998) state that information acquisition in organizations is fundamental to effective decision making and quality organizational outcomes. Kerr and Tindale (2004) found that with setting of challenging goals as a group, organizations experience higher productivity and satisfaction. Latham, Winters, and Locke (1994) also found that members' participation in goal setting led to a higher level of goal commitment and self- 
efficacy. Kozlowski and Ilgen (2006) conclude that factors influencing the development of self-efficacy can be used to develop team efficacy. The authors state that, "In particular, we believe that team leadership and team-training interventions are leverage points for shaping the development of team efficacy and potency," and that "teams with greater team-level efficacy and potency will be more effective (Kozlowski and Ilgen 2006, p. 91)."

In educational organizations, teachers are actors in both organizational rationales discussed by Black and Gregersen, suggesting educational organizations benefit greatly in many different ways from teacher empowerment and involvement in decision making. Conley (1991) identifies two aims or purposes of teacher participation in decision making. These two purposes are based on what Conley believes to be assumptions researchers make about school structure: a bureaucratic model and a professional model. "The bureaucratic or administrative model emphasizes the formal authority of administrators to delegate responsibilities to subordinates, formulate rules to govern subordinate behavior, and implement centralized control, planning, and decision making" (Conley, 1991, p. 228). This bureaucratic model views participation as a vehicle toward teacher compliance with administrative decisions. In a different manner, the professional model aims to provide teachers with professional considerations they expect. "The professional model emphasizes the professional discretion and expertise of teachers in diagnosing and addressing student learning needs" (Conley, 1991,p. 228). While both perspectives see employee satisfaction and morale as the goal, they differ in how those benefits are focused. The bureaucratic model focuses on the advantage of fewer problems for administrators. The professional model focuses on teachers being given the 
power to be professional decision makers, leading to higher job satisfaction. Benefits of teachers as professional decision makers can be seen in many ways within educational organizations.

Research has found that there is a positive effective on teacher performance when teachers are involved in participatory decision making (Somech \& Wenderow, 2006). By including teachers in participatory decision making, schools will benefit with better school and teacher outcomes (Somech, 2010). Marks and Louis (1999) suggest improvement in organizational learning by stating:

Multilevel analyses demonstrate a strong and consistent relationship between organizational learning and teacher empowerment, measured both as a school organizational characteristic and as an experience of individual teachers. The relationship is particularly strong for empowerment in the domains of teacher work life and student school experience (p. 707).

Schools are reliant upon teacher involvement in decision making when managing the process of restructuring (Taylor \& Bogotch, 1994). Educational administrators are better provided with important information close to the source of school problems (Tschannen-Moran, 2001). With teachers' involvement, immediate and unexpected problems can be handled more quickly and efficiently by those directly affected (Durham, Knight, \& Locke, 1997). Muijs and Harris (2006) state, “Successful school improvement is dependent upon the ability of individual schools to manage change and development" (p. 961). Harris (2005) summarized that "Most recent literature on change and school improvement suggests that the form of leadership most often identified with improved learning outcomes is one that is distributed or shared" (p. 259).

Researchers have found that participation in decision making "is related to teacher job satisfaction and loyalty, goal commitment, stress, militancy, role ambiguity and 
conflict, and work alienation (Bacharach, Bamberger, Conley, \& Bauer, 1990; Conley, 1991; Estler, 1988; see also Hackman \& Oldham, 1980, as cited in Smylie 1992, p. 53 54)." Bogler and Nir (2012) also found that teacher empowerment was a crucial factor in higher levels of job satisfaction based on teacher self-efficacy, earned status, and respect. Hulpia, Devos, and Van Kerr (2011) suggest that teachers who believe their school is run by a cooperative leadership team feel committed to the school. These leadership teams were characterized by group cohesion, clear and unambiguous roles, and goal orientation. The researchers believe that "It is important for teachers that their school is not led by a solo leader working on an island. Instead, the school should be led by a leadership team that works together in a cohesive and open way (Hulpia, Devos, and Van Kerr, 2011,p. 754)."

Teachers' attitudes are based partly on the optimism provided by the knowledge that they are working toward attainable outcomes through collaboration. It is this ingredient that instills a will to achieve. Perceptions of teachers that they are part of a group and share in the decisions of the school lead to their efficacy and ownership of responsibility. This perception is partly due to the vicarious pleasure taken in the achievements of other group members (Messick, 2005). The psychology of perception is a powerful one and affects self-regulatory mechanisms, including motivation and action (Bandura \& Wood, 1989; Lumpkin \& Lichtenstein, 2005). Perceptions of leadership behaviors rely on subordinate cognition, and cognitive mechanisms vary between individual perceivers (Brown \& Lord, 2001). The differences between individual perceivers include affective and motivational processes involved in perception and judgment. Abilities and skills of perceivers have also been shown to impact the qualities 
of their judgments. Similarly, the judgments of leaders are dependent upon subordinates' interpretations of leaders' traits and behaviors (Klimoski \& Donahue, 2001).

Teacher motivation is improved with perceptions of opportunities for involvement in decision making. Improvement can be made through demonstrations of trust by the principal such as inclusion in group processes, resolving problems and conflicts, and staff development (Peterson \& Behfar, 2005). When principals share decision making responsibilities, teachers are more motivated to provide input, creativity, and action toward analyzing and meeting a school's challenges (Pounder, 1998). Additionally, involvement in collaborative leadership motivates teachers to see projects through to completion and goals through to fruition (Clift, Veal, Holland, Johnson, \& McCarthy, 1995). Retention is yet another teacher-related outcome impacted by involvement in decision making. Factors leading to teachers' exit from the profession similarly include low morale, dissatisfaction, and burn out (Evans, 1998; Whitaker, Whitaker, \& Lumpa, 2009). When principals include teacher in the decision making process, teachers are giving a greater feeling of professional pride and job satisfaction (Gorton \& Alston, 2012).

Literature in the area of teacher involvement in decision making continues to show variability (Conley, 1991; Rice \& Schneider, 1994; Marks \& Louis, 1999; Bogler \& Somech, 2004; Wahlstrom \& Louis, 2008). As its variability remains of interest, teacher involvement in decision making is an important element of variants such as shared decision making (Conway \& Calzi, 1995; Leech, 1999; Streck, 2009), participative decision making (Somech \& Wenderow, 2006; Somech, 2010), participative management (Somech, 2002; Benoliel \& Somech, 2010), distributed leadership (Goldstein, 2004; 
Heck \& Hallinger, 2010; Jackson \& Marriott, 2012), school-based decision making (Ferris 1992; Newcombe \& McCormick, 2001), empowerment (Marks \& Louis, 1997, 1999; Hoy \& Sweetland, 2000), collective leadership (Leithwood \& Mascall, 2008), and teacher-leaders (Gigante \& Firestone, 2008; Weiner 2011).

Research has been varied in regard to the dimensions and framing of teacher participation in decision making. Alutto and Belasco (1972) conducted their teacher participation research by focusing on the difference or "discrepancy score" between teachers' perceived involvement in decision making and desired involvement in decision making. Participants responding to twelve decisional situations led authors to argue:

One can deal effectively with decisional participation by considering a continuum of participation typified by the following three conditions: decisional deprivation - actual participation in fewer decisions than desired, decisional equilibrium - actual participation in as many decisions as desired, and decisional saturation - actual participation in a greater number of decisions than desired (Alutto \& Belasco, 1972, p. 118).

Mohrman, Cooke, and Mohrman (1978) defined three dimensions: technical, managerial, and negotiations. Duke, Showers, and Imber (1980) identified nine areas in which school decisions are made: instructional coordination, curriculum development, staff development, evaluation, general school improvement, personnel, rules and discipline, general administration, and policymaking. Bacharach, Bamberger, Conley, and Bauer (1990) identify four decision dimensions: a technical core, evaluation and development, resource allocation, and distribution of human resources. Charters and Packard (1979), Herriott and Firestone (1984), Schneider (1985), and Duke and Gansneder (1990) categorized participation in two larger dimensions: a technical core, or classroom instruction and school-wide, managerial issues. Bacharach, et. al (1990) specified that these two domains were operational and strategic in nature. The technical 
domain was seen as operational and the managerial domain was seen as strategic (Conley 1991, p. 235).

As research continued to find, teacher participation in decision making can be viewed in terms of actual or perceived involvement and desired or willingness to be involved. Russell (1992) developed the Teacher Involvement and Participation Scale (TIPS) survey by determining eight areas in which teacher involvement in decision making is implemented: goals/vision/mission, facilitating procedures and structures, curriculum/instruction, budgeting, staffing, staff development, operations, and standards. Smylie (1992) looked at teachers' preferences by measuring their willingness to be involved in four areas of decision making: personnel, curriculum and instruction, staff development, and general administration. The author classified teachers' willingness to participate as being associated with four factors: the principal-teacher working relationship, norms influencing working relationships among teachers, teachers' perceived capacity to contribute to or make decisions, and teachers' sense of responsibility and accountability in their work with students. The author found that teachers are more willing to participate in curricular or instructional decisions than they are to be involved in general administrative decisions.

Ferrara and Repa (1993) felt the best method of measuring teacher involvement in decision making was to combine the two approaches previously used by Russell and Smylie. Ferrara and Repa's Teacher Decision-making Instrument (TDI) measures eight categories: planning, policy, curriculum/instruction, pupil personnel, staff personnel, staff development, school/community, and budget/management. 
Taylor and Tashakkori (1997) research took a related approach and identified four types of teachers: empowered: those who want to participate and do; disenfranchised: those who want to participate but do not; involved: those who do not want to participate but do; and disengaged: those who do not want to participate and do not. Overall, the results indicated that most teachers expressed a relatively strong desire to participate, and teachers declaring the greatest job satisfaction were those who reported high levels of participation.

There are a few variables associated with teacher involvement in decision making. School level has been found to be a significant factor in predicting levels of teachers' involvement in decision making. Secondary schools' structures are typically organized independently into different functions or subjects. Specialized teachers are less likely to collaborate and interact with other teachers of different content. Secondary school teachers tend to operate in relative isolation from one other, and minimize coordination (Mohrman, Lawler, \& Mohrman, 1992).

School size has also been found to affect variability in teachers' participation in decision making (George \& Jones, 1997; Rosenblatt \& Somech, 1998; Somech, 2002). Larger schools can affect established processes and organizational culture in schools (Somech, 2002). Another variable related to levels of teacher participation in decision making is that of principal's seniority (Rosenblatt \& Somech, 1998; Somech \& DrachZahavy, 2000; Somech, 2002). 


\section{Leadership in Schools}

Somech (2002) simultaneously examined five dimensions of participative management in schools: decision domain, degree of participation, structure, target of participation, and rationale. Somech and Wenderow (2006) similarly focused on one of those dimensions when studying technical and managerial as two overarching areas of decision domain. The researchers measured principals' levels of participatory and directive leadership styles with instruments developed by Sagie, Zaidman, AmichaiHamburger, Te'eni, and Schwartz (2002). These instruments measured “teachers' overall ability to influence decisions and offer opinions and suggestions to the leader" and "the extent to which the leader provides school members with a framework for decision making and action in line with the leader's vision" (Somech and Wenderow, 2006, p. 755).

Somech and Wenderow (2006) suggest that technical and managerial domains would be best paired with certain leadership styles. If the principal acknowledges a higher level of competence from teachers in specific areas (e.g. technical domain), the principal could be more participative in classroom instruction related decisions. These decisions would include instructional policies, classroom discipline polices, and resolving learning problems. If the principal felt more competent to make some decisions than teachers (e.g. managerial domain), his/her leadership style would be more directive when considering school-wide issues. These issues would include setting school goals, hiring staff, allocating budget, and evaluating teachers (Somech and Wenderow, 2006, p. 751). The authors base these ideas on contingency theory (Vroom \& Jago, 1998) and cognitive resource theory of leadership (Fiedler, 1989, 1995; Murphy \& Fiedler, 1992). 
Contingency theory states that no one leadership style is appropriate for all employees in all organizations or contexts. Cognitive resource theory states that a subordinate's performance is positively affected when either the leader is directive when possessing higher relevant competence or when the leader is participative when the subordinate has higher relevant competence (Somech and Wenderow, 2006, p. 752).

In their research on delegation and consultation, Yukl and Fu (1999) found that four items correlated significantly with leaders' delegation to followers. These four factors were competence, goal congruence, job level, and time together (p. 226). Yukl and $\mathrm{Fu}(1999)$ also suggest that one of the most important reasons for leaders' to delegate responsibilities to followers were leaders' beliefs about subordinates' competence and dependability. If a leader believes that a subordinate has the skills and knowledge to meet expectations, the leader would be more likely to delegate responsibility.

The concept of leader-member exchange has evolved through the work of Graen and Cashman (1975), Graen, Novak, and Sommerkamp (1982), Bauer and Green (1996) and Cogliser and Schriesheim (2000). Leader-member exchange involves the relationships that build between a leader and subordinates. These relationships rely on the leaders' experiences with subordinates and determine the amount to which subordinates are involved in decisions. Somech and Wenderow reiterate the importance of leader-member exchange, trust, and leaders' beliefs:

Previous research (e.g.,Yukl, 2002; Yukl \& Fu, 1999) indicates that participation in decision making requires some extent of agreement between leader and member on job issues, trust, and leader's perceptions of competence. Therefore, according to the LMX model, subordinates experiencing the reciprocal trust characteristic of high-quality exchanges with their immediate supervisors should be asked to participate in many nontrivial decisions affecting the work unit (Wayne, Shore, Bommer \& Tetrick, 
2002), which in turn will foster their performance. (Somech and Wenderow, 2006, p. 753)

In the literature both trust and leader beliefs about followers are relevant when discussing the amount to which followers are empowered. In school organizations, the principal serves the role of leader, while the teachers serve the role of followers or subordinates. Leader beliefs about the competence of followers (efficacy beliefs) are present in school organizations. One way to define principals' beliefs about teachers' competency is principals' collective efficacy beliefs about teachers.

\section{Collective Teacher Efficacy}

Bandura's concept of social cognitive theory lays the ground work for elements related to teacher efficacy, namely the self-efficacy mechanism in human agency, human agency in triadic reciprocal causation, and determinism and the exercise of self-influence. Decisions involving choice and judgments of personal efficacy are factors that influence behaviors. People will tend to participate or avoid activities based on their perceived capabilities (Bandura, 1977, 1986, 1997).

Gibson and Dembo (1984) surveyed teachers using their Teacher Efficacy Scale. After identifying those teachers determined to be of high and low efficacy, the authors observed each of four high and four low efficacy teachers in the classroom. The authors found that high efficacy teachers and low efficacy teachers displayed different behaviors in the classroom. High efficacy teachers used less small group work time and intellectual games than low efficacy teachers. Low efficacy teachers gave more criticism and possessed less persistence per incorrect answer. 
Ashton and Webb (1986) went further when exploring the concept of a teacher's sense of efficacy. A teacher's sense of efficacy was important to the authors because they wanted to find a way to support what they saw as the most important component of successful schools: the quality and determination of the classroom teacher. Based on research performed by the Rand Corporation, Ashton and Webb were convinced, that a teacher's motivation and professional self-esteem was the key to student achievement ( $\mathrm{p}$. 1). Teachers' sense of efficacy was defined as 'teachers' situation-specific expectation that they can help students learn" (p. 3).

Efficacy can be shaped by beliefs about students' capacity for learning and influences feelings, thoughts, effort, persistence, and activity selection. Teachers with low sense of efficacy doubt and avoid situations beyond their capabilities. Their concern over competence and inadequacies raises stress and lowers teaching effectiveness. Teachers with high sense of efficacy believe they have the capability to positively affect student achievement and consequently try harder when confronted with challenges (p. 3).

Sense of (general) teaching efficacy and sense of personal teaching efficacy are the two dimensions of teachers' sense of efficacy (p. 3). Teachers determine their actions based on an integration of these two dimensions. Teachers with high sense of teaching efficacy believe that teaching can affect student outcomes even when taking into account external factors. Teachers with a low sense of teaching efficacy believe that some students will not learn regardless of teachers' capabilities and efforts in schools. Sense of personal teaching efficacy is the individual's assessment of his/her own competence and influence choices of classroom management and instructional strategies. If a teacher has a low sense of personal teaching efficacy, he/she may not address a student's off-task 
behavior or poor achievement because of a lack in belief that he/she can affect those issues (p. 4).

The evolution of Ashton and Webb's concept of teacher's sense of efficacy leads back to the Rand study's two items:

1. When it comes right down to it, a teacher really can't do much because most of a student's motivation and performance depends on his or her home environment.

2. If I try really hard, I can get through to even the most difficult or unmotivated students (Berman et al., 1977, pp. 136-137, as cited in Ashton \& Webb, 1986, p. 8)

The authors also used Bandura's version of the cognitive social learning theory of self-efficacy to build their conceptual framework (p. 8). Ashton and Webb went on to discuss Fenstermacher's (1979) work in regard to beliefs and behaviors:

Teachers behave as they do because of subjectively held beliefs that their behaviors are appropriate. They will maintain those behaviors unless evidence is presented that challenges their subjectively reasonable beliefs. If researchers wish to change those behaviors, Fenstermacher argued, they must first understand the intentions and beliefs underlying teachers' behaviors... Once we understand teachers' motivation, we can identify strategies for changing the beliefs that maintain their ineffective behaviors (p. 10).

There are three parts to the ecological structure of the educational environment that help in understanding the variables associated with teachers' sense of efficacy: microsystem (the teacher's immediate setting), mesosystem (the interrelations among the teachers' major settings), and exosystem (the formal and informal social structures, e.g. socioeconomic levels, media, and other agencies) (p. 13). The microsystem includes: student 
characteristics, teacher characteristics, teacher ideology, role definitions, class size, and activity structure. The mesosystem includes: school size and demographic characteristics, school norms, collegial relations, principal-teacher relations, decisionmaking structures, and home-school relations. The exosystem includes the nature of the school district and legislative and judicial mandates.

Teaching low-achieving students can make it difficult for a teacher to maintain a sense of professional accomplishment (p. 66). Competency criteria are harder to meet in classrooms with low-achieving students (p. 67). In Ashton and Webb's study, low senseof-efficacy teachers were more likely blame low-achieving students using claims: lack of ability, insufficient motivation, character deficiencies, or poor home environments (p. 68). Low sense-of-efficacy teachers were not troubled about their students' shortcomings because they felt there was little they could do to impact the problem (p. 71). High sense-of-efficacy teachers believed the opposite. Struggling students' problems were seen as challenges to be met. Low achieving students were seen as "reachable, teachable, and worthy of attention and effort" (p. 72). Low sense-of-efficacy teachers were more distrustful of their students and sought security in their positional authority. High senseof-efficacy teachers built warm relationships and were more likely to establish friendly relationships less based on personal authority (pp. 75-76). High sense-of-efficacy teachers made fewer and less negative comments than low sense-of-efficacy teachers (p. 86).

Self-efficacy beliefs are context specific (Bandura, 1997; Tschannen-Moran \& Hoy, 2007). Some school-level variables associated with teachers' self-efficacy beliefs 
include climate and structure of the school, the leadership of the principal, and the collective efficacy of the organization (Tschannen-Moran \& Hoy, 2007, p. 946).

Goddard, Hoy, \& Hoy (2000) formed their model of collective teacher efficacy based on the work of Bandura (1997) and Tschannen-Moran, Hoy, \& Hoy (1998). Collective teacher efficacy is a property of group dynamics and attributes. "It is the 'groups' shared belief in its conjoint capabilities to organize and execute courses of action required to produce given levels of attainments" (Bandura, 1997, p. 477, as quoted in Goddard, Hoy, \& Hoy, 2000, p. 482).

Shared perceptions of group members about "the performance capability of a social system as a whole" (Bandura, 1997, p. 469) directly relate to teachers' shared beliefs as members of school organizations. As is true with self-efficacy, collective efficacy is associated with the tasks, level of effort, persistence, shared thoughts, stress levels, and achievement of groups (Goddard, Hoy, \& Hoy, 2000, p. 482). Due to their closely related natures, Goddard, Hoy, \& Hoy believed that there might be the same benefits for student achievement with collective teacher efficacy at the school level as there was seen earlier with teachers' sense of efficacy at the individual level (Goddard, Hoy, \& Hoy, 2000, p. 483). Teachers are confronted with many challenges including public accountability, shared responsibility for student outcomes, and minimal control over work environments (Bandura, 1997). These potential challenges to collective teacher efficacy might be overcome with the "moral resources" of exercised collective social perceptions. "The potential for efficacy to grow rather than to diminish thought use is also indicated by the cyclical nature of efficacy implied by reciprocal causality (Bandura;1997)" (Goddard, Hoy, \& Hoy, 2000, p. 483). Reciprocal causality implies that 
strengthened collective organizational efficacy and improved organizational performance will feed one another. By developing collective teacher efficacy, a school may also see continued growth in student achievement (p. 483).

Organizations learn in similar ways as individuals (Cook \& Yanon, 1996). Collective efficacy can be drawn from self-efficacy theory in a similar fashion that social cognitive theory can be expanded to the organizational level. The human agency aspect of social cognitive theory can by extended to a school's collective organizational agency, or the school's intentional pursuit of its educational goals. Organizational learning and functioning also depends on its knowledge, vicarious learning, self-reflection, and selfregulation of its individual members (Goddard, Hoy, \& Hoy, 2000, pp. 483-484).

Bandura's work $(1986,1997)$ focused on four sources of self-efficacy information that also apply to collective teacher efficacy: mastery experience, vicarious experience, social persuasion, and emotional arousal. Mastery experiences are when teachers experience successes and failures and are developed by overcoming difficulties with persistence. Of the four sources, mastery experience was found to be the most powerful (Tschannen-Moran \& Hoy, 2007). Vicarious experiences are when teachers observe other teachers' success through direct observation, stories, and research. Social persuasion develops staff beliefs in capabilities through talks, workshops, professional development, and feedback about achievement. Organizations have affective states in which they react to stress. Organizations with high efficacy can adapt and cope with pressure and disruptive forces. (Goddard, Hoy, \& Hoy, 2000, p. 484). 
There are two elements in the development of collective teacher efficacy: analysis of the teaching task and assessment of teaching competence. These elements are weighed in relation to one another when perceptions of collective teacher efficacy are formed. The analysis of the teaching task occurs at both the individual and school levels when teachers assess what will be required as they engage in teaching. Factors influencing teachers' assessment of potential success include the abilities and motivations of students, the availability of instructional materials, the presence of community resources and constraints, and appropriateness of the school's physical facilities (Goddard, Hoy, \& Hoy, 2000, p. 485).

As the two elements of collective teacher efficacy are directly connected, assessment of teaching competence is reliant upon judgments made when analyzing the teaching task. Inferences produced at the school level pertain to the faculty's teaching skills, methods, training, and expertise. A belief that all students in the school can succeed may also influence teachers' judgments (Goddard, Hoy, \& Hoy, 2000, p.485). The findings of the researchers' study showed that group competence and task analysis are highly related in schools and combine to form an overall conception of collective efficacy. Collective teacher efficacy was found to be positively associated with student achievement, specifically with regard to mathematics and reading at the elementary school level (Goddard, Hoy, \& Hoy, 2000, p. 500).

The literature suggests that principals' collective efficacy beliefs about teachers may lend insight into the extent to which principals' provide teacher with opportunities to be involved in decision making. The literature also suggests that whether or not a principal empowers teachers may depend on the principals' trust in teachers. 
Trust

Organizations rely on trust and cooperation. Trust has been described both as “mortar binding leader and follower" (Nanus, 1989) and "a remarkably efficient lubricant" for complex organizational transactions (Powell, 1990). Pounder (1998) believed that for educational organizations as well, trust is a critical part of successful collaboration.

Trust and cooperation influence interpersonal and group behavior and are related to one another (Ferrin, Bligh, \& Kohles, 2008). Kouzes and Pozner (2002) identify trust as "at the heart of collaboration" and "the central issue within and outside organizations" (p. 244). Although the importance of trust seems easily supported, when it comes to defining trust, Tschannen-Moran and Hoy (1998) state: "Trust is a complex concept. It has been difficult to pin down because it is based on many factors, varies with the expectations held in different kinds of relationships, and changes over the course of a relationship" (p. 335).

Trust is fragile and is connected to uncertainty in decision making. When one has control over another's actions or responses, trust is not an issue. When one does not have control, there is a risk that the other party will cause damage if proven untrustworthy. This possibility is the dilemma of trust in organizations (Tschannen-Moran, 2004). Trust can be developed if the behavior supports it. Walker, Kutsyuruba, \& Noonan (2011) state: "The development of trust is buttressed when the expected behavior materializes. The path-dependent connection between trust and risk taking arises from a reciprocal relationship: opportunities for trust leads to risk taking and vice versa" (p. 474). 
Baier (1986) claimed trust is: “...reliance on others' competence and willingness to look after, rather than harm, things one cares about which are entrusted to their care" (p. 259). The author's definition of trust includes aspects of vulnerability in cooperative relationships. Baier (1994) later states:

We have to rely on our own judgment and on our ability to improve our judgment, if we are to enter and sustain mutually beneficial relationships of trust-involving cooperation. Trust is acceptance of vulnerability to harm that others could inflict, but which we judge that they will not in fact inflict" (p. 152).

Trust has risen in conjunction with educational organizational collaboration.

Tschannen-Moran (2004) has completed extensive research on the nature of trust within schools and states, "Teachers are more likely to be innovative and effective in an atmosphere of trust. Strong professional communities are built through joint deliberation and decision making” (p. 107). In schools with high levels of trust and collaboration, teachers are more likely to provide accurate and relevant information about problems and challenges in the school. Principals who communicate openly with teachers enhance their perception of trust and engender greater openness. Tschannen-Moran identifies the value in this type of relationship:

When principals exchange thoughts and ideas freely with teachers, it not only enhances perceptions of trust but leads to greater openness on the part of teachers as well (Butler, 1991). Teachers are more willing to share their thoughts, feelings, and ideas, thus making these valuable resources available for school improvement (Zand, 1997) (Tschannen-Moran, 2004, p. 25)

Based on previous research, Tschannen-Moran (2004) arrived at the following definition of trust: "Trust is one's willingness to be vulnerable to another based on the confidence that the other is benevolent, honest, open, reliable, and competent (Mishra, 
1996; Tschannen-Moran and Hoy, 1998, 2000)" (p. 17). Benevolence refers to the care that one demonstrates for others. Trust assures that good will is extended to the trusting individual without exploitation of vulnerability. If one trusts another, he/she will not be afraid to seek assistance or feel in jeopardy of being judged as inadequate (TschannenMoran, 2004, pp. 19, 21). Honesty is a reflection of authentic behavior that is supported with accountability, avoiding manipulation, and being "real." There is no shifting of blame or failure to accept responsibility (Tshcannen-Moran, 2004, pp. 22, 24). Openness is particularly important when considering the potential for principals to share decision making with teachers. Tschannen-Moran explains:

Openness is a process by which people make themselves vulnerable to others by sharing information, influence, and control (Zand, 1997). Openness in information means disclosure of facts, alternatives, judgments, intentions, and feelings. Openness in control accepts dependence rooted in a confidence in the reliability of others and the delegation of important tasks to them. Openness in influence allows others to initiate change to plans, goals, concepts, criteria, and resources (Tschannen-Moran, 2004, p. 25).

Reliability is when a person or group can be counted on to do what is expected on a consistent basis (Tschannen-Moran, 2004, p. 29). Competence refers to the perceived skill level that is necessary to complete the task or meet expectations. Principals and teachers depend on one another's competence to meet appropriate standards and accomplish goals (Tschannen-Moran, 2004, p. 30).

The principal-teacher relationship provides a "window" into a school's trust dynamics. Teachers and principals are dependent on one another while pursuing the goal of educating students (Tschannen-Moran, 2004, p. 18). Principals can foster trust by involving teachers in important decisions (Tschannen-Moran, 2004, p. 188). Trusting 
and trustworthy behaviors enhance a principal's abilities. According to TschannenMoran (2004):

In addition to their role as instructional leader and coach, principals are also charged with the responsibility for management and administration. Here, too, the effective understanding and implementation of the five facets of trust are important to a principal's effectiveness and success. In their managerial capacity, trusting and trustworthy principals will earn critical efficiencies in what is at times an overwhelming task. Principals willing to delegate control will find that they are not so bound by the need to do everything themselves (p. 182).

When it comes time for principals to make decisions about school goals, policies, issues, and operations, the inclusion of teachers depends on the trust and beliefs that the principal holds about teachers. Tschannen-Moran (2004) reiterated the role of trust as a "glue" or "lubricant" and expounded on those ideas:

As 'glue' trust binds organizational participants to one another. Without it, things fall apart. To be productive and to accomplish organizational goals, schools need cohesive and cooperative relationships... Trust binds leaders to followers... As 'lubricant,' trust greases the machinery of an organization. Trust 'lubricates' communication and contributes to greater efficiency when people can have confidence in other people's words and deeds (Arrow, 1974) (p. 16)

Mishra (1996) summarized that trust can be defined as a set of beliefs and expectations about competence and responsibility. The author's definition was based upon research regarding vulnerability and expectations or beliefs (Barber, 1983; Deutsch, 1973; Luhmann, 1979; Moorman, Zaltman, \& Deshpande, 1992). Four dimensions were identified: "Trust is one party's willingness to be vulnerable to another party based on the belief that the latter party is (a) competent, (b) open, (c) concerned, and (d) reliable" (p. 265).

Mishra goes further to explain trust's role in decentralized decision making. Leaders increase dependence on others and entail greater risk when delegating decision 
making to members at lower levels of an organization. Trusting behaviors in leaders are based on leaders' beliefs about employees' competence and knowledge:

Even if the assumption of opportunism is removed, risk still remains due to possible incompetence or ignorance on the part of those receiving authority, as critics of agency theory have noted (Donaldson, 1990). As noted earlier, accepting greater dependence or risk is at the core of trusting behavior (Deutsch, 1973; Lewis \& Weigert 1985a), and trust as a belief facilitates trusting behavior (Mishra, 1996, p. 272).

Leaders may or may not believe subordinates are competent enough to be trusted. Trust has a great deal to do with these assessments based on opinion, judgment, or estimation (Solomon \& Flores, 2001). Principals make judgments about whether or not teachers have the skills necessary to be involved in decisions influencing school outcomes.

Trust evolves and changes. It develops gradually over time as parties move through stages (Lewicki and Bunker, 1996, in Kramer \& Tyler, Eds., p. 124). Part of this increase in identification-based trust stems from an organization's collective identity. In addition trust is at a higher level for members within an organization. Members tend to have higher levels of trust through mutual group identity (Kramer, Brewer, and Hanna, 1996). There is also a steady accumulation of social capital over time resulting in higher levels of cooperation and organizational trust (Kramer \& Tyler, Eds., 1996, p. 379).

\section{Conclusion}

Principals demonstrate their trust in teachers through their leadership styles and behaviors, and teachers interpret their trust through their perceptions of the principal's behaviors (Tschannen-Moran, 2004; Wahlstrom \& Louis, 2008). Somech (2002) 
suggests that principals' leadership styles are based on their values and beliefs. Whether or not principals choose to involve teachers in decision making relies upon the principals' beliefs about teachers' knowledge and skills or competency (Yukl \& Fu, 1999; Yukl, 2002). Hallinger (2011) also states that the ways in which principals exercise their leadership is moderated by personal characteristics. Specifically, the author lists personal values, beliefs, knowledge, and experience of leaders as sources of variation in leadership practice (Hallinger 2011, p. 127). Perceived ability of colleagues is a predictor of trust and that trust is in turn a predictor for risk-taking behaviors (Serva, Fuller, \& Mayer, 2005; Wahlstrom \& Louis, 2008).

Based on a review of the literature, it is reasonable to assume that principals' collective efficacy beliefs about teachers may explain some amount of variability in teachers' perceived opportunities for involvement in decision making. Trust plays the mediating role in the educational organizational relationship between principals and teachers. This suggests a conceptual framework represented by the following diagram:

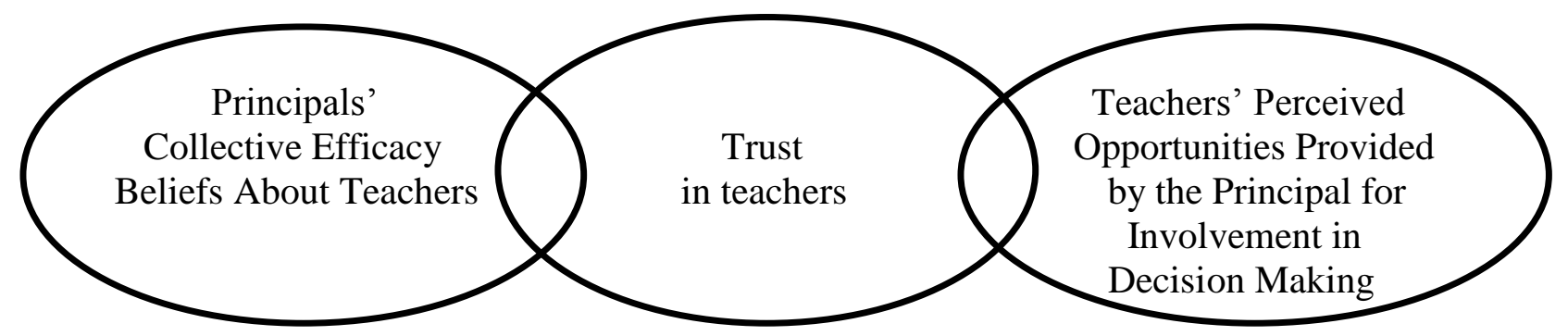




\section{Chapter Three}

\section{Research Methods}

This chapter will discuss the study's design, population, instrumentation, research questions, data collection, and data analysis procedures.

\section{Design}

The purpose of this study was to determine the extent to which principals' collective efficacy beliefs about teachers contributes to the variance in teachers' perceived opportunities provided by the principal for involvement in decision making over and above that explained by school size, years of experience of the principal, and years of experience of teachers. The independent variables were principals' collective efficacy beliefs and its constructs of task analysis and group competence. The dependent variable was teachers' perceived opportunities for involvement in decision making as measured by the Russell (1992) Teacher Involvement and Participation Scale (TIPS), and its seven subscales of goals/vision/mission (GVM); standards (STND); curriculum and instruction (CI); budget (BDGT); staffing (STFF); operations (OPER); and staff development (SDEV). Control variables included school size, principals' years of experience at the school, and teachers' years of experience at the school. In order to achieve the purpose of the study, the design was descriptive and correlational and sought 
to answer the research questions using hierarchical multiple regression. Survey methodology was used to collect data.

\section{Population/Sample}

The population for this study was elementary school principals in three large, contiguous, intermediate school districts of a Midwestern state. The three districts were selected based on their accessibility for the researcher. Permission was gained from the three superintendents of the intermediate school districts. Next, the superintendents of each local district were contacted regarding the study. Two superintendents declined to participate in the study. This prevented the researcher from contacting 18 elementary schools. One district, which contained two elementary schools, declined based on internal political conflict. The second district, which contained 16 elementary schools, declined based on the frequency with which overall research requests were made in the year. The high number of requests is due to the district's quality of being the largest urban district in the region. All other local superintendents granted permission to contact their elementary schools. The remaining districts were suburban or rural in nature.

After gaining permission from local superintendents, all of the remaining 58 elementary schools within the three districts were contacted. The principal and all fulltime certified classroom teachers were invited to participate. Thirty-two principals agreed to have their schools participate in the study. Twenty-six schools either failed to respond or declined to participate. Of the 32 schools who participated, responses were received from both principals and teachers at 26 of the schools. After an investigation of the scatterplot for outliers, 3 of the 26 schools were removed. The remaining 23 schools 
were used in the study's analysis. The study's small sample size needs to be considered a limitation due to its reduced ability to find statistical significance and achieve statistical power. The study's sample of convenience needs to be considered a limitation, and findings should not be generalized to other populations.

\section{Instrumentation}

Two instruments were used to collect the data concerning the variables of principals' collective efficacy beliefs, teachers' perceived opportunities for decision making, school size, principals' years of experience, and teachers' years of experience. The Goddard Collective Efficacy Scale Short Form was utilized to assess principals' efficacy beliefs about teachers with additional items for measuring the variables of school size and principal's years of experience. The Russell Teacher Involvement and Participation Scale was utilized to assess teachers' perceived opportunities for involvement in decision making with an additional item for measuring the variable of teachers' years of experience.

Goddard \& Hoy Collective Efficacy Scale Short Form

The independent variables of principals' total collective efficacy beliefs about teachers (CEB) and its two constructs, group competence (GC) and task analysis (TA), were defined by the Goddard Collective Efficacy Scale (CES) Short Form. The Collective Efficacy Scale was modeled on Dembo and Gibson's (1984) Likert-type scale 
on teacher efficacy (Goddard, Hoy, \& Hoy, 2000, p. 487). In order to properly assess the construct without influential wording, the 16-item Dembo and Gibson Scale was adjusted to contain both positive and negative word choice (p. 488). Four categories were developed: Group Competence positive (GC+), Group Competence negative (GC-), Task Analysis positive (TA+), and Task Analysis negative (TA-). After a field test, the researchers conducted a pilot study of 70 teachers at 70 schools across five states (p. 488). Construct validity was established through comparisons to existing scales (p. 494). The scale had internal reliability measured at alpha $=.96$ (p. 496). A sample item is, "Teachers in the school are able to get through to the most difficult students" (p. 495). Responses range from "strongly agree" to "strongly disagree" (p. 488).

\section{Scoring of the Principal Survey}

The CES Short Form measures responses on a 6-point Likert-type scale (1strongly disagree to 6-strongly agree) and is scored as follows:

1. Total Principal Collective Efficacy Beliefs $(\mathrm{CEB})=$ mean of items 1-12

2. Group Competence $(\mathrm{GC})=$ mean of items $1,2,3,4,5$, \& 9

3. Task Analysis $(\mathrm{TA})=$ mean of items $6,7,8,10,11, \& 12$

Russell Teacher Involvement and Participation Scale

The dependent variable, teachers' perceived opportunities for involvement in decision making (DM), was assessed by Russell's (1992) Teacher Involvement in 
Participation Scale (TIPS). Content validity for the survey was established through a panel of experts who matched items with subscales (Lester \& Bishop, 2000, p. 107). The study was piloted at five schools identified as having a wide range of shared decision making. Internal validity for the TIPS survey was measured at a level of alpha $=.96$ (p. 107). The instrument's reliability as measured by Cronbach's alpha was .96 (Russell, 1992, p. 92). Responses range from a value of 1 for "almost never" to 5 for "almost always" on a five-point Likert-type scale (Lester \& Bishop, 2000, p. 108). For the purpose of this study, the stem of the questionnaire and the wording of items were altered. The decision making area of facilitating procedures and structures was excluded because the items were aimed at teacher to teacher relationships having little relevance to teachers' perceptions of the amount to which the principal offered opportunities for involvement in decision making. Items in the remaining seven areas that were deemed not useful for the purpose of the study were removed. For example, an excluded item was "The school's goals are consistent with my vision of the school," as it does not measure whether the principal offered opportunities for involvement with sharing, establishing, and developing the school's goals, vision, and mission. Other items included in the survey addressed this area. The stem of the survey was, "Circle the number that best indicates the degree to which you perceive that in this past school year, your principal provided teachers at your school with opportunities to:." The wording of some items was changed to match the stem. For example, "Teachers help to establish school priorities" was changed to "Establish school priorities." The removal of survey items and alteration of wording was based on review and recommendations from the 
dissertation committee. These changes should be considered a limitation, as the validity and reliability of the survey may be different from its original calculations.

\section{Scoring of the Teacher Survey}

The TIPS instrument measures responses on a five-point Likert-type scale (1-almost never; 2-seldom; 3-sometimes; 4-frequently; 5-almost always) and is scored as follows:

1. Total Decision Making $(\mathrm{DM})=$ mean of items 1-32

2. Goals/Mission/Values $(\mathrm{GMV})=$ mean of items $1-4$

3. Standards $(\mathrm{STND})=$ mean of items $5-8$

4. Curriculum/Instruction $(\mathrm{CI})=$ mean of items $9-15$

5. Budget $(\mathrm{BDGT})=$ mean of items $16-19$

6. Staffing $(\mathrm{STFF})=$ mean of items $20-23$

7. Operations $(\mathrm{OPER})=$ mean of items $24-28$

8. Staff Development $($ SDEV $)=$ mean of items $29-32$ 


\section{Research Questions}

The research questions were designed to determine the extent to which principals' collective efficacy beliefs about teachers are associated with variability in teachers' perceived opportunities for involvement in decision making. The research questions were as follows:

\section{Research Question 1}

To what extent do principals' total collective efficacy beliefs (CEB) account for variability in teachers' perceived opportunities for involvement in decision making (DM) over and above that explained by school size, years of experience at the current school for the principal, and years of experience at the current school for teachers?

\section{Research Question 2}

To what extent do principals' group competence $(G C)$ beliefs account for variability in teachers' perceived opportunities for involvement in decision making (DM) over and above that explained by school size, years of experience at the current school for the principal, and years of experience at the current school for teachers?

\section{Research Question 3}

To what extent do principals' task analysis (TA) beliefs account for variability in teachers' perceived opportunities for involvement in decision making (DM) over and above that explained by school size, years of experience at the current school for the principal, and years of experience at the current school for teachers? 


\section{Data Collection}

The researcher first obtained approval from both the researcher's dissertation committee and the University of Virginia’s Institutional Review Board (IRB). Upon approval from those two bodies, the researcher then followed the procedures provided by the school district administrators of the sample in order to obtain approval to conduct the study. Intermediate superintendents were the first contacts made by the researcher, followed by local superintendents. Contact was made initially by e-mail, and subsequent contacts were made by e-mail or phone, depending on the preference of the superintendent. All contacts included a cover letter introducing the researcher and the study, the IRB approval letter, and the survey materials. Superintendents were informed of the voluntary nature of participation, IRB approval, ethical nature, and anonymity of the study. After approval from superintendents who wished to participate, those districts' principals were contacted with invitations to participate in the study.

Principals that agreed to participate received electronic communication regarding the approval notification from school district administrators and the University of Virginia's Institutional Review Board, as well as the appropriate surveys. Principals then approved distribution of the teacher surveys to teachers at their schools. Survey instructions made principals and teachers aware of the purpose of the study and assured that any identifiable information would be stripped from survey responses. Surveys for both principal and teachers were distributed and completed electronically via e-mail link to the website QuestionPro. Survey responses were only accessible by the researcher and were password protected. Once data collection was completed, any identifiable 
information was stripped. After initial e-mails were sent with cover letters and survey information, ten days were allowed to pass before follow-up e-mails were sent in an attempt to increase response rates.

In the three intermediate school districts, all 76 elementary schools were invited to participate. Of those 76 schools, the researcher received permission from local superintendents to contact 58 of the principals regarding the study. Of those 58 principals, 32 agreed to participate. Of those 32 schools who participated, responses were received from both principals and teachers at 26 of the schools.

\section{Data Analysis}

After collecting and organizing the data, a scatterplot was graphed using data from the correlation between the independent variable of interest principals' total collective efficacy beliefs (CEB) and teachers' perceptions of opportunities for involvement in decision making (DM). After an investigation of the scatterplot for outliers, three of the 26 schools were removed. This resulted in a sample size of 23 . Displayed in Table 3.1 are descriptive statistics for the response rates of teacher participants at schools where principals also completed surveys. Table 3.2 displays the teacher response rates by school. 
Table 3.1

Descriptive Statistics for Sample School Participating Teacher Response Rates in Percentage

\begin{tabular}{ccccc}
\hline $\mathrm{N}$ & Minimum & Maximum & $\overline{\mathrm{X}}$ & $\mathrm{SD}$ \\
\hline 23 & 13.04 & 57.90 & 33.19 & 11.49
\end{tabular}

Table 3.2

Teacher Response Rates by School

\begin{tabular}{cccc}
\hline School & $\begin{array}{c}\text { Teacher } \\
\text { Respondents }\end{array}$ & $\begin{array}{c}\text { Teachers } \\
\text { Total }\end{array}$ & $\begin{array}{c}\text { Response Rate (in } \\
\text { Percentage) }\end{array}$ \\
\hline 1 & 16 & 32 & 50.00 \\
2 & 13 & 27 & 48.15 \\
3 & 4 & 16 & 25.00 \\
4 & 4 & 16 & 25.00 \\
5 & 7 & 23 & 30.43 \\
6 & 5 & 14 & 36.71 \\
7 & 5 & 20 & 25.00 \\
8 & 6 & 20 & 30.00 \\
9 & 9 & 27 & 37.04 \\
10 & 8 & 22 & 40.91 \\
11 & 8 & 31 & 29.03 \\
12 & 6 & 15 & 40.00 \\
13 & 6 & 18 & 38.89 \\
14 & 5 & 23 & 21.74 \\
15 & 11 & 19 & 57.89 \\
16 & 5 & 19 & 26.32 \\
17 & 3 & 16 & 18.75 \\
18 & 4 & 15 & 26.67 \\
19 & 4 & 16 & 25.00 \\
20 & 10 & 31 & 32.26 \\
21 & 5 & 16 & 31.25 \\
22 & 3 & 29 & 55.17 \\
23 & 5.04 & 13.04
\end{tabular}


The statistical procedure utilized to answer the study's research questions was hierarchical multiple regression analysis. Agresti and Finlay recommend multiple regression for a quantitative response variable and several quantitative explanatory variables (Agresti \& Finlay, 1997, p. 528). Hierarchical multiple regression analysis is a powerful tool that appropriately met the needs of the study. It served this role by determining the extent to which the independent variables (principals' total collective efficacy beliefs, group competence, and task analysis) accounted for variability in the dependent variable (teachers' perceived opportunities for involvement in decision making) over and above that of the independent control variables (school size, principal's years of experience, and teachers' years of experience).

Hierarchical multiple regression was chosen for this study instead of automatic selection. Automatic selection methods include backward elimination, forward selection, and stepwise regression. Backward elimination begins with all independent variables considered and deletes predictors in order of least significance until only significant predictors remain (p. 529). Forward selection starts with no potential explanatory variables and adds them in order of significance (p. 530). Each step adds significant variables providing the largest boost in $\mathrm{R}^{2}$ (p. 531). Stepwise multiple regression is a type of forward selection that drops variables from the model at each step of addition if they no longer provide significant unique contribution due to overlap with other variables (p. 532). Agresti and Finlay recommend against automated selection if theoretical construction has formed the model (p. 533). Through a review of literature, a set of predictor variables had been determined for this study. The purpose of the study was to determine to what extent principals' collective efficacy beliefs account for variability 
over and above the control variables. In order to attempt the prevention of a type I error, research questions were grouped and kept to a minimum as to reduce the total number of models being tested.

\section{Effect Size and Power}

The use of statistical significance in hypothesis testing may invite criticism, with the manner of its use having importance. Rejecting a null hypothesis based on statistical significance allows a researcher to eliminate chance or sampling error as a reason for differences between samples; however, little is given indicating the importance of findings in regard to variables' practical significance. The findings of statistical significance might be more a result of factors such as the power of the study's design or sample size (Fan \& Konold, 2010, p. 444). By considering effect size, researchers are aided in showing the importance and magnitude of sample results. In order to give practical meaning to the study's findings, or practical significance, effects sizes and regression coefficients were interpreted in context, not statistical significance alone.

This study observed the variance-accounted-for measures of $\mathrm{R}^{2}, \Delta \mathrm{R}^{2}$, and adj. $\mathrm{R}^{2}$ as effect size measurements. $\mathrm{R}^{2}$ was calculated by dividing the $\mathrm{SS}_{\text {source }}$ by the $\mathrm{SS}_{\text {total }}(\mathrm{p}$. 445). This formula is usually used for regression analysis and represents the independent or predictor variable(s) in the numerator and the total variance of the dependent variable in the denominator (p. 446). An additionally helpful measure effect size is that of $\mathrm{R}_{\text {changed }}^{2}$ or $\Delta \mathrm{R}^{2} . \Delta \mathrm{R}^{2}$ is calculated by finding the difference between the $\mathrm{R}^{2}$ of the full model and the $\mathrm{R}^{2}$ of the reduced model: $R_{\Delta}^{2}=R_{k+j}^{2}-R_{k}^{2}$. For this study $\Delta \mathrm{R}^{2}$ was 
especially useful, as it calculated the unique contribution of the variable(s) of interest over and above the other predictor variables. One more effect size measurement that was looked at was adj. $\mathrm{R}^{2}$. Adj. $\mathrm{R}^{2}$ is a corrected variance-accounted-for measure (p. 446). While it can be useful in reducing sizes that have overestimated an effect due to the number of predictors used in the prediction formula, adj. $\mathrm{R}^{2}$ may in fact reduce the value too much and result in negative $\mathrm{R}^{2}$ values.

In addition to these three $\mathrm{R}^{2}$ effect sizes, a related effect size, Cohen's $\mathrm{f}^{2}$, was also calculated. Cohen's $\mathrm{f}^{2}$ is another form of effect size based on $\mathrm{R}^{2}$, using the formula $\left(\mathrm{R}^{2}{ }_{\mathrm{AB}}\right.$ $\left.-\mathrm{R}_{\mathrm{A}}^{2}\right) /\left(1-\mathrm{R}_{\mathrm{AB}}^{2}\right)$ for hierarchical multiple regression. The term " $\mathrm{R}^{2}{ }_{\mathrm{AB}}$ " represents the full model, while " $\mathrm{R}_{\mathrm{A}}^{2}$ " represents the reduced model. The full model includes all predictors and control variables. The reduced model includes only the control variables.

Calculating Cohen's $\mathrm{f}^{2}$ assists in the calculation of achieved power, but also assigns conventional labels to the effect size: small, medium, and large. Effect sizes of .02,.15, .35 are considered small, medium, and large, respectively (Cohen, 1988, p. 413-414). After assigning conventional labels of size, Cohen's $\mathrm{f}^{2}$ was then used in conjunction with alpha error probability rate, sample size, number of predictors to carry out a post-hoc test for achieved power.

According to Miles and Shevlin (2001), power is "the probability of finding a result given that the effect does exist in the population" (p. 120). When calculating power, by convention, the alpha level is always set to .05 and the power level is always set to .80 . The probability of a Type II error is the probability of failing to find this effect that exists in the population and can be calculated as (1-power) (p. 121). Given an alpha level, an effect size, the number of predictors, and the number of participants, 
achieved power can be calculated. Miles and Shevlin recommended the use a statistical software, one of which is Faul and Erdfelder's G*Power (p. 121).

\section{Summary of Methodology}

This study was a descriptive-correlational study that used hierarchical multiple regression to answer the study's research questions. The study's population was 23 elementary schools from three contiguous districts in a Midwestern state. Quantitative data was collected using survey methodology. The independent variables of interest, principal's total collective efficacy beliefs about teachers (CEB) and its constructs of group competence (GC) and task analysis (TA), were measured using the Goddard Collective Efficacy Scale Short Form. The principal survey also collected data for the independent variables of school size (SS) and principal's years of experience (PYE). The dependent variable, teachers' perceived opportunities for involvement in decision making (DM), was measured by the Russell Teacher Involvement and Participation Scale. The teacher survey also collected data for the independent control variable of teachers' years of experience (TYE). 


\title{
Chapter Four \\ Presentation and Analysis of Data
}

\begin{abstract}
Introduction
This purpose of this chapter is to present the analyses of data. The study was descriptive-correlational and sought to determine the relationship between principals' collective efficacy beliefs about teachers and teachers' perceived opportunities for involvement in decision making. The analyses of data focused on the extent to which the independent variables of interest (principals' collective efficacy beliefs about teachers) explained variability in the dependent variable (teachers' perceived opportunities for involvement in decision making) over and above that explained by the control variables of school size, principal's years of experience, and teachers' years of experience. This chapter presents descriptive statistics, correlations, regression analysis, effect sizes, and power analysis. Statistical programs used for calculations included IBM's Statistical Package for the Social Sciences (SPSS) v. 21 and Faul and Erdfelder's G*Power v. 3.1.7.
\end{abstract}

\section{Descriptive Statistics}

This section presents the descriptive statistics for the dependent measure, independent control measures, and independent measures of interest. The dependent variable was teachers' perceived opportunities for involvement in decision making. 
Independent control variables were school size, principal's years of experience, and teachers' years of experience. The independent variables of interest were principals' overall collective efficacy beliefs about teachers and its two constructs: group competence and task analysis.

\section{Dependent Variable}

The dependent variable, teachers' perceived opportunities for involvement in decision making, was measured using Russell's Teacher Involvement and Participation Scale (1992). The instrument measured seven areas: Goals/Mission/Values, Standards, Curriculum/Instruction, Budget, Staffing, Operations, and Staff Development. Possible scores for overall decision making on the 32-item five-point Likert-type scale instrument ranged from 32 to 160 . An item score of " 1 " indicated that the teacher perceived opportunity for involvement as occurring almost never. An item score of "5" indicated that the teacher perceived opportunity for involvement as occurring almost always. An overall measure of decision making was achieved by taking the sum of all items. The scores of each school's teachers were averaged to calculate the overall mean and determine the value for the dependent variable, overall decision making (DM). 
Table 4.1 presents the number of schools in the study's analysis $(\mathrm{N})$, and the minimum, maximum, mean $(\overline{\mathrm{X}})$, and standard deviation $(\mathrm{SD})$ for the dependent variable, overall decision making (DM). The mean score for overall decision making in the study's population was 103.10 , with a standard deviation of 13.88 . A score of 74.5 was the lowest, while the highest score was 133.50 .

Table 4.1

Descriptive Statistics for the Dependent Variable: Teachers' Perceived Opportunities for Involvement in Decision Making (DM)

\begin{tabular}{cccccc}
\hline Variable & $\mathrm{N}$ & Minimum & Maximum & $\overline{\mathrm{X}}$ & $\mathrm{SD}$ \\
\hline $\mathrm{DM}$ & 23 & 74.50 & 133.50 & 103.10 & 13.88
\end{tabular}

Table 4.2 presents each school's number of teacher respondents $(\mathrm{N})$, and the minimum, maximum, mean $(\overline{\mathrm{X}})$, and standard deviation $(\mathrm{SD})$ for the dependent variable, overall decision making (DM). 
Table 4.2

Descriptive Statistics by School for the Dependent Variable: Teachers' Perceived Opportunities for Involvement in Decision Making (DM)

\begin{tabular}{cccccc}
\hline School & N & Minimum & Maximum & $\bar{X}$ & SD \\
\hline 1 & 16 & 62 & 153 & 105.19 & 24.18 \\
2 & 13 & 63 & 126 & 95.69 & 22.42 \\
3 & 4 & 82 & 124 & 97.75 & 18.19 \\
4 & 4 & 98 & 149 & 115.75 & 22.72 \\
5 & 7 & 96 & 152 & 105.85 & 20.42 \\
6 & 5 & 90 & 155 & 119.60 & 29.83 \\
7 & 5 & 79 & 111 & 96.40 & 11.91 \\
8 & 6 & 78 & 149 & 108.00 & 31.23 \\
9 & 9 & 56 & 125 & 86.33 & 28.50 \\
10 & 8 & 47 & 120 & 91.88 & 24.25 \\
11 & 8 & 78 & 147 & 114.25 & 19.75 \\
12 & 6 & 96 & 150 & 118.50 & 24.26 \\
13 & 6 & 45 & 92 & 74.50 & 16.74 \\
14 & 5 & 89 & 117 & 110.80 & 12.26 \\
15 & 11 & 51 & 134 & 101.36 & 25.01 \\
16 & 5 & 77 & 105 & 92.80 & 10.50 \\
17 & 3 & 65 & 147 & 103.67 & 41.20 \\
18 & 4 & 88 & 134 & 110.50 & 24.37 \\
19 & 4 & 114 & 160 & 133.50 & 19.28 \\
20 & 10 & 65 & 113 & 83.90 & 15.40 \\
21 & 5 & 69 & 129 & 92.80 & 22.32 \\
22 & 16 & 55 & 127 & 91.75 & 20.53 \\
23 & 3 & 89 & 134 & 120.50 & 22.65 \\
& & & & &
\end{tabular}

Independent Variables

The independent control variables were school size (SS), principal's years of experience (PYE), and teachers' years of experience (TYE). School size was defined as the total number of enrolled students at the school. Principal's years of experience was defined as the total years of experience at his/her current school. Teachers' years of experience was defined as the mean years of experience of teacher respondents at the school. 
Table 4.3 includes the number of schools in the study $(\mathrm{N})$, the minimum, maximum, mean $(\overline{\mathrm{X}})$, and the standard deviation $(\mathrm{SD})$ for the independent control variables. The smallest school included in the study had an enrollment of 250 students, while the largest school had an enrollment of 867 students. The mean enrollment was 446.48 , with a standard deviation of 176.56. One year was the lowest reported years of experience for a principal, while the highest number of years was 24 . The mean for principal's years of experience was 6.78 , with a standard deviation of 6.51 . The lowest average years of experience for teachers was 3.64, while the highest number of years was 25.25. The mean for teachers' years of experience was 13.02 , with a standard deviation of 4.90 .

Table 4.3

Descriptive Statistics for the Independent Control Variables: School Size (SS), Principal's Years of Experience (PYE), and Teachers' Years of Experience (TYE)

\begin{tabular}{cccccc}
\hline Variable & N & Minimum & Maximum & $\bar{X}$ & SD \\
\hline SS & 23 & 250 & 867 & 446.48 & 176.56 \\
PYE & 23 & 1 & 24 & 6.78 & 6.51 \\
TYE & 23 & 3.64 & 25.25 & 13.02 & 4.90
\end{tabular}

Table 4.4 displays the descriptive statistics by school for the independent variables of school size (SS), principal's years of experience (PYE), and teachers' years of experience (TYE). Also included in the table are TYE minimum, TYE maximum, TYE standard deviation (SD), MEAP (Michigan Educational Assessment Program) mean 
score for math and reading, and MEAP mean proficiency percentage for math and reading.

Table 4.4

Descriptive Statistics by School for School Size (SS), Principal's Years of Experience (PYE), Teachers' Years of Experience (TYE), MEAP Score, and MEAP proficiency

\begin{tabular}{cccc|ccc|cc}
\hline School & SS & PYE & TYE & $\begin{array}{c}\text { TYE } \\
\text { Min. }\end{array}$ & $\begin{array}{c}\text { TYE } \\
\text { Max. }\end{array}$ & $\begin{array}{c}\text { TYE } \\
\text { SD }\end{array}$ & $\begin{array}{c}\text { MEAP } \\
\text { Score }\end{array}$ & $\begin{array}{c}\text { MEAP } \\
\text { Prof. }\end{array}$ \\
\hline 1 & 864 & 18 & 15.44 & 3 & 36 & 9.56 & 435.58 & 60.68 \\
2 & 867 & 12 & 13.15 & 6 & 23 & 5.35 & 445.98 & 75.88 \\
3 & 250 & 13 & 9.75 & 3 & 17 & 7.80 & 437 & 60.77 \\
4 & 287 & 4 & 6.75 & 1 & 9 & 3.86 & 429.77 & 52.33 \\
5 & 392 & 15 & 12.57 & 3 & 25 & 9.16 & 431.4 & 54.92 \\
6 & 315 & 6 & 7.80 & 3 & 19 & 7.16 & 429.69 & 50.84 \\
7 & 489 & 24 & 15.80 & 3 & 35 & 11.69 & 442.67 & 70.74 \\
8 & 500 & 7 & 13.33 & 5 & 22 & 5.96 & 386.33 & 61.18 \\
9 & 478 & 15 & 41.00 & 6 & 24 & 5.39 & 436.28 & 62.1 \\
10 & 403 & 2 & 9.88 & 1 & 23 & 8.53 & 446.95 & 76.22 \\
11 & 600 & 3 & 8.88 & 1 & 24 & 8.13 & 441.98 & 69.55 \\
12 & 350 & 3 & 20.50 & 9 & 28 & 6.75 & 429.32 & 53.1 \\
13 & 386 & 3 & 11.33 & 3 & 19 & 7.50 & 435.4 & 61.2 \\
14 & 628 & 1 & 8.40 & 1 & 25 & 10.09 & 389.25 & 70.53 \\
15 & 441 & 5 & 3.64 & 3 & 17 & 3.63 & 483.04 & 58.47 \\
16 & 320 & 1 & 14.00 & 1 & 25 & 11.73 & 438.24 & 63.15 \\
17 & 355 & 2 & 18.00 & 1 & 30 & 15.13 & 477.04 & 46.23 \\
18 & 250 & 11 & 9.25 & 3 & 19 & 7.14 & 433.18 & 53.87 \\
19 & 271 & 2 & 25.25 & 17 & 41 & 10.72 & 421.54 & 36.27 \\
20 & 625 & 1 & 16.10 & 3 & 42 & 14.36 & 438.12 & 64.7 \\
21 & 265 & 1 & 12.00 & 1 & 22 & 9.51 & 439.07 & 66.05 \\
22 & 550 & 6 & 14.25 & 1 & 27 & 7.84 & 433.97 & 60.44 \\
23 & 383 & 1 & 19.33 & 1 & 44 & 22.19 & 436.54 & 66.53
\end{tabular}

The independent variables of interest were principal's overall collective efficacy beliefs about teachers (CEB) and its two constructs - group competence (GC) and task analysis (TA). CEB was measured using the 12-item, 6 point Likert-type Goddard Collective Efficacy Scale (CES) Short Form and its two constructs - group competence and task analysis. An item score of " 1 " indicated that the principal strongly disagreed. 
An item score of "6" indicated that the principal strongly agreed. Group competence (GC) beliefs was defined by the mean of six group competence items, while task analysis beliefs (TA) was defined by the mean of the task analysis items. Overall efficacy beliefs was defined by the sum of all CEB items.

Table 4.5 displays the number of schools in the study $(\mathrm{N})$, the minimum and maximum score, the mean $(\overline{\mathrm{X}})$, and the standard deviation $(\mathrm{SD})$ for the independent variables of interest. The lowest principal's total collective efficacy belief score was 3.42, while the highest was 5.75. The overall mean for total collective efficacy beliefs was 4.69 with a standard deviation of .56. The lowest group competence score was 2.83, while the highest was 5.83. The overall mean for group competence was 5.06 with a standard deviation of .67. The lowest task analysis score was 2.00 , while the highest was 5.67. The overall mean for task analysis scores was 4.31 with a standard deviation of .96 .

Table 4.5

Descriptive Statistics for the Independent Variables of Interest: Principal's Overall Collective Efficacy Beliefs about Teachers (CEB) and Its Two Constructs - Group Competence (GC) and Task Analysis (TA)

\begin{tabular}{cccccc}
\hline Variable & $\mathrm{N}$ & Minimum & Maximum & $\overline{\mathrm{X}}$ & $\mathrm{SD}$ \\
\hline CEB & 23 & 3.42 & 5.75 & 4.69 & .56 \\
GC & 23 & 2.83 & 5.83 & 5.06 & .67 \\
TA & 23 & 2 & 5.67 & 4.31 & .96
\end{tabular}


Table 4.6 includes the scores by school for the independent variables of principal's overall collective efficacy beliefs about teachers (CEB) and its two constructs: group competence (GC) and task analysis (TA).

Table 4.6

Scores by School for Overall Collective Efficacy Beliefs (CEB), Group Competence (GC), and Task Analysis (TA)

\begin{tabular}{cccc}
\hline School & CEB & GC & TA \\
\hline 1 & 5.33 & 5.83 & 4.83 \\
2 & 5.75 & 5.83 & 5.67 \\
3 & 4.75 & 5.17 & 4.33 \\
4 & 3.83 & 5.17 & 2.50 \\
5 & 4.83 & 5.33 & 4.33 \\
6 & 4.33 & 4.83 & 3.83 \\
7 & 4.8 & 5.60 & 4.00 \\
8 & 5.25 & 5.67 & 4.83 \\
9 & 5.42 & 5.67 & 5.17 \\
10 & 5.50 & 5.67 & 5.33 \\
11 & 4.25 & 4.00 & 4.50 \\
12 & 3.42 & 4.83 & 2.00 \\
13 & 4.33 & 5.00 & 3.67 \\
14 & 4.17 & 2.83 & 5.50 \\
15 & 4.82 & 5.20 & 4.50 \\
16 & 4.67 & 4.17 & 5.17 \\
17 & 4.33 & 5.17 & 3.50 \\
18 & 4.42 & 5.00 & 3.83 \\
19 & 4.00 & 4.83 & 3.17 \\
20 & 5.25 & 5.50 & 5.00 \\
21 & 4.33 & 5.17 & 5.50 \\
22 & 4.58 & 5.00 & 4.17 \\
23 & 4.42 & 5.00 & 3.83 \\
& & &
\end{tabular}




\section{Correlations}

Pairwise correlation analysis was conducted to investigate the relationship between the dependent variables, independent control variables, and independent variables of interest. Shown in Table 4.7 is the matrix for the correlations of these variable pairs.

\section{Table 4.7}

Matrix of Pearson's Product-Moment Correlation Coefficient for Variables: DM, SS, $P Y E, T Y E, C E B, G C$, and TA

\begin{tabular}{|c|c|c|c|c|c|c|c|}
\hline & $\mathrm{DM}$ & $\mathrm{SS}$ & PYE & TYE & CEB & $\mathrm{GC}$ & TA \\
\hline DM & - & -.22 & -.14 & .23 & $-.58 * *$ & -.31 & $-.50 *$ \\
\hline SS & & - & .29 & .01 & $.47 *$ & .13 & $.49 *$ \\
\hline PYE & & & - & -.03 & .36 & $.49 *$ & .10 \\
\hline TYE & & & & - & -.14 & .17 & -.29 \\
\hline CEB & & & & & - & $.59 * *$ & $.82 * *$ \\
\hline GC & & & & & & - & .02 \\
\hline TA & & & & & & & - \\
\hline \multicolumn{8}{|c|}{ * Correlation is significant at the 0.05 level (2-tailed). } \\
\hline \multicolumn{8}{|c|}{ ** Correlation is significant at the 0.01 level (2-tailed). } \\
\hline
\end{tabular}

\section{Decision Making}

There was a statistically significant negative correlation between decision making (DM) and two of the independent variables - total collective efficacy beliefs (CEB) and 
task analysis (TA). Total collective efficacy beliefs and decision making had a negative correlation of $r=-.58$ and a statistical significance of $\mathrm{p}<.01$. Task analysis and decision making had a negative correlation of $r=-.50$ and a statistical significance of $p=.01$. Of the other independent variables, group competence and decision making had the next strongest correlation coefficient of $r=-.31$ and a statistical significance of $\mathrm{p}=.16$.

Independent Variables

There was a statistically significant positive correlation between school size (SS) and two of the independent variables - total collective efficacy beliefs (CEB) and task analysis (TA). Total collective efficacy beliefs and school size had a positive correlation with school size of $r=.47$ and a statistical significance of $\mathrm{p}=.02$. Task analysis and school size had a positive correlation of $r=.49$ and a statistical significance of $\mathrm{p}=.02$. Of the other variables, principal's years of experience (PYE) and school size had the next strongest correlation of $r=.29$ and a statistical significance level of $\mathrm{p}=.17$.

There was a statistically significant positive correlation between principal's years of experience and one other independent variable - group competence, with a coefficient of $r=.49$ and a statistical significance of $\mathrm{p}=.02$. Of the other variables, total collective efficacy beliefs and principal's years of experience had the next strongest correlation of $r$ $=.36$ and a statistical significance of $\mathrm{p}=.09$. 


\section{Regression Analysis}

In order to answer the research questions, hierarchical multiple regression was used to determine the extent to which the independent variables accounted for variability in teachers' perceived opportunities for involvement in decision making above and beyond the variability associated with school size, principal's years of experience, and teachers' years of experience.

\section{Research Question 1}

To what extent do principals' total collective efficacy beliefs account for variability in teachers' opportunities for involvement in decision making over and above that explained by school size, principal's years of experience, and teachers' years of experience?

Table 4.8 displays the data generated from the hierarchical multiple regression of total collective efficacy beliefs and control variables on decision making. The regression contains four models, three reduced (1-3) and one full (4), entered in blocks. The first three models contain the predictor variables of school size (SS), principal's years of experience (PYE), and teachers' years of experience (TYE). In the final block, model 4 added the independent variable of principal's total collective efficacy beliefs (CEB).

In model 1 , the predictor school size produced a $\Delta \mathrm{R}^{2}$ of .046 , accounting for $4.6 \%$ of the variance in decision making. In model 2 , the predictor principal's years of experience produced a $\Delta \mathrm{R}^{2}$ of .007 , accounting for an additional $0.7 \%$ of the variance in decision making. In model 3 , the predictor teachers' years of experience produced a $\Delta \mathrm{R}^{2}$ of .051 , accounting for an additional $5.1 \%$ of the variance in decision making. The total 
variability explained by the three predictors school size (SS), principal's years of experience (PYE), and teachers' years of experience (TYE) was $10.4 \%$ of the variability in overall decision making.

In model 4, the addition of the predictor principal's total collective efficacy beliefs produced a $\Delta \mathrm{R}^{2}$ of .264 . An additional $26.4 \%$ of the variance in decision making was explained by principal's total collective efficacy beliefs over and above that explained by SS, PYE, and TYE. The $\Delta \mathrm{F}$ for overall collective efficacy beliefs was 7.515, with statistical significance at $\mathrm{p}=.01$. The full model, with the inclusion of all four independent variables accounted for a total $\mathrm{R}^{2}$ of .368 .

Table 4.8

Hierarchical Multiple Regression Analysis of Variability in Decision Making Explained by Principals' Overall Collective Efficacy Beliefs (CEB)

\begin{tabular}{ccccccc}
\hline $\begin{array}{c}\text { Model/ } \\
\text { Block }\end{array}$ & Variable + & $\mathrm{R}^{2}$ & adj. $\mathrm{R}^{2}$ & $\Delta \mathrm{R}^{2}$ & $\Delta \mathrm{F}$ & sig. $\Delta \mathrm{F}$ \\
\hline 1 & SS & .046 & -.001 & .046 & 1.020 & .32 \\
2 & PYE & .053 & -.041 & .007 & .148 & .71 \\
3 & TYE & .104 & -.037 & .051 & 1.077 & .31 \\
4 & CEB & .368 & .228 & .264 & 7.515 & $.01 *$ \\
$* \mathrm{p} \leq .05$ & & & & & &
\end{tabular}

Dependent Variable: DM

$\mathrm{SS}=$ school size, $\mathrm{PYE}=$ principal's years of experience, TYE $=$ teachers' years of experience, and CEB = total collective efficacy beliefs 


\section{Research Question 2}

To what extent does group competence account for variability in teachers' opportunities

for involvement in decision making over and above that explained by school size,

principal's years of experience, and teachers' years of experience?

Table 4.9 displays the data generated from the hierarchical multiple regression of group competence and control variables on decision making. The regression contains four models, three reduced (1-3) and one full (4), entered in blocks. The first three models contain the predictor variables of school size (SS), principal's years of experience (PYE), and teachers' years of experience (TYE). In the final block, model 4 added the independent variable of group competence (GC).

As previously stated, in model 1 the predictor school size produced a $\Delta \mathrm{R}^{2}$ of .046 , accounting for $4.6 \%$ of the variance in decision making. In model 2 , the predictor principal's years of experience produced a $\Delta \mathrm{R}^{2}$ of .007 , accounting for an additional $0.7 \%$ of the variance in decision making. In model 3, the predictor teachers' years of experience produced a $\Delta \mathrm{R}^{2}$ of .051 , accounting for an additional $5.1 \%$ of the variance in decision making. The total variability explained by the three predictors school size (SS), principal's years of experience (PYE), and teachers' years of experience (TYE) was $10.4 \%$ of the variability in overall decision making.

In model 4 , the addition of the predictor group competence produced a $\Delta \mathrm{R}^{2}$ of .107. An additional $10.7 \%$ of the variance in decision making was explained by group competence over and above that explained by SS, PYE, and TYE. The $\Delta \mathrm{F}$ for group competence was 2.446 , with statistical significance at $\mathrm{p}=.14$. The full model, with the inclusion of all four independent variables accounted for a total $\mathrm{R}^{2}$ of .211 . 
Table 4.9

Hierarchical Multiple Regression Analysis of Variability in Decision Making Explained by Group Competence (GC)

\begin{tabular}{ccccccc}
\hline $\begin{array}{c}\text { Model/ } \\
\text { Block }\end{array}$ & Variable + & $\mathrm{R}^{2}$ & adj. $\mathrm{R}^{2}$ & $\Delta \mathrm{R}^{2}$ & $\Delta \mathrm{F}$ & sig. $\Delta \mathrm{F}$ \\
\hline 1 & $\mathrm{SS}$ & .046 & -.001 & .046 & 1.020 & .32 \\
2 & PYE & .053 & -.041 & .007 & .148 & .71 \\
3 & TYE & .104 & -.037 & .051 & 1.077 & .31 \\
4 & GC & .211 & .036 & .107 & 2.446 & .14 \\
$* \mathrm{p} \leq .05$ & & & & & &
\end{tabular}

Dependent Variable: DM

SS = school size, PYE = principal's years of experience, TYE = teachers' years of experience, and GC $=$ group competence

Research Question 3

To what extent does task analysis account for variability in teachers' opportunities for involvement in decision making over and above that explained by school size, principal's years of experience, and teachers' years of experience?

Table 4.10 displays the data generated from the hierarchical multiple regression of task analysis and control variables on decision making. The regression contains four models, three reduced (1-3) and one full (4), entered in blocks. The first three models contain the predictor variables of school size (SS), principal's years of experience (PYE), 
and teachers' years of experience (TYE). In the final block, model 4 added the independent variable of group competence (GC).

Once again, in model 1 the predictor school size produced a $\Delta \mathrm{R}^{2}$ of .046 , accounting for $4.6 \%$ of the variance in decision making. In model 2 , the predictor principal's years of experience produced a $\Delta \mathrm{R}^{2}$ of .007 , accounting for an additional $0.7 \%$ of the variance in decision making. In model 3, the predictor teachers' years of experience produced a $\Delta \mathrm{R}^{2}$ of .051 , accounting for an additional $5.1 \%$ of the variance in decision making. The total variability explained by the three predictors school size (SS), principal's years of experience (PYE), and teachers' years of experience (TYE) was $10.4 \%$ of the variability in overall decision making.

In model 4 , the addition of the predictor task analysis produced a $\Delta R^{2}$ of .168 . An additional $16.8 \%$ of the variance in decision making was explained by task analysis over and above that explained by SS, PYE, and TYE. The $\Delta \mathrm{F}$ for task analysis was 4.170 , with statistical significance at $\mathrm{p}=.06$. The full model, with the inclusion of all four independent variables accounted for a total $\mathrm{R}^{2}$ of .273 . 
Table 4.10

Hierarchical Multiple Regression Analysis of Variability in Decision Making Explained by Task Analysis (TA)

\begin{tabular}{ccccccc}
\hline $\begin{array}{c}\text { Model/ } \\
\text { Block }\end{array}$ & Variable + & $\mathrm{R}^{2}$ & adj. $\mathrm{R}^{2}$ & $\Delta \mathrm{R}^{2}$ & $\Delta \mathrm{F}$ & sig. $\Delta \mathrm{F}$ \\
\hline 1 & $\mathrm{SS}$ & .046 & -.001 & .046 & 1.020 & .32 \\
2 & PYE & .053 & -.041 & .007 & .148 & .71 \\
3 & TYE & .104 & -.037 & .051 & 1.077 & .31 \\
4 & TA & .273 & .111 & .168 & 4.170 & .06 \\
$* \mathrm{p} \leq .05$ & & & & & &
\end{tabular}

Dependent Variable: DM

SS $=$ school size, $\mathrm{PYE}=$ principal's years of experience, $\mathrm{TYE}=$ teachers' years of experience, and TA $=$ task analysis

Table 4.11 displays the data generated from hierarchical multiple regression of group competence and task analysis, jointly (GC+TA), and control variables on decision making (DM). The regression contains two models, one reduced and one full, entered in blocks. The first model contains the control variables of school size (SS), principal's years of experience (PYE), and teachers' years of experience (TYE). In the second block, model 2 added the independent variables of group competence (GC) and task analysis (TA).

In model 1 the predictors school school size (SS), principal's years of experience (PYE), and teachers' years of experience (TYE) produced a $\Delta \mathrm{R}^{2}$ of .104, accounting for $10.4 \%$ of the variance in decision making. In model 2 , the addition of the predictors group competence and task analysis produced a $\Delta \mathrm{R}^{2}$ of .263 . An additional $26.3 \%$ of the variance in decision making was explained by group competence and task analysis, 
jointly, over and above that explained by SS, PYE, and TYE. The $\Delta \mathrm{F}$ for group competence and task analysis was 3.534, with statistical significance of $p=.05$. The full model, with the inclusion of all fiva independent variables accounted for a total $\mathrm{R}^{2}$ of .367.

Table 4.11

Hierarchical Multiple Regression Analysis of Variability in Decision Making Explained by Group Competence (GC) and Task Analysis (TA)

\begin{tabular}{ccccccc}
\hline $\begin{array}{c}\text { Model/ } \\
\text { Block }\end{array}$ & Variable + & $\mathrm{R}^{2}$ & adj. $\mathrm{R}^{2}$ & $\Delta \mathrm{R}^{2}$ & $\Delta \mathrm{F}$ & sig. $\Delta \mathrm{F}$ \\
\hline 1 & SS, PYE, TYE & .104 & -.037 & .104 & .736 & .54 \\
2 & GC, TA & .367 & .181 & .263 & 3.534 & $.05^{*}$ \\
$* \mathrm{p} \leq .05$ & & & & \\
Dependent Variable: DM & \\
SS = school size, PYE = principal's years of experience, TYE = teachers' years of experience, GC = group \\
competence, and TA = task analysis
\end{tabular}

\section{Coefficients}

Regression coefficients utilize unit-based interpretation of the relationship between independent and dependent variables. Prediction equations consist of a constant $(a)$, where the prediction line intersects the $\mathrm{y}$-axis at $\mathrm{x}=0$ and a series of coefficients $(b)$ for each independent variable $(x)$. This results in an equation of $y=a+b_{1} x_{1}+b_{2} x_{2}+$ $b_{3} x_{3} \ldots$ With these coefficients a researcher can describe the change in the dependent variable in terms of independent variable coefficients. Coefficients can be either 
unstandardized (in variable measurement units) or standardized (in variable standard deviations).

Table 4.12 displays the regression coefficients for the prediction equation of the independent variable, total collective efficacy beliefs (CEB), on the dependent variable (DM), holding constant the variables of school size, principal's years of experience, and teachers' years of experience. For the variable principal's total collective efficacy beliefs, the unstandardized coefficient B was -14.377 . The standardized coefficient beta for CEB was -.611. The t-score for CEB coefficients was -2.741 with a statistical significance of $\mathrm{p}=.01$.

Table 4.12

Regression Coefficients for the Full Model Prediction Equation of CEB on DM, with Control Variables of SS, PYE, and TYE.

\begin{tabular}{ccccc}
\hline & $\begin{array}{c}\text { Unstandardized } \\
\text { Coefficient B }\end{array}$ & $\begin{array}{c}\text { Standardized } \\
\text { Coefficient Beta }\end{array}$ & T & sig. \\
\hline SS & 162.321 & - & 6.798 & .00 \\
PYE & .004 & .053 & .245 & .81 \\
TYE & .139 & .065 & .321 & .75 \\
CEB & .411 & .145 & .766 & .45 \\
$* \mathrm{p} \leq .05$ & -14.377 & -.611 & -2.741 & $.01 *$ \\
$\begin{array}{l}\text { SS }=\text { school size, PYE }=\text { principal's years of experience, TYE }=\text { teachers' years of experience, and CEB = total } \\
\text { collective efficacy beliefs }\end{array}$
\end{tabular}


Table 4.13 displays the regression coefficients for the prediction equation of the independent variable, group competence (GC), on the dependent variable (DM), holding constant the variables of school size, principal's years of experience, and teachers' years of experience. For the variable group competence, the unstandardized coefficient B was 7.926. The standardized coefficient beta for GC was -.385. The t-score for GC coefficients was -1.564 with a statistical significance of $p=.14$.

Table 4.13

Regression Coefficients for the Full Model Prediction Equation of GC on DM, with Control Variables of SS, PYE, and TYE.

\begin{tabular}{ccccc}
\hline & $\begin{array}{c}\text { Unstandardized } \\
\text { Coefficient B }\end{array}$ & $\begin{array}{c}\text { Standardized } \\
\text { Coefficient Beta }\end{array}$ & $\mathrm{t}$ & sig. \\
\hline (Constant) & 137.769 & - & 5.518 & .00 \\
SS & -.016 & -.201 & -.916 & .37 \\
PYE & .241 & .113 & .450 & .66 \\
TYE & .835 & .295 & 1.377 & .19 \\
GC & -7.926 & -.385 & -1.564 & .14 \\
$* \mathrm{p} \leq .05$ & & & \\
SS $=$ school size, PYE $=$ principal's years of experience, TYE $=$ teachers' years of experience, and GC = group \\
competence
\end{tabular}

Table 4.14 displays the regression coefficients for the prediction equation of the independent variable, task analysis (TA), on the dependent variable (DM), holding constant the variables of school size, principal's years of experience, and teachers' years 
of experience. For the variable task analysis, the unstandardized coefficient B was 7.287. The standardized coefficient beta for TA was -.502. The t-score for TA coefficients was -2.042 with a statistical significance of $\mathrm{p}=.06$.

Table 4.14

Regression Coefficients for the Full Model Prediction Equation of TA on DM, with Control Variables of SS, PYE, and TYE.

\begin{tabular}{ccccc}
\hline & $\begin{array}{c}\text { Unstandardized } \\
\text { Coefficient B }\end{array}$ & $\begin{array}{c}\text { Standardized } \\
\text { Coefficient Beta }\end{array}$ & $\mathrm{t}$ & sig. \\
\hline (Constant) & 131.066 & - & 7.507 & .00 \\
SS & .005 & .063 & .256 & .81 \\
PYE & -.236 & -.111 & -.526 & .75 \\
TYE & .219 & .077 & .362 & .45 \\
TA & -7.287 & -.502 & -2.042 & .06 \\
$* \mathrm{p} \leq .05$ & & & \\
$\mathrm{SS}=$ school size, PYE $=$ principal's years of experience, TYE $=$ teachers' years of experience, and TA = task analysis
\end{tabular}

Table 4.15 displays the regression coefficients for the prediction equation of the independent variables, group competence and task analysis, jointly (GC+TA), on the dependent variable (DM), holding constant the variables of school size, principal's years of experience, and teachers' years of experience. For the variable group competence, the unstandardized coefficient B was -7.455. The standardized coefficient beta for GC was .362. The $\mathrm{t}$-score for GC coefficients was -1.594 with a statistical significance of $\mathrm{p}=.13$. For the variable task analysis, the unstandardized coefficient B was -7.018. The 
standardized coefficient beta for TA was -.483. The t-score for TA coefficients was 2.047 with a statistical significance of $\mathrm{p}=.06$.

Table 4.15

Regression Coefficients for the Full Model Prediction Equation of GC+TA on DM, with Control Variables of SS, PYE, and TYE.

\begin{tabular}{ccccc}
\hline & $\begin{array}{c}\text { Unstandardized } \\
\text { Coefficient B }\end{array}$ & $\begin{array}{c}\text { Standardized } \\
\text { Coefficient Beta }\end{array}$ & $\mathrm{t}$ & sig. \\
\hline (Constant) & 162.963 & - & 6.244 & .00 \\
SS & .004 & .047 & .199 & .85 \\
PYE & .153 & .072 & .309 & .76 \\
TYE & .419 & .148 & .706 & .49 \\
GC & -7.455 & -.362 & -1.594 & .06 \\
TA & -7.018 & -.483 & -2.047 & \\
$* \mathrm{p} \leq .05$ & &
\end{tabular}

\section{Effect Sizes}

$\Delta \mathrm{R}^{2}$

Principal's total collective efficacy beliefs about teachers (CEB) had the largest $\mathrm{R}^{2}$ effect size of the independent variables of interest. CEB had a $\Delta \mathrm{R}^{2}$ of .264, explaining $26.4 \%$ of the variability in DM over and above that explained by SS, PYE, and TYE. Task analysis had the next largest $\mathrm{R}^{2}$ effect size of the independent variables of interest. Task analysis had an $\Delta \mathrm{R}^{2}$ of .168, explaining $16.8 \%$ of the variability in DM over and above that explained by SS, PYE, and TYE. The smallest effect size was group 
competence. Group competence had a $\Delta \mathrm{R}^{2}$ of .107 , explaining $10.7 \%$ of the variability in DM over and above that explained by SS, PYE, and TYE. Group competence and task analysis entered jointly (GC+TA) had a $\Delta \mathrm{R}^{2}$ of .263 , explaining $26.3 \%$ of the variability in DM over and above that explained by SS, PYE, and TYE.

Cohen's f ${ }^{2}$

Table 4.16 displays Cohen's $\mathrm{f}^{2}$ effect size for the independent variables CEB, GC, TA, and GC+TA. With an $\mathrm{R}_{\mathrm{AB}}^{2}$ of .368 (full model with all predictors and control variables) and $\mathrm{R}_{\mathrm{A}}^{2}$ of .104 (only control variables), principal's total collective efficacy beliefs about teachers (CEB) had a large $\mathrm{f}^{2}$ effect size of .359. With an $\mathrm{R}_{\mathrm{AB}}^{2}$ of .211 and $\mathrm{R}_{\mathrm{A}}^{2}$ of .104 , group competence (GC) had a small $\mathrm{f}^{2}$ effect size of .136. With an $\mathrm{R}_{\mathrm{AB}}^{2}$ of .273 and $\mathrm{R}_{\mathrm{A}}^{2}$ of .104 , task analysis (TA) had a medium $\mathrm{f}^{2}$ effect size of .232 . With an $\mathrm{R}_{\mathrm{AB}}^{2}$ of .273 and $\mathrm{R}_{\mathrm{A}}^{2}$ of .104 , group competence and task analysis entered jointly (GC+TA) had a large $\mathrm{f}^{2}$ effect size of .357 .

Table 4.16

Cohen's $f^{2}$ Effect Size for CEB, GC, and TA, Given $R_{A}^{2}$ and $R_{A B}^{2}$

\begin{tabular}{ccccc}
\hline & $\mathrm{R}_{\mathrm{A}}^{2}$ & $\mathrm{R}_{\mathrm{AB}} \mathrm{f}^{2}$ & Size \\
\hline CEB & .104 & .368 & .359 & Large \\
$\mathrm{GC}$ & .104 & .211 & .136 & Small \\
TA & .104 & .273 & .232 & Medium \\
GC+TA & .104 & .367 & .357 & Large \\
CEB $=$ total collective efficacy beliefs, $\mathrm{GC}=$ group competence, and TA $=$ task analysis
\end{tabular}




\section{Power}

Power was calculated using Faul and Erdfelder's G*Power post hoc test for achieved power with $\mathrm{f}^{2}$ effect sizes of .359 (CEB), .136 (GC), .232 (TA), and .357 (GC+TA), alpha level of $\mathrm{p} \leq .05,4$ predictors, and sample size of $\mathrm{N}=23$, only one of the independent variables of interest was near the conventional power threshold of .80 . Table 4.17 displays the data generated by the power analyses. Principal's total collective efficacy beliefs achieved a power of .78, while group competence, task analysis, and GC+TA achieved levels of .39, .59, and .65 , respectively.

Table 4.17

Test of Statistical Power for Variables CEB, GC, TA, and GC+TA Regressed on DM, while controlling for SS, PYE, and TYE

\begin{tabular}{ccc}
\hline Variable $(\mathrm{s})$ & $\mathrm{f}^{2}$ & Power \\
\hline CEB & .359 & .78 \\
GC & .136 & .39 \\
TA & .232 & .59 \\
GC+TA & .357 & .65 \\
CEB $=$ total collective efficacy beliefs, GC $=$ group competence, and TA = task analysis &
\end{tabular}

Ancillary Findings

Overall Decision Making Standard Deviation

One type of descriptive data drawn from this study is the standard deviations of the dependent variable decision making within each school. These data allow one to pose 
the question: how do each of the independent variables of interest relate to the variability of individual teacher scores within a school?

Calculations were conducted to produce the standard deviations of each school's sample of teacher scores. These standard deviations were then pairwise correlated with the three independent variables of interest. Shown in table 4.18 are the correlations between decision making standard deviation (DMSD), overall decision making (DM), and independent variables (SS, PYE, TYE, CEB, GC, and TA).

The largest correlation coefficient was that of decision making standard deviation and the construct of group competence with $r=.39$. This $r$ coefficient was also the only correlation to approach statistical significance of $p \leq .05$ with value of $p=.07$. The next largest correlation coefficient was that of decision making standard deviation (DMSD) and the dependent variable of overall decision making (DM) with $r=.21$. This $r$ coefficient fell far short of reaching statistical significance of $\mathrm{p} \leq .05$ with a value of $\mathrm{p}=$ .34 .

Table 4.18

Pearson's Product-Moment Correlation Coefficients for Variables: DMSD, DM, SS, PYE, TYE, CEB, GC, and TA

\begin{tabular}{|c|c|c|c|c|c|c|c|}
\hline & $\mathrm{DM}$ & SS & PYE & TYE & CEB & GC & TA \\
\hline DMSD & .21 & -.11 & -.05 & .03 & .06 & .39 & -.20 \\
\hline \multicolumn{8}{|c|}{ * Correlation is significant at the 0.05 level (2-tailed). } \\
\hline \multicolumn{8}{|c|}{ ** Correlation is significant at the 0.01 level (2-tailed). } \\
\hline $\begin{array}{l}\text { DMSD = d } \\
\text { years of ex } \\
\text { competenc }\end{array}$ & making & $\begin{array}{l}\text { d devi } \\
\text { ers' ye } \\
\text { is }\end{array}$ & $M=o v$ & $\begin{array}{l}\text { cision } \mathrm{m} \\
=\text { total } \mathrm{c}\end{array}$ & $\begin{array}{l}S=\text { sch } \\
\text { e effica }\end{array}$ & & \\
\hline
\end{tabular}


Table 4.19 displays the data generated from hierarchical multiple regression of group competence and control variables on decision making standard deviation. The regression contains four models, three reduced (1-3) and one full (4), entered in blocks. The first three models contain the predictor variables of school size (SS), principal's years of experience (PYE), and teachers' years of experience (TYE). In the final block, model 4 added the independent variable of group competence (GC).

In model 1 the predictor school size produced a $\Delta \mathrm{R}^{2}$ of .011 , accounting for $1.1 \%$ of the variance in decision making standard deviation. In model 2 , the predictor principal's years of experience produced a $\Delta \mathrm{R}^{2}$ of .000 , accounting for no additional variance in decision making standard deviation. In model 3, the predictor teachers' years of experience produced a $\Delta \mathrm{R}^{2}$ of .001 , accounting for an additional $0.1 \%$ of the variance in decision making standard deviation. The total variability explained by the three predictors school size (SS), principal's years of experience (PYE), and teachers' years of experience (TYE) was $1.3 \%$ of the variability in decision making standard deviation.

In model 4 , the addition of the predictor group competence produced a $\Delta \mathrm{R}^{2}$ of .226. An additional $22.6 \%$ of the variance in decision making standard deviation was explained by group competence over and above that explained by SS, PYE, and TYE. The $\Delta \mathrm{F}$ for group competence was 5.329 , with statistical significance at $\mathrm{p}=.03$. The full model, with the inclusion of all four independent variables accounted for a total $\mathrm{R}^{2}$ of .238 
Table 4.19

Hierarchical Multiple Regression Analysis of Variability in Decision Making Standard Deviation Explained by Group Competence (GC)

\begin{tabular}{ccccccc}
\hline Model & Variable + & $\mathrm{R}^{2}$ & adj. $\mathrm{R}^{2}$ & $\Delta \mathrm{R}^{2}$ & $\Delta \mathrm{F}$ & sig. $\Delta \mathrm{F}$ \\
\hline 1 & $\mathrm{SS}$ & .011 & -.036 & .011 & .240 & .63 \\
2 & PYE & .012 & -.087 & .000 & .005 & .94 \\
3 & TYE & .013 & -.143 & .001 & .019 & .89 \\
$*_{\mathrm{p}} \leq .05$ & $\mathrm{GC}$ & .238 & .069 & .226 & 5.329 & $.03 *$
\end{tabular}

Dependent Variable: DMSD

DMSD = decision making standard deviation, $\mathrm{SS}=$ school size, $\mathrm{PYE}=$ principal's years of experience, TYE = teachers' years of experience, and GC = group competence

Table 4.20 displays the regression coefficients for the prediction equation of the independent variable, group competence (GC), on the dependent variable (DMSD), holding constant the variables of school size, principal's years of experience, and teachers' years of experience. For the variable group competence, the unstandardized coefficient B was 5.640. The standardized coefficient beta for TA was .558. The t-score for GC coefficients was 2.308 with a statistical significance of $\mathrm{p}=.03$. 
Table 4.20

Regression Coefficients for the Full Model Prediction Equation of GC on DMSD, with Control Variables of SS, PYE, and TYE.

\begin{tabular}{ccccc}
\hline & $\begin{array}{c}\text { Unstandardized } \\
\text { Coefficient B }\end{array}$ & $\begin{array}{c}\text { Standardized } \\
\text { Coefficient Beta }\end{array}$ & $\mathrm{t}$ & sig. \\
\hline (Constant) & -1.543 & - & -.128 & .90 \\
$\mathrm{SS}$ & -.004 & -.092 & -.427 & .67 \\
$\mathrm{PYE}$ & -.310 & -.296 & -1.198 & .25 \\
$\mathrm{TYE}$ & -.096 & -.069 & -.329 & .75 \\
$\mathrm{GC}$ & 5.640 & .558 & 2.308 & $.03 *$ \\
$* \mathrm{p} \leq .05$ & & & & \\
Dependent Variable: DMSD & & &
\end{tabular}

DMSD = decision making standard deviation, $\mathrm{SS}=$ school size, $\mathrm{PYE}=$ principal's years of experience, $\mathrm{TYE}=$ teachers' years of experience, and GC = group competence 
Areas of Decision Making

The Russell Teacher Involvement and Participation Scale measured seven areas of decision making, goals/vision/mission (GVM), standards (STND), curriculum and instruction (CI), budget (BDGT), staffing (STFF), operations (OPER), and staff development (SDEV). Table 4.21 displays descriptive statistics for these seven areas.

Table 4.21

Descriptive Statistics for Areas of Decision Making

\begin{tabular}{ccccc}
\hline $\begin{array}{c}\text { Decision } \\
\text { Making Area }\end{array}$ & $\overline{\mathrm{X}}$ & Minimum & Maximum & SD \\
\hline GVM & 3.84 & 2.93 & 4.50 & .41 \\
STND & 3.63 & 2.63 & 4.38 & .38 \\
CI & 3.52 & 2.80 & 4.25 & .43 \\
BDGT & 2.40 & 1.38 & 4.31 & .72 \\
STFF & 2.49 & 1.58 & 3.56 & .59 \\
OPER & 2.69 & 1.93 & 3.95 & .52 \\
SDEV & 3.54 & 2.50 & 4.63 & .51 \\
GVM = goals/vision/mission, STND = standards, CI = curriculum and instruction, BDGT = budget, STFF = staffing, \\
OPER = operations, and SDEV = staff development
\end{tabular}


Table 4.22

Descriptive Statistics by School for Areas of Decision Making

\begin{tabular}{c|ccccccc|cc}
\hline School & GVM & STND & CI & BDGT & STFF & OPER & SDEV & Mean & SD \\
& & & & & & & & & \\
\hline 1 & 3.88 & 3.62 & 3.78 & 2.44 & 2.41 & 2.60 & 3.73 & 3.21 & .69 \\
2 & 3.52 & 3.52 & 3.48 & 2.17 & 2.08 & 2.57 & 3.33 & 2.95 & .66 \\
3 & 3.75 & 3.63 & 3.50 & 2.38 & 2.00 & 2.65 & 3.25 & 3.02 & .68 \\
4 & 4.25 & 3.81 & 3.51 & 3.13 & 3.56 & 3.5 & 3.88 & 3.66 & .36 \\
5 & 4.32 & 3.79 & 2.80 & 2.40 & 3.46 & 2.49 & 3.75 & 3.29 & .73 \\
6 & 4.50 & 4.15 & 4.23 & 3.35 & 2.55 & 3.28 & 4.1 & 3.74 & .69 \\
7 & 3.75 & 3.55 & 3.26 & 2.15 & 2.32 & 2.44 & 4.1 & 3.08 & .77 \\
8 & 4.08 & 3.97 & 3.63 & 3.17 & 2.63 & 3.02 & 3.38 & 3.41 & .52 \\
9 & 3.56 & 3.17 & 3.08 & 1.58 & 1.58 & 2.07 & 2.89 & 2.56 & .81 \\
10 & 3.25 & 3.38 & 3.32 & 1.91 & 2.56 & 2.30 & 3.19 & 2.84 & .58 \\
11 & 4.09 & 4.00 & 4.20 & 1.97 & 2.41 & 2.43 & 4.31 & 3.34 & 1.02 \\
12 & 3.75 & 3.83 & 3.79 & 3.38 & 3.08 & 3.30 & 3.92 & 3.58 & .32 \\
13 & 3.04 & 2.63 & 2.95 & 1.38 & 1.68 & 1.93 & 2.50 & 2.30 & .64 \\
14 & 4.25 & 3.80 & 3.34 & 2.60 & 2.60 & 3.28 & 3.60 & 3.35 & .61 \\
15 & 3.80 & 3.80 & 3.64 & 2.07 & 2.52 & 2.65 & 3.64 & 3.16 & .72 \\
16 & 4.10 & 3.45 & 3.54 & 1.50 & 1.65 & 2.12 & 3.65 & 2.86 & 1.07 \\
17 & 4.00 & 3.58 & 3.31 & 2.58 & 3.08 & 3.07 & 3.33 & 3.28 & .44 \\
18 & 4.00 & 3.75 & 3.71 & 3.00 & 3.00 & 3.05 & 3.81 & 3.48 & .44 \\
19 & 4.38 & 4.38 & 4.25 & 4.31 & 3.56 & 3.95 & 4.63 & 4.21 & .35 \\
20 & 2.93 & 2.98 & 3.07 & 2.13 & 1.88 & 2.10 & 2.68 & 2.54 & .49 \\
21 & 3.70 & 3.30 & 3.54 & 1.40 & 1.95 & 2.40 & 2.95 & 2.75 & .86 \\
22 & 3.67 & 3.67 & 2.86 & 2.19 & 2.25 & 2.45 & 3.41 & 2.93 & .66 \\
23 & 3.75 & 3.75 & 4.24 & 2.08 & 2.42 & 2.20 & 3.33 & 3.11 & .87
\end{tabular}

GVM = goals/vision/mission, $\mathrm{STND}=$ standards, $\mathrm{CI}=$ curriculum and instruction, $\mathrm{BDGT}=$ budget, $\mathrm{STFF}=$ staffing, OPER $=$ operations, and SDEV $=$ staff development

The seven areas of decision making, goals/vision/mission (GVM), standards (STND), curriculum and instruction (CI), budget (BDGT), staffing (STFF), operations (OPER), and staff development (SDEV), each measure a separate area of decision making involvement. In order to observe information that may be obscured by the grand mean score for overall decision making (DM), the seven areas (or groups) were compared 
based on their individual overall sample mean scores (or outcomes). The aim of this comparison was to find subsets within decision making that were statistically different. These subsets would allow for more detailed analysis that may otherwise be shrouded due to the grand mean score of overall decision making. The statistical procedures used for comparison were analysis of variance (ANOVA) and the Tukey HSD post-hoc test.

Table 4.23 displays the data generated from the analysis of variance. With a statistical significance of $p<.001$, at least one of the seven areas was found to be statistically different.

Table 4.23

Analysis of Variance (ANOVA) Comparing Means of the Seven Areas of Decision Making (DM)

\begin{tabular}{cccccc}
\hline & Sum of Squares & $d f$ & Mean Square & F & sig. \\
\hline Between Groups & 50.678 & 6 & 8.446 & 31.114 & $.00^{*}$ \\
Within Groups & 41.806 & 154 & .271 & & \\
$\quad$ Total & 92.484 & 160 & & & \\
& & & & & \\
$* \mathrm{p}<.001$ & & & &
\end{tabular}

When an analysis of variance test containing more than two groups rejects the null hypothesis, a post hoc test provides further analysis. Tukey’s Honestly Significant Different (HSD) post hoc test determines which means are statistically different and which are not (Gravetter \& Wellnau, 2008). Two subsets were determined to be contained within overall decision making (DM). Subset A (DMSETA) contained the areas of goals/vision/mission (GVM), standards (STND), curriculum and instruction (CI), and staff development (SDEV). Subset B (DMSETB) contained the areas of budget 
(BDGT), staffing (STFF), and operations (OPER). Table 4.24 displays the data from a Tukey post hoc test for the seven areas of decision making. The mean differences between the four areas contained within subset A and the three areas in subset B were all statistically significant at $\mathrm{p}<.001$. 
Table 4.24

Tukey Post Hoc Test for the Seven Areas of Decision Making

\begin{tabular}{|c|c|c|c|}
\hline $\begin{array}{c}\text { Decision Making } \\
\text { Area (I) }\end{array}$ & $\begin{array}{c}\text { Decision Making } \\
\text { Area }(\mathrm{J})\end{array}$ & $\begin{array}{c}\text { Mean Difference } \\
(\mathrm{I}-\mathrm{J})\end{array}$ & Sig. \\
\hline \multirow[t]{6}{*}{ GVM } & STND & .21 & .82 \\
\hline & CI & .32 & .38 \\
\hline & BDGT & $1.44 *$ & .00 \\
\hline & STFF & $1.35^{*}$ & .00 \\
\hline & OPER & $1.15^{*}$ & .00 \\
\hline & SDEV & .30 & .44 \\
\hline \multirow[t]{6}{*}{ STND } & GVM & -.21 & .82 \\
\hline & CI & .11 & .99 \\
\hline & BDGT & $1.23^{*}$ & .00 \\
\hline & STFF & $1.14 *$ & .00 \\
\hline & OPER & $.94 *$ & .00 \\
\hline & SDEV & .09 & .99 \\
\hline \multirow[t]{6}{*}{$\mathrm{CI}$} & GVM & -.32 & .38 \\
\hline & STND & -.11 & .99 \\
\hline & BDGT & $1.12 *$ & .00 \\
\hline & STFF & $1.03 *$ & .00 \\
\hline & OPER & $.83 *$ & .00 \\
\hline & SDEV & -.01 & 1.00 \\
\hline \multirow[t]{6}{*}{ BDGT } & GVM & $-1.44 *$ & .00 \\
\hline & STND & $-1.23 *$ & .00 \\
\hline & CI & $-1.12 *$ & .00 \\
\hline & STFF & -.09 & 1.00 \\
\hline & OPER & -.29 & .51 \\
\hline & SDEV & $-1.13^{*}$ & .00 \\
\hline \multirow[t]{6}{*}{ STFF } & GVM & $-1.35 *$ & .00 \\
\hline & STND & $-1.14 *$ & .00 \\
\hline & CI & $-1.03 *$ & .00 \\
\hline & BDGT & .09 & 1.00 \\
\hline & OPER & -.20 & .85 \\
\hline & SDEV & $-1.05^{*}$ & .00 \\
\hline \multirow[t]{6}{*}{ OPER } & GVM & $-1.15^{*}$ & .00 \\
\hline & STND & $-.94 *$ & .00 \\
\hline & CI & $-.83 *$ & .00 \\
\hline & BDGT & .29 & .51 \\
\hline & STFF & .20 & .85 \\
\hline & SDEV & $-.85 *$ & .00 \\
\hline \multirow[t]{6}{*}{ SDEV } & GVM & -.30 & .44 \\
\hline & STND & -.09 & 1.00 \\
\hline & CI & .01 & 1.00 \\
\hline & BDGT & $1.13^{*}$ & .00 \\
\hline & STFF & $1.05 *$ & .00 \\
\hline & OPER & $.85^{*}$ & .00 \\
\hline
\end{tabular}

* The mean difference is significant at the 0.05 level.

GVM = goals/vision/mission, STND = standards, CI = curriculum and instruction, BDGT = budget, STFF = staffing, OPER $=$ operations, and SDEV $=$ staff development 
Table 4.25 displays a matrix of bivariate correlations for the variables of decisionmaking subset A (DMSETA), decision-making subset B (DMSETB), overall decision making (DM), and independent variables. Decision-making subset A and decisionmaking subset B had a positive correlation of $r=.73$ and statistical significance of $\mathrm{p}<$ .01. Decision-making subset A and overall decision-making had a positive correlation of $r=.92$ and statistical significance of $\mathrm{p}=.00$. Decision-making subset $\mathrm{A}$ and overall collective efficacy beliefs had a negative correlation of $r=-.49$ and statistical significance of $\mathrm{p}=.02$. Decision-making subset $\mathrm{B}$ and overall decision-making had a positive correlation of $r=.83$ and statistical significance of $\mathrm{p}<.01$. Decision-making subset B and overall collective efficacy beliefs had a negative correlation of $r=-.57$ and statistical significance of $\mathrm{p}=.01$. Decision-making subset $\mathrm{B}$ and task analysis had a negative correlation of $r=-.612$ and statistical significance of $\mathrm{p}<.01$.

Table 4.25

Pearson's Product-Moment Correlation Coefficients for Variables: DMSETA, DMSETB, DM, SS, PYE, TYE, CEB, GC, and TA

\begin{tabular}{ccccccccc}
\hline & DMSETB & DM & SS & PYE & TYE & CEB & GC & TA \\
\hline DMSETA & $.73 * *$ & $.92 * *$ & -.18 & -.012 & .077 & $-.489 *$ & -.340 & -.364 \\
DMSETB & - & $.83 * *$ & -.259 & -.078 & .208 & $-.570 * *$ & -.130 & $-.612 * *$
\end{tabular}

* Correlation is significant at the 0.05 level (2-tailed).

** Correlation is significant at the 0.01 level (2-tailed).

DMSETA = decision making subset $\mathrm{A}, \mathrm{DMSETB}=$ decision making subset $\mathrm{B}, \mathrm{SS}=$ school size, $\mathrm{PYE}=$ principal's years of experience, TYE = teachers' years of experience, $\mathrm{CEB}=$ total collective efficacy beliefs, $\mathrm{GC}=$ group competence, and TA $=$ task analysis 
Table 4.26 displays the data generated from the hierarchical multiple regression of total collective efficacy beliefs (CEB) and control variables on decision making subset A (DMSETA). The regression contains four models, three reduced (1-3) and one full (4), entered in blocks. The first three models contain the predictor variables of school size (SS), principal's years of experience (PYE), and teachers' years of experience (TYE). In the final block, model 4 added the independent variable of principal's total collective efficacy beliefs (CEB).

In model 1 , the predictor school size produced a $\Delta \mathrm{R}^{2}$ of .032 , accounting for $3.2 \%$ of the variance in decision making subset A. In model 2 , the predictor principal's years of experience produced a $\Delta \mathrm{R}^{2}$ of .002 , accounting for an additional $0.2 \%$ of the variance in decision making subset A. In model 3, the predictor teachers' years of experience produced a $\Delta \mathrm{R}^{2}$ of .006 , accounting for an additional $0.6 \%$ of the variance in decision making subset A. The total variability explained by the three predictors school size (SS), principal's years of experience (PYE), and teachers' years of experience (TYE) was $4.0 \%$ of the variability in decision making subset A.

In model 4 , the addition of the predictor principal's total collective efficacy beliefs produced a $\Delta \mathrm{R}^{2}$ of .231 . An additional $23.1 \%$ of the variance in decision making subset A was explained by principal's total collective efficacy beliefs over and above that explained by SS, PYE, and TYE. The $\Delta \mathrm{F}$ for overall collective efficacy beliefs was 5.711, with statistical significance at $\mathrm{p}=.03$. The full model, with the inclusion of all four independent variables accounted for a total $R^{2}$ of .271 . 
Table 4.26

Hierarchical Multiple Regression Analysis of Variability in Decision Making Areas

Subset A Explained by Principals' Overall Collective Efficacy Beliefs (CEB)

\begin{tabular}{ccccccc}
\hline Model & Variable + & $\mathrm{R}^{2}$ & $\operatorname{adj} . \mathrm{R}^{2}$ & $\Delta \mathrm{R}^{2}$ & $\Delta \mathrm{F}$ & sig. $\Delta \mathrm{F}$ \\
\hline 1 & $\mathrm{SS}$ & .032 & -.014 & .032 & .694 & .41 \\
2 & PYE & .034 & -.063 & .002 & .038 & .85 \\
3 & TYE & .040 & -.111 & .006 & .127 & .59 \\
4 & CEB & .271 & .109 & .231 & 5.711 & $.03 *$ \\
$* \mathrm{p} \leq .05$ & & & & & &
\end{tabular}

Dependent Variable: DMSETA

DMSETA = decision making subset $\mathrm{A}, \mathrm{SS}=$ school size, $\mathrm{PYE}=$ principal's years of experience, $\mathrm{TYE}=$ teachers' years of experience, and CEB $=$ total collective efficacy beliefs

Table 4.27 displays the regression coefficients for the prediction equation of the independent variable, total collective efficacy beliefs (CEB), on the dependent variable (DMSETA), holding constant the variables of school size, principal's years of experience, and teachers' years of experience. For the variable total collective efficacy beliefs, the unstandardized coefficient B was -.369. The standardized coefficient beta for CEB was -.572 . The $\mathrm{t}$-score for CEB coefficients was -2.390 with a statistical significance of $\mathrm{p}=.03$. 
Table 4.27

Regression Coefficients for the Full Model Prediction Equation of CEB on DMSETA, with Control Variables of SS, PYE, and TYE.

\begin{tabular}{|c|c|c|c|c|}
\hline & $\begin{array}{c}\text { Unstandardized } \\
\text { Coefficient B }\end{array}$ & $\begin{array}{c}\text { Standardized } \\
\text { Coefficient Beta }\end{array}$ & $\mathrm{t}$ & sig. \\
\hline (Constant) & 5.247 & - & 7.466 & .00 \\
\hline $\mathrm{SS}$ & .000 & .037 & .161 & .87 \\
\hline PYE & .011 & .183 & .840 & .41 \\
\hline TYE & .000 & .005 & .025 & .98 \\
\hline CEB & -.369 & -.572 & -2.390 & $.03 *$ \\
\hline \multicolumn{5}{|l|}{$* \mathrm{p} \leq .05$} \\
\hline \multicolumn{5}{|c|}{ Dependent Variable: DMSETA } \\
\hline
\end{tabular}

Table 4.28 displays the data generated from the hierarchical multiple regression of total collective efficacy beliefs (CEB) and control variables on decision making subset B (DMSETB). The regression contains four models, three reduced (1-3) and one full (4), entered in blocks. The first three models contain the predictor variables of school size (SS), principal's years of experience (PYE), and teachers' years of experience (TYE). In the final block, model 4 added the independent variable of principal's total collective efficacy beliefs (CEB).

In model 1 , the predictor school size produced a $\Delta \mathrm{R}^{2}$ of .067 , accounting for $6.7 \%$ of the variance in decision making subset B. In model 2 , the predictor principal's years of experience produced a $\Delta \mathrm{R}^{2}$ of .000 , accounting for no additional variance in decision making subset B. In model 3, the predictor teachers' years of experience 
produced a $\Delta \mathrm{R}^{2}$ of .044 , accounting for an additional $4.4 \%$ of the variance in decision making subset B. The total variability explained by the three predictors school size (SS), principal's years of experience (PYE), and teachers' years of experience (TYE) was $11.1 \%$ of the variability in decision making subset B.

In model 4, the addition of the predictor principal's total collective efficacy beliefs produced a $\Delta \mathrm{R}^{2}$ of .249 . An additional $24.9 \%$ of the variance in decision making subset B was explained by principal's total collective efficacy beliefs over and above that explained by SS, PYE, and TYE. The $\Delta \mathrm{F}$ for overall collective efficacy beliefs was 6.994, with statistical significance of $p=.02$. The full model, with the inclusion of all four independent variables accounted for a total $\mathrm{R}^{2}$ of .360 .

Table 4.28

Hierarchical Multiple Regression Analysis of Variability in Decision Making Areas Subset B Explained by Principals' Overall Collective Efficacy Beliefs (CEB)

\begin{tabular}{ccccccc}
\hline Model & Variable + & $\mathrm{R}^{2}$ & adj. $\mathrm{R}^{2}$ & $\Delta \mathrm{R}^{2}$ & $\Delta \mathrm{F}$ & sig. $\Delta \mathrm{F}$ \\
\hline 1 & $\mathrm{SS}$ & .067 & .023 & .067 & 1.516 & .23 \\
2 & PYE & .067 & -.026 & .000 & .000 & .99 \\
3 & TYE & .111 & -.029 & .044 & .944 & .34 \\
4 & CEB & .360 & .218 & .249 & 6.994 & $.02 *$ \\
$* \mathrm{p} \leq .05$ & & & & & &
\end{tabular}

Dependent Variable: DMSETB

DMSETB $=$ decision making subset $\mathrm{B}, \mathrm{SS}=$ school size, $\mathrm{PYE}=$ principal's years of experience, $\mathrm{TYE}=$ teachers' years of experience, and $\mathrm{CEB}=$ total collective efficacy beliefs 
Table 4.29 displays the regression coefficients for the prediction equation of the independent variable, total collective efficacy beliefs (CEB), on the dependent variable (DMSETB), holding constant the variables of school size, principal's years of experience, and teachers' years of experience. For the variable total collective efficacy beliefs, the unstandardized coefficient B was -.579. The standardized coefficient beta for CEB was .593. The $\mathrm{t}$-score for CEB coefficients was -2.645 with a statistical significance of $\mathrm{p}=$ .02 .

Table 4.29

Regression Coefficients for the Full Model Prediction Equation of CEB on DMSETB, with Control Variables of SS, PYE, and TYE.

\begin{tabular}{ccccc}
\hline & $\begin{array}{c}\text { Unstandardized } \\
\text { Coefficient B }\end{array}$ & $\begin{array}{c}\text { Standardized } \\
\text { Coefficient Beta }\end{array}$ & $\mathrm{t}$ & sig. \\
\hline (Constant) & 4.984 & - & 5.001 & .00 \\
SS & .000 & -.023 & -.107 & .92 \\
PYE & .013 & .146 & .712 & .49 \\
CEB & .016 & .132 & .693 & .50 \\
$* \mathrm{p} \leq .05$ & -.579 & -.593 & -2.645 & $.02 *$
\end{tabular}

Dependent Variable: DMSETB

DMSETB $=$ decision making subset $\mathrm{B}, \mathrm{SS}=$ school size, $\mathrm{PYE}=$ principal's years of experience, $\mathrm{TYE}=$ teachers' years of experience, and CEB $=$ total collective efficacy beliefs 
Table 4.30 displays the data generated from the hierarchical multiple regression of task analysis (TA) and control variables on decision making subset B (DMSETB). The regression contains four models, three reduced (1-3) and one full (4), entered in blocks. The first three models contain the predictor variables of school size (SS), principal's years of experience (PYE), and teachers' years of experience (TYE). In the final block, model 4 added the independent variable of task analysis (TA).

In model 1 , the predictor school size produced a $\Delta \mathrm{R}^{2}$ of .067 , accounting for $6.7 \%$ of the variance in decision making subset B. In model 2 , the predictor principal's years of experience produced a $\Delta \mathrm{R}^{2}$ of .000 , accounting for no additional variance in decision making subset B. In model 3, the predictor teachers' years of experience produced a $\Delta \mathrm{R}^{2}$ of .044 , accounting for an additional $4.4 \%$ of the variance in decision making subset B. The total variability explained by the three predictors school size (SS), principal's years of experience (PYE), and teachers' years of experience (TYE) was $11.1 \%$ of the variability in decision making subset B.

In model 4, the addition of the predictor principal's total collective efficacy beliefs produced a $\Delta \mathrm{R}^{2}$ of .267 . An additional $26.7 \%$ of the variance in decision making subset B was explained by task analysis over and above that explained by SS, PYE, and TYE. The $\Delta \mathrm{F}$ for task analysis was 7.746 , with statistical significance at $\mathrm{p}=.01$. The full model, with the inclusion of all four independent variables accounted for a total $\mathrm{R}^{2}$ of 379 . 
Table 4.30

Hierarchical Multiple Regression Analysis of Variability in Decision Making Areas Subset B Explained by Task Analysis (TA)

\begin{tabular}{ccccccc}
\hline Model & Variable + & $\mathrm{R}^{2}$ & adj. $\mathrm{R}^{2}$ & $\Delta \mathrm{R}^{2}$ & $\Delta \mathrm{F}$ & sig. $\Delta \mathrm{F}$ \\
\hline 1 & $\mathrm{SS}$ & .067 & .023 & .067 & 1.516 & .23 \\
2 & PYE & .067 & -.026 & .000 & .000 & .99 \\
3 & TYE & .111 & -.029 & .044 & .944 & .34 \\
4 & TA & .379 & .241 & .267 & 7.746 & $.01 *$ \\
$* \mathrm{p} \leq .05$ & & & & & &
\end{tabular}

Dependent Variable: DMSETB

DMSETB $=$ decision making subset $\mathrm{B}, \mathrm{SS}=$ school size, $\mathrm{PYE}=$ principal's years of experience, $\mathrm{TYE}=$ teachers' years of experience, and TA $=$ task analysis

Table 4.31 displays the regression coefficients for the prediction equation of the independent variable, task analysis (TA), on the dependent variable (DMSETB), holding constant the variables of school size, principal's years of experience, and teachers' years of experience. For the variable task analysis, the unstandardized coefficient B was -.381 . The standardized coefficient beta for TA was -.632. The t-score for TA coefficients was -2.783 with a statistical significance of $\mathrm{p}=.01$. 
Table 4.31

Regression Coefficients for the Full Model Prediction Equation of TA on DMSETB, with Control Variables of SS, PYE, and TYE.

\begin{tabular}{|c|c|c|c|c|}
\hline & $\begin{array}{c}\text { Unstandardized } \\
\text { Coefficient B }\end{array}$ & $\begin{array}{c}\text { Standardized } \\
\text { Coefficient Beta }\end{array}$ & $\mathrm{t}$ & sig. \\
\hline (Constant) & 4.064 & - & 6.072 & .00 \\
\hline SS & .000 & .060 & .267 & .79 \\
\hline PYE & -.003 & -.034 & -.177 & .86 \\
\hline TYE & .003 & .024 & .120 & .91 \\
\hline TA & -.381 & -.632 & -2.783 & $.01 *$ \\
\hline \multicolumn{5}{|l|}{$* \mathrm{p} \leq .05$} \\
\hline \multicolumn{5}{|c|}{ Dependent Variable: DMSETB } \\
\hline
\end{tabular}

Table 4.32 displays the data generated from the hierarchical multiple regression of task analysis (TA) and control variables on decision making subset A (DMSETA). The regression contains four models, three reduced (1-3) and one full (4), entered in blocks. The first three models contain the predictor variables of school size (SS), principal's years of experience (PYE), and teachers' years of experience (TYE). In the final block, model 4 added the independent variable of task analysis (TA).

In model 1 , the predictor school size produced a $\Delta \mathrm{R}^{2}$ of .032 , accounting for $3.2 \%$ of the variance in decision making subset A. In model 2 , the predictor principal's years of experience produced a $\Delta \mathrm{R}^{2}$ of .002 , accounting for an additional $0.2 \%$ of the variance in decision making subset A. In model 3, the predictor teachers' years of 
experience produced a $\Delta \mathrm{R}^{2}$ of .006 , accounting for an additional $0.6 \%$ of the variance in decision making subset $\mathrm{A}$. The total variability explained by the three predictors school size (SS), principal's years of experience (PYE), and teachers' years of experience (TYE) was $4.0 \%$ of the variability in decision making subset A.

In model 4 , the addition of the predictor task analysis produced a $\Delta R^{2}$ of .093 . An additional $9.3 \%$ of the variance in decision making subset A was explained by task analysis over and above that explained by SS, PYE, and TYE. The $\Delta \mathrm{F}$ for task analysis was 1.941 , with statistical significance at $p=.18$. The full model, with the inclusion of all four independent variables accounted for a total $\mathrm{R}^{2}$ of .134 .

Table 4.32

Hierarchical Multiple Regression Analysis of Variability in Decision Making Areas Subset A Explained by Task Analysis (TA)

\begin{tabular}{ccccccc}
\hline Model & Variable + & $\mathrm{R}^{2}$ & adj. $\mathrm{R}^{2}$ & $\Delta \mathrm{R}^{2}$ & $\Delta \mathrm{F}$ & sig. $\Delta \mathrm{F}$ \\
\hline 1 & $\mathrm{SS}$ & .032 & -.014 & .032 & .694 & .41 \\
2 & PYE & .034 & -.063 & .002 & .038 & .85 \\
3 & TYE & .040 & -.111 & .006 & .127 & .59 \\
4 & TA & .134 & .059 & .093 & 1.941 & .18 \\
$* \mathrm{p} \leq .05$ & & & & & &
\end{tabular}

Dependent Variable: DMSETA

DMSETA $=$ decision making subset $\mathrm{A}, \mathrm{SS}=$ school size, $\mathrm{PYE}=$ principal's years of experience, $\mathrm{TYE}=$ teachers' years of experience, and TA $=$ task analysis

Table 4.33 displays the data generated from the hierarchical multiple regression of group competence (GC) and control variables on decision making subset A (DMSETA). 
The regression contains four models, three reduced (1-3) and one full (4), entered in blocks. The first three models contain the predictor variables of school size (SS), principal's years of experience (PYE), and teachers' years of experience (TYE). In the final block, model 4 added the independent variable of group competence (GC). In model 1 , the predictor school size produced a $\Delta \mathrm{R}^{2}$ of .032 , accounting for $3.2 \%$ of the variance in decision making subset A. In model 2 , the predictor principal's years of experience produced a $\Delta \mathrm{R}^{2}$ of .002 , accounting for an additional $0.2 \%$ of the variance in decision making subset A. In model 3, the predictor teachers' years of experience produced a $\Delta \mathrm{R}^{2}$ of .006 , accounting for an additional $0.6 \%$ of the variance in decision making subset A. The total variability explained by the three predictors school size (SS), principal's years of experience (PYE), and teachers' years of experience (TYE) was $4.0 \%$ of the variability in decision making subset A.

In model 4 , the addition of the predictor group competence produced a $\Delta \mathrm{R}^{2}$ of .171. An additional $17.1 \%$ of the variance in decision making subset A was explained by group competence over and above that explained by SS, PYE, and TYE. The $\Delta \mathrm{F}$ for group competence was 3.890 , with statistical significance at $\mathrm{p}=.06$. The full model, with the inclusion of all four independent variables accounted for a total $\mathrm{R}^{2}$ of .211 . 
Table 4.33

Hierarchical Multiple Regression Analysis of Variability in Decision Making Areas Subset A Explained by Group Competence (GC)

\begin{tabular}{ccccccc}
\hline Model & Variable + & $\mathrm{R}^{2}$ & adj. $\mathrm{R}^{2}$ & $\Delta \mathrm{R}^{2}$ & $\Delta \mathrm{F}$ & sig. $\Delta \mathrm{F}$ \\
\hline 1 & $\mathrm{SS}$ & .032 & -.014 & .032 & .694 & .41 \\
2 & PYE & .034 & -.063 & .002 & .038 & .85 \\
3 & TYE & .040 & -.111 & .006 & .127 & .73 \\
$*_{\mathrm{p} \leq .05}$ & GC & .211 & .035 & .171 & 3.890 & .06
\end{tabular}

Dependent Variable: DMSETA

DMSETA $=$ decision making subset $\mathrm{A}, \mathrm{SS}=$ school size, $\mathrm{PYE}=$ principal's years of experience, $\mathrm{TYE}=$ teachers' years of experience, and $\mathrm{GC}=$ group competence

Table 4.34 displays the regression coefficients for the prediction equation of the independent variable, group competence (GC), on the dependent variable (DMSETA), holding constant the variables of school size, principal's years of experience, and teachers' years of experience. For the variable group competence, the unstandardized coefficient B was -.274. The standardized coefficient beta for GC was -.485. The t-score for GC coefficients was -1.972 with a statistical significance of $\mathrm{p}=.06$. 
Table 4.34

Regression Coefficients for the Full Model Prediction Equation of GC on DMSETA, with Control Variables of SS, PYE, and TYE.

\begin{tabular}{|c|c|c|c|c|}
\hline & $\begin{array}{c}\text { Unstandardized } \\
\text { Coefficient B }\end{array}$ & $\begin{array}{c}\text { Standardized } \\
\text { Coefficient Beta }\end{array}$ & $\mathrm{t}$ & sig. \\
\hline (Constant) & 4.930 & - & 7.199 & .00 \\
\hline SS & .000 & -.202 & -.922 & .37 \\
\hline PYE & .017 & .291 & 1.157 & .26 \\
\hline TYE & .013 & .168 & .738 & .44 \\
\hline GC & -.274 & -.485 & -1.972 & .06 \\
\hline \multicolumn{5}{|l|}{$* \mathrm{p} \leq .05$} \\
\hline \multicolumn{5}{|c|}{ Dependent Variable: DMSETA } \\
\hline
\end{tabular}

Summary

This chapter presented descriptive statistics and correlations, regression analysis, effect sizes, and power analysis. Regression analysis was conducted to answer the research questions, while effect sizes and power analysis were conducted to assist in the interpretation of results.

A matrix presented the correlations between bivariate pairs of independent variables (SS, PYE, TYE, CEB, GC, and TA) and the dependent variable (DM). Decision making had negative correlations with principal's total collective efficacy beliefs, as well as the construct of task analysis. While not statistically significant at the 
.05 level, the construct of group competence was the next most powerful correlational, also in a negative direction. In a similar manner, school size also had its strongest statistically significant correlations with principal's total collective efficacy beliefs and the construct of task analysis. Unlike decision making, these correlations were positive in direction. The independent variable of principal's years of experience had its only statistically significant correlation at $\mathrm{p} \leq .05$ with the construct of group competence and was positive in direction. Principal's total collective efficacy beliefs had a stronger correlation with the construct of task analysis than it did with the construct of group competence. While other pairwise correlations between independent variables and the dependent variable suggested somewhat valuable practical significance, none approached a statically significant level of $\mathrm{p} \leq .05$.

Regression analysis suggested that principal's collective efficacy beliefs accounted for variability in teachers' perceived opportunities for involvement in decision making over and above that explained by school size, principal's years of experience, and teachers' years of experience. Principal's total collective efficacy beliefs (CEB) accounted for $26.4 \%$ of the variability in decision making over and above that explained by SS, PYE, and TYE. The statistical significance of CEB's contribution was at $\mathrm{p}=.01$. The construct of task analysis (TA) had the next strongest practical significance by accounting for $16.8 \%$ of the variability in decision making over and above that explained by SS, PYE, and TYE. The statistical significance of TA's contribution was at a $\mathrm{p}=.06$. The construct of group competence (GC) had the smallest practical significance by accounting for $10.7 \%$ of the variability in decision making over and above that explained by SS, PYE, and TYE. The statistical significance of GC's contribution was $p=.14$. 
Effect sizes varied greatly for the three independent variables of interest. The variance-accounted-for effect sizes of $\Delta \mathrm{R}^{2}$ showed principal's total collective efficacy beliefs (CEB) to have the largest effect size, followed by group competence and task analysis entered jointly (GC+TA), task analysis (TA), and lastly group competence (GC). Cohen's $\mathrm{f}^{2}$ values were .359 for principal's total collective efficacy beliefs (CEB), .357 for group competence and task analysis entered jointly (GC+TA), .232 for the construct of task analysis (TA), and .136 for the construct of group competence (GC). These sizes conventionally qualify as large, large, medium, and small, respectively. Principal's total collective efficacy beliefs (CEB) surpassed the conventional threshold of .8, while the constructs of task analysis and group competence fell far short.

Data from ancillary findings suggested a positive relationship between group competence and decision making standard deviation. An additional $22.6 \%$ of the variance in decision making standard deviation was explained by group competence over and above that explained by school size (SS), principal's years of experience (PYE), and teachers' years of experience (TYE). An analysis of variance of the seven areas of decision making suggested two statistically different subsets. Subset A (DMSETA) contained the areas of goals/vision/mission (GVM), standards (STND), curriculum and instruction (CI), and staff development (SDEV). Subset B (DMSETB) contained the areas of budget (BDGT), staffing (STFF), and operations (OPER).

Data suggested that total collective efficacy beliefs had a negative relationship with both subset A and subset B. An additional $23.1 \%$ of the variance in decision making subset A was explained by principal's total collective efficacy beliefs over and above that explained by SS, PYE, and TYE, with a statistical significance of $p=.03$. An additional 
$24.9 \%$ of the variance in decision making subset B was explained by principal's total collective efficacy beliefs over and above that explained by SS, PYE, and TYE, with a statistical significance of $p=.02$. Data suggested that task analysis had a negative relationship with subset B. An additional $26.7 \%$ of the variance in decision making subset B was explained by task analysis over and above that explained by SS, PYE, and TYE, with a statistical significance of $p=.01$. Data suggested that group competence had a negative relationship with both subset A. An additional $17.1 \%$ of the variance in decision making subset A was explained by group competence over and above that explained by SS, PYE, and TYE, with a statistical significance of $\mathrm{p}=.06$. 


\section{Chapter Five}

\section{Summary and Conclusion}

In this fifth chapter, the following sections are presented: an overview of the study, summary of the findings, implications for practitioners, and recommendations for future research.

\section{Overview of Study}

Through a review of literature, a theoretical framework was formed. Based upon previous research, it was reasonable to assume that principals' collective efficacy beliefs about teachers may explain some of the variability in teachers' perceptions about the amount to which they are offered opportunities for involvement in decision making. The theoretical framework was developed around the mediating role of trust. Trust in organizations is complex. Relationships between leaders and followers determine many factors revolving around trust, including behaviors. The behaviors of principals are somewhat rooted in their beliefs about teachers. If principals believe their teachers have the necessary skills and knowledge, they may be more likely to delegate power to teachers and involve teachers in decision making.

The purpose of this study was to determine the extent to which principals' collective efficacy beliefs about teachers accounted for variability in teachers' perceived 
opportunities for involvement in decision making over and above that explained by school size, principal's years of experience, and teachers' years of experience. In order to achieve its purpose, the study asked three research questions:

\section{Research Question 1}

To what extent do principals' total collective efficacy beliefs account for variability in teachers' opportunities for involvement in decision making over and above that explained by school size, principal's years of experience, and teachers' years of experience?

\section{Research Question 2}

To what extent does group competence account for variability in teachers' opportunities for involvement in decision making over and above that explained by school size, principal's years of experience, and teachers' years of experience?

\section{Research Question 3}

To what extent does task analysis account for variability in teachers' opportunities for involvement in decision making over and above that explained by school size, principal's years of experience, and teachers' years of experience?

\section{Review of Methodology}

This study was a descriptive-correlational study that utilized hierarchical multiple regression to answer the study's research questions. The study's population included 23 elementary schools from three contiguous districts in a Midwestern state. Quantitative data was collected using survey methodology. The independent variables of interest - 
principal's total collective efficacy beliefs about teachers (CEB) and its constructs of group competence (GC) and task analysis (TA), were measured using the Goddard Collective Efficacy Scale Short Form. The principal survey also collected data for the independent variables of school size (SS) and principal's years of experience (PYE). The dependent variable - teachers' perceived opportunities for involvement in decision making (DM) was measured using the Russell Teacher Involvement and Participation Scale. The teacher survey also collected data for the independent control variable of teachers' years of experience (TYE).

\section{Summary of the Findings}

This summary of the study's findings will review the results of the research questions, and present a discussion of the findings. The discussion of the findings will interpret the data from chapter four as well as make comparisons and observations in regard to the literature.

\section{Research Question 1}

To what extent do principals' total collective efficacy beliefs account for variability in teachers' opportunities for involvement in decision making over and above that explained by school size, principal's years of experience, and teachers' years of experience?

Principal's total collective efficacy beliefs (CEB) accounted for $26.4 \%$ of the variability in teachers' perceived opportunities for involvement in decision making (DM) 
over and above that explained by school size $\left(\mathrm{R}^{2}=.05\right)$, principal's years of experience $\left(\mathrm{R}^{2}=.01\right)$, and teachers' years of experience $\left(\mathrm{R}^{2}=.05\right)$. The $\Delta \mathrm{F}$ change for the addition of CEB was significant at $\mathrm{p}=.01$. Cohen's effect size $\mathrm{f}^{2}$ for CEB was .40 , classified as a "large" effect size. The $\mathrm{R}^{2}$ for the full model, including all four predictors was .37 , accounting for $36.8 \%$ of the variability in decision making.

Research Question 2

To what extent does group competence account for variability in teachers' opportunities for involvement in decision making over and above that explained by school size, principal's years of experience, and teachers' years of experience?

The construct of group competence accounted for $10.7 \%$ of the variability in teachers' perceived opportunities for involvement in decision making (DM) over and above that explained by school size $\left(\mathrm{R}^{2}=.05\right)$, principal's years of experience $\left(\mathrm{R}^{2}=.01\right)$, and teachers' years of experience $\left(\mathrm{R}^{2}=.05\right)$. The $\Delta \mathrm{F}$ change for the addition of GC was significant at $\mathrm{p}=.14$. Cohen's effect size $\mathrm{f}^{2}$ for GC was .14 , classified as a "small” effect size. The $\mathrm{R}^{2}$ for the full model, including all four predictors was .21 , accounting for $21.1 \%$ of the variability in decision making.

Research Question 3

To what extent does task analysis account for variability in teachers' opportunities for involvement in decision making over and above that explained by school size, principal's years of experience, and teachers' years of experience? 
The construct of task analysis (TA) accounted for $16.8 \%$ of the variability in teachers' perceived opportunities for involvement in decision making (DM) over and above that explained by school size $\left(\mathrm{R}^{2}=.05\right)$, principal's years of experience $\left(\mathrm{R}^{2}=.01\right)$, and teachers' years of experience $\left(\mathrm{R}^{2}=.05\right)$. The $\Delta \mathrm{F}$ change for the addition of TA was significant at $\mathrm{p}=.06$. Cohen's effect size $\mathrm{f}^{2}$ for TA was .23 , classified as a "medium" effect size. The $\mathrm{R}^{2}$ for the full model, including all four predictors was .27 , accounting for $27.3 \%$ of the variability in decision making.

\section{Discussion of Findings}

Principal's total collective efficacy beliefs about teachers (CEB) demonstrated the strongest practical significance as a predictor of decision making (DM), while controlling for school size (SS), principal's years of experience (PYE), and teachers' years of experience (TYE). Principal's total collective efficacy beliefs (CEB) accounted for $26.4 \%$ of the variability in teachers' perceived opportunities for involvement in decision making $(\mathrm{DM})$ over and above that explained by school size $\left(\mathrm{R}^{2}=.05\right)$, principal's years of experience $\left(\mathrm{R}^{2}=.01\right)$, and teachers' years of experience $\left(\mathrm{R}^{2}=.05\right)$. The $\Delta \mathrm{F}$ change for the addition of CEB was significant at $p=.01$. Cohen's effect size $\mathrm{f}^{2}$ for CEB was .40 , classified as a "large" effect size.

The study's data suggested that the higher the level of principals' total collective efficacy beliefs, teachers perceived fewer opportunities for involvement in decision making. The t-score for CEB coefficients was -2.74 with a statistical significance level of $\mathrm{p}=.01$. For principal's total collective efficacy beliefs, the unstandardized coefficient 
B was -14.377. With every one point increase in principal's total collective efficacy beliefs about teachers on the principal survey instrument, teachers' overall perception of opportunities for involvement in decision making decreased by 14.38 points on the teacher survey instrument. The standardized coefficient beta for CEB was -.61. With every one standard deviation increase in CEB, DM decreased by .61 standard deviations.

Task analysis (TA) was the next most practically significant and statistically significant predictor of decision making, while controlling for PYE, SS, and TYE. The construct of task analysis (TA) accounted for $16.8 \%$ of the variability in teachers' perceived opportunities for involvement in decision making (DM) over and above that explained by school size, principal's years of experience, and teachers' years of experience. The $\Delta \mathrm{F}$ change for the addition of TA was significant at $\mathrm{p}=.06$. Cohen's effect size $\mathrm{f}^{2}$ for TA was .23, classified as a "medium" effect size.

Once again, the study's data suggested that the higher the level of principals' task analysis, teachers perceived fewer opportunities for involvement in decision making. The $\mathrm{t}$-score for TA coefficients was -2.04 with a statistical significance level of $\mathrm{p}=.06$. For task analysis, the unstandardized coefficient B was -7.29 . With every one point increase in principal's task analysis on the principal survey instrument, teachers' overall perception of opportunities for involvement in decision making decreased by 7.29 points on the teacher survey instrument. The standardized coefficient beta for TA was -.50. With every one standard deviation increase in TA, DM decreased by .50 standard deviations.

Group competence (GC) was the least practically significant predictor of decision making compared to total collective efficacy beliefs (CEB) and task analysis (TA), while 
controlling for PYE, SS, and TYE. Group competence accounted for $10.7 \%$ of the variability in teachers' perceived opportunities for involvement in decision making (DM) over and above that explained by school size, principal's years of experience, and teachers' years of experience. The $\Delta \mathrm{F}$ change for the addition of GC was significant at $\mathrm{p}$ $=.14$. Cohen's effect size $\mathrm{f}^{2}$ for GC was .14, classified as a "small" effect size. Once more, the study's data suggested that the higher the level of principals' beliefs of group competence, teachers perceived fewer opportunities for involvement in decision making.

Of the control variables, data suggested that school size and teacher's years of experience were comparable predictors of decision making, while principal's years of experience did not contribute a practically significant amount while controlling for school size and teachers' years of experience. Principal's years of experience was expected to have a positive relationship with decision making, as the literature seems to support that position. Kramer, Brewer, and Hanna (1996) suggest that the accumulation of social capital over time would result in higher levels of cooperation and organizational trust. The findings of this study may suggest that an element is missing from the theoretical framework that counteracts or attenuates the effect of a principal's years of experience.

The findings of this study suggested that there may be a significant relationship between group competence and decision making standard deviation (DMSD), but DMSD does not appear to be related to any other independent variable nor overall teachers' perceived opportunities for involvement in decision making (DM). These findings suggest that the higher a principal's beliefs of group competence, teachers' perceptions are more widely spread in regard to the amount with which they are offered opportunities for involvement in decision making. 
The findings of the study suggest that decision making areas goals/vision/mission (GVM), standards (STND), curriculum and instruction (CI), and staff development (SDEV) are areas in which principals offer more opportunities for teacher involvement than the areas of budget (BDGT), staffing (STFF), and operations (OPER). The sample's overall mean scores were 3.84 for goals/vision/mission, 3.63 for standards, 3.52 for curriculum and instruction, and 3.54 for staff development. The sample's overall mean scores were 2.40 for budget, 2.49 for staffing, and 2.69 for staff development. An ANOVA found at least one of these means to be statistically different. A Tukey post-hoc test assisted in finding two subsets that were statistically similar. Subset A included the decision making areas of goals/vision/mission (GVM), standards (STND), curriculum and instruction (CI), and staff development (SDEV). Subset B included the decision making areas of budget (BDGT), staffing (STFF), and operations (OPER).

A reinterpretation of the theoretical framework's foundations is useful to derive meaning from what appears to be findings which are contradictory. Additional factors may need to be considered in order to make sense of the data. The findings of this study were unexpected, as they are in opposition to the hypothesis suggested by the theoretical framework. The results of the regression analyses did suggest a relationship between principals' collective efficacy beliefs about teachers and teachers' perceived opportunities for involvement in decision making; however, the relationship had a negative direction. The findings suggest that where there is a principal who has higher collective efficacy beliefs concerning teachers, that principal may offer fewer opportunities for teachers' involvement in decision making. 
While it might be difficult to explain why the negative relationship was found, this contradictory finding is not without precedent in regard to the area of school leadership and shared decision making, as much of the same theoretical framework is the foundation for other related research. Printy, Marks, and Bowers (2009) explore the idea of how a principal's method of reaching student achievement may be through what is considered a complex blend of employed strategies. Printy, Marks, and Bowers (2009) incorporate ideas of Rosenholtz (1985) when stating the following:

Rather as the best means for achieving the unitary goal of student achievement, principals should mobilize teachers toward collective efforts. As Rosenholtz noted however, teachers provide their colleagues with essential technical support for teaching as well as motivational support to continue working toward the goal. From her observations, quality teaching and learning occur in schools where teachers dedicate collected efforts to achieve desired results - in the direction established by the principal (p. 508).

A school may be high achieving and retain teachers who feel they are participating in a successful collective environment, but still primarily under the direction of the principal's instructional leadership. While they may feel that they are collectively and actively participating in a plan, it may not be their plan. Printy, Marks, and Bowers describe their work in this way,

The original plan for the current study was to first seek understanding of why transformational leadership by the principal appears to be a necessary but insufficient condition for activating shared instructional leadership, then to explore the variety of ways in which teachers respond to transformational principals, with attention paid to the influence and conditions that appear to activate shared instructional leadership (p. 506).

The authors go on to explain that, "Our focus broadened a bit when we realized that teachers as well as principals contributed transformational influence to the leadership present in these schools" (p. 506). While this study did control 
for one teacher factor (years of experience), there certainly may be other more influential teacher-based factors, which influence the amount to which teachers perceive their involvement in decision making as stated in the limitations section. For example, in a similar fashion to the Printy, Marks, and Bowers study, research may control for the factor of principal's leadership beliefs in regard to the balance and blend of instructional leadership and transformational leadership. Instructional leadership views the principal in a hierarchical structure as the primary source of expertise at the school when dealing with instruction. Transformational leadership includes teacher empowerment, where teachers are encouraged to be collaborative partners on issues of budgets, hiring, curriculum, and instruction (Printy Marks, and Bowers, 2003). A principal's interpretation concerning the balance between instructional and transformational leadership may be associated with the amount to which they share decision making, but be unrelated to efficacy beliefs or trust.

Understanding trust and its presence or lack thereof, may have played a role in the unexpected results. The findings of this study seem to contradict what one might expect from the literature on trust; however, Tschannen-Moran and Hoy (1998) do recognize that trust is complex in organizations, especially in the context of schools. Factors revolving around trust and related influences on principals may cause a disconnect between the beliefs of principals and their perceived behaviors. The resultant behavior of principals who value and trust their teachers' knowledge and skill may be more congruent with internal motives of the principal that do not result in more opportunities for teachers' involvement 
in decision making. The principal's objective is to improve the achievement, productivity, and general well-being of the school. A principal's collective efficacy beliefs about teachers may be appropriately related to the amount of trust of which they place on teachers' knowledge and skills, but may not predict the amount of delegation of power or involvement in decision making for directives within the school. There is sometimes this dilemma of trust in schools (Tschannen-Moran, 2004).

An exploration of this idea would be to consider a principal who has low efficacy beliefs about his/her teachers and does not trust that the teachers can or will carry out the preferred approach to a problem or directives. In this scenario of low efficacy beliefs, the principal may choose not to impose his/her preferred directive upon the body of teachers because the principal does not believe the teachers are capable of executing the plan. If the principal has low efficacy beliefs about teachers, he/she may alternatively choose to ask teachers what limited skills, knowledge, or ideas they do possess that can address the issue. Instead of having limited opportunities for involvement in decision making, the teachers are very involved. With what are a perceived limited collection of skills, teachers may be presented with opportunities to offer what they believe are the approach or solutions that they can carry out in substitution for the principal's preferred action, which they cannot.

In contrast, a principal who believes that teachers possess strong teaching skills and knowledge might view them as a powerful tool or amplifier for his/her own preferred directive. The teachers may be told exactly what approach will be conducted at the school, not because the principal believes the teachers cannot come up with solutions on 
their own, but because the principal believes they are capable of whatever goals and objectives are set before them. Instead of resorting to asking teachers what limited solutions they are capable of providing, the principal may believe he/she knows what direction to take, therefore reducing the amount of opportunities for teacher involvement in decision making. The principal already believes teachers can execute the plan and does not see the need for teacher input.

The literature suggests two areas of collective efficacy beliefs - task analysis and group competence (Goddard, Hoy, \& Hoy, 2000). The findings of this study found negative relationships between decision making and both overall collective efficacy about teachers (CEB), and the construct of task analysis (TA). This finding suggests that in fact, a principal who has higher efficacy beliefs about the manner in which teachers' analyze what is required in the process of teaching, or task analysis, causes the principal to offer fewer opportunities for involvement in decision making. This finding is in contradiction to the literature, with studies such as Yukl and Fu (1999) suggesting that higher efficacy beliefs would lead to greater amounts of delegation.

As task analysis is part of the larger set of overall collective efficacy beliefs, it is possible to understand how CEB may be negatively related to DM. An explanation of the findings may be that if principals believe that they are past the point of having to concern themselves with involving teachers' in a dyadic action of assessing the required teaching resources, they will offer fewer opportunities for involvement in decision making. In addition to Yukl and Fu, Somech and Wenderow (2006) also suggest that delegation is contingent upon reciprocal trust and quality leader-member exchanges, which with the 
lack thereof may create results similar to this study's findings. If principals do not continual demonstrate trust, teacher may also not demonstrate trust.

Somech (2002) suggested that principals' leadership styles are based on their beliefs. Hallinger (2011) also suggested that personal beliefs and knowledge can influence the ways in which principals exercise their leadership. With the findings of this study suggesting a relationship is present between, but in a direction in contradiction to the theoretical framework, the framework may be missing an element that precedes or follows trust and how it relates to collective efficacy beliefs. This missing element may, in fact, be a part of trust itself, as the literature does suggest that trust is a complex issue to understand (Tschannen-Moran, 2001; Tschannen-Moran, 2004).

Principals with high trust levels toward teachers may result in both higher and lower levels of opportunities for involvement in decision making. Similarly, principals with low levels of trust toward teachers may also result in both higher and lower levels of opportunities for involvement in decision making. The framework of the study should not be discarded, but there are likely additional details and variables that need to be evaluated in order to better understand the relationship. It might be valuable to include trust as an independent variable within the framework, which may in turn improve prediction.

In schools where principals have low levels of trust in teachers' abilities or efficacy, there may be more opportunities offered by the principal for teachers to be involved in decision making. Upon first thought, this could seem counterintuitive. One might assume that a principal would want to remain directive or micromanage where 
teachers are lacking. Instead, an increase in the frequency with which opportunities are offered to teachers may be an attempt by the principal to stimulate or promote growth in his/her staff. While there may be some failure in the short term, the long-term benefits would outweigh the costs.

Principals in high-achieving schools may have more confidence in their teachers, or higher collective efficacy beliefs about their teachers, and may be less inclined to see interaction as necessary for school improvement or achievement. If the school already performs well, not interfering or changing established teacher mechanisms and conducting business as usual may result in less principal-teacher or leader-member exchange, and as a consequence, less reciprocated trust and less perceived teacher involvement in decision making. Where there are fewer decisions to be made, it may be reasonable to expect fewer perceived opportunities for involvement in decision making. Sue-Chan, Au, and Hackett's (2012) research on organizational trust and leader-member exchange suggested, “...the behavior of one dyad partner toward the other predicts the target's trust in the agent of the behavior, in turn predicting the target's experience of relationship quality.” The authors continue, “...whereas the supervisor's ability to activate and satisfy a subordinate's desires for personal growth and advancement should be most prominent in garnering the subordinate's trust" (pp. 459-460). The problem with this scenario of low principal-teacher interaction is two-fold. First, there would potentially be a shortage in the raw number of change experiences. Second, the relationship and trust building experiences on the part of the teacher in principal-teacher dyads may lead individual teachers to have lower levels of trust in the principal. Relationships between individual teachers and the principal may be of importance in 
understanding how teachers perceive the frequency with which principals offer opportunities for involvement in decision making. It may be of interest to incorporate measurement of whether teachers with positive principal relationships perceive themselves as being offered more opportunities.

An alternative speculation would involve the level of static achievement already attained by high-achieving schools. Research has revealed the positive relationship between collective teacher efficacy and student achievement (Goddard, Hoy, \& Hoy, 2000). In schools where high achievement is the norm, a principal's leadership objectives may not focus on changing curriculum, scheduling, or goals, as it might in a low-achieving school. A school with high achievement may have fewer issues, and therefore fewer opportunities for principals and teachers to collaborate on resolving those issues.

Understanding how task analysis may individually relate to opportunities offered by the principal is complicated. Goddard, Hoy, and Hoy explain, "Because the analyses of task and competence occur simultaneously, it is difficult to separate these two domains of collective teacher efficacy. They interact with each other as collective teacher efficacy emerges" (p. 485). Task analysis includes the assessment of what is important to teachers being successful at the school. The elements of task analysis are reflected in the representative items of the Collective Efficacy Scale. They evaluate, “...what constitutes successful teaching in their school, what barriers or limitations must be overcome, and what resources are available to achieve success" (p. 485). It is logical to suspect that these questions are related to the amount to which a principal offers opportunities for involvement in decision making because it could be related to the previously suggested 
bi-directionality of certain factors such as student achievement. A principal could view the student body as being capable of managing whatever the principal could ask of teachers without much consultation. A principal could also view the student body as being less capable based on community factors and seek suggestions from the teaching force. High or low task analysis could both result in more direction with less opportunities and vice versa. The same would be true for low task analysis. This again demonstrates how further research may better provide an understanding of a complex conceptual framework.

\section{Implications for Practice}

This study's theoretical framework suggested that it was reasonable to assume that a principal's collective efficacy beliefs about teachers would engender greater trust in teachers, and as a result, would lead principals to delegate responsibility and power to teachers in ways including that of providing opportunities for involvement in decision making. The findings of this study suggest a relationship between principals' collective efficacy beliefs and teachers' involvement in decision making contrary to the expectations of the theoretical framework. This does not mean, however, that the theoretical framework does not have merit and needs to be discarded. There is a dearth of research investigating the relationship between this specific pair of independent and dependent variables. Due to this lack of research, more needs to be done before recommendations can be given to practitioners. As this study has suggested, the relationship between principals' collective efficacy beliefs and teachers' perceived 
opportunities for involvement in decision making is not fully understood. There is scarce evidence to support any actions that could be taken based on the findings of this study alone, let alone the general lack of research on the topic. The contradictory findings do, however, provide thought for future research and are included at the end of this chapter.

\section{Limitations}

Certain factors must be considered with this study. Limitations include the lack of a random sample. Participants had the choice to participate in the study and may not best represent the population when trying to generalize the findings. Another consideration of the study is the reality that cognitive mechanisms vary between individual perceivers (Brown \& Lord, 2001). The differences between individual perceivers include affective and motivational processes involved in perception and judgment. Abilities and skills of perceivers have also been shown to impact the qualities of their judgments. Similarly, the judgments of leaders are dependent upon interpretations of leaders' traits and behaviors (Klimoski \& Donahue, 2001). Due to the expected individual differences of teachers' perceptions and responses, variability of respondents scores were analyzed in addition to item means. This analysis can be found in the fourth chapter's ancillary findings.

When examining the results of this study, it is important to understand the study's population. The sample utilized was one of convenience with a collection of schools located in one region of a Midwestern state. The relevance of this study's findings is specific to the study's population and should not be generalized to other populations. 
The findings of the study must be considered in regard to the validity and reliability of the measurements used: the Goddard (2002) Collective Efficacy Scale Short Form and the Russell (1992) Teacher Involvement and Participation and Scale (TIPS). The definitions of terms for this study are specific to the instruments and how they were measured. Those definitions limit the operational implications of the study. The study only controlled for the variables of school size, principal's years of experience, and teachers' years of experience. There may certainly be other variables as or more influential than the covariates of this study.

As previously stated, there are many factors that may account for variability in teachers' perceived involvement in decision making. The study's theoretical framework does not capture the complexity of the factors at play. Unexplored areas of research may include determinants that more accurately explain the variability in principal's beliefs and behaviors or teachers' perceptions about opportunities for involvement in decision making. This study was unable to control or account for all of those possible factors and this inability must be taken into consideration when examining the results.

The voluntary participation of respondents may not allow for a true reflection of principal's collective efficacy beliefs about teachers or teachers perceived opportunities for involvement in decision making. As this is an educational or social science study, it is almost impossible for truly experimental work to be conducted in an ethical manner. Instead educational studies must be non-experimental or quasi-experimental in nature. The variables within the study can therefore not be manipulated. This limitation must be considered when examining the design of the study and its findings. 


\section{Recommendations for Future Research}

Based on the findings of this study, the following recommendations are made for future research:

1. As there is little to no literature dealing with the specific relationship between principals' collective efficacy beliefs about teachers and teachers perceived opportunities for involvement in decision making, this study needs to be replicated in order to support or refute the findings of the negative relationship suggested by this study.

2. Future research may use alternative instruments for the measurement of principal's collective efficacy beliefs about teachers or teachers' perceived opportunities for involvement in decision making. Instruments in future research may include more precise measurements of resources such as time, space, and materials. These instruments may help reinforce the oppositional findings of this study or may instead produce the expected results of the current theoretical framework.

3. If the study is replicated and the findings are congruent with the findings of this study, the oppositional results of the findings may beg for a deeper theoretical framework, incorporating additional elements.

4. Future research may focus on the nature of the relationship between leaders' beliefs about followers and the internal factors that determine their behaviors. The impetus for their behaviors may be a more complex blend of intrinsic and extrinsic values that complement or supplement trust and efficacy beliefs or potentially constrain the sharing or delegation of power. Beliefs about followers' 
skills, knowledge, and related competencies in concert with trust may simply not be a complete enough picture of what contributes to leader behaviors.

5. The study found a statistically significant correlation between school size and principal's total collective efficacy beliefs, as well as the construct of task analysis. Future research might explore school-level factors other than school size that influence principal behaviors in regard to the probability of involving teachers in decision making.

6. With similar reasoning, future research may also explore school-level or organizational factors related to school size that influence principal or leader beliefs about teachers or followers.

7. The study also found a statistically significant correlation between principal's years of experience and the construct of group competence. Future research may explore other personal traits or qualities of principals that may predict the frequency with which principals involve teachers in decision making.

8. The study found a statistical difference between two subsets of decision making areas. Future research may explore the factors related to these subsets or each individual decision making area. A study that explores the differences between the decision making areas may be useful.

9. Instructional and transformational leadership beliefs of principals may be a beneficial area of research when investigating teachers' involvement in decision making. 
10. Likewise, collective efficacy beliefs may affect the ratio or balance between transformational and instructional styles of a principal. A study to explore this relationship may be useful.

11. Future research may focus on the variables related with teacher perceptions and how these variables may differ both in the individual teacher and the many dyads between principals and teachers.

12. A speculation of the study is that an unexplored factor may be a school's level of student achievement. Future research could control for student achievement when looking at principals' collective efficacy beliefs and teachers' involvement in decision making. 


\section{References}

Agresti, A. \& Finlay, B. (1997). Statistical Methods for the Social Sciences (3rd ed.). Upper Saddle River, NJ: Prentice Hall.

Alutto, J. A., \& Belasco, J. A. (1972). A typology for participation in organizational decision making. Administrative Science Quarterly, 17(1), 117-125.

Arrow, K. J. (1974). The limits of organization. New York: Norton.

Ashton, P. A., \& Webb, R. B. (1986). Making a difference: Teachers'Sense of Efficacy and Student Achievement. New York: Longman Group.

Bacharach, S.B., Bamberger, P., Conley, S.C., \& Bauer, S. (1990). The dimensionality of decision participation in educational organization: The value of a multi-domain evaluative approach. Educational Administration Quarterly, 26, 126-127.

Baier, A. (1986). Trust and antitrust. Ethics, 96(2), 231-260.

Baier, A. (1994). Moral Prejudices. Cambridge, MA: Harvard University Press.

Bandura, A. (1977). Social Learning Theory. New York: General Learning Press.

Bandura, A. (1986). Social Foundations of Thought and Action. Englewood Cliffs, NJ: Prentice-Hall.

Bandura, A. (1997). Self-efficacy: The exercise of control. New York: W.H. Freeman and Co.

Bandura, A., \& Wood, R. (1989). The effect of perceived controllability and performance standards of self-regulation of complex decision making. Journal of Personality and Social Psychology, 56(5), 805-814.

Barber, B. (1983). The logic and limits of trust. New Brunswick, NJ: Rutgers University Press.

Bauer, T. N., \& Green, S. G. (1996). Development of leader-member exchange: A longitudinal test. Academy of Management Journal, 30, 1538-1567. 
Benoliel, P., \& Somech, A. (2010). Who benefits from participative management? Journal of Educational Administration, 48(3), 285-308.

Black, J. S., \& Gregersen, H. B. (1997). Participative decision-making: An integration of multiple dimensions. Human Relations, 50(7), 859-878.

Bogler, R., \& Nir, A. E. (2012). The importance of teachers' perceived organizational support to job satisfaction: What's empowerment got to do with it? Journal of Educational Administration, 50(3), 287-306.

Bogler, R., \& Somech, A. (2004). Influence of teacher empowerment on teachers' organizational commitment, professional commitment and organizational citizenship behavior in schools. Teacher and Teacher Education, 20, 277-289.

Boyd, D., Grossman, P., Ing, M., Lankford, H., Loeb, S., \& Wyckoff, J. (2011). The influence of school administrators on teacher retention decisions. American Educational Research Journal, 48(2), 303-333.

Brown, D. J., \& Lord, R. G. (2001). Leadership and perceiver cognition: Moving beyond first order constructs. In M. London (Ed.), How people evaluate others in organizations, (181-202). Mahwah, NJ: Lawrence Erlbaum.

Butler, J. K. (1991). Towards an understanding and measuring conditions of trust: Evolution of a conditions of trust inventory. Journal of Management, 17, 643663.

Chang, M. L. (2009). An appraisal perspective of teacher burnout: Examining the emotional work of teachers. Educational Psychology Review, 21, 193-218.

Clift, R. T., Veal, M. L., Holland, P., Johnson, M., \& McCarthy, J. (1995). Collaborative leadership and shared decision making. New York: Teachers College Press.

Cogliser, C. C., \& Schriesheim, C. A. (2000). Exploring work unit context and leadermember exchange: A multi-level perspective. Journal of Organizational Behavior, 21, 487-511.

Conley, S. (1991). Review of research on teacher participation in school decision making. Review of Research in Education, 17, 225-266.

Conway, J. A., \& Calzi, F. (1995). The dark side of shared decision making. Educational Leadership, 53(4), 45-49.

Cook, S. D. N., \& Yanon, D. (1996). Culture and organizational learning. In M. D. Cohen \& L. S. Sproull (Eds.), Organizational learning (430-459). Thousand Oaks, CA: Sage. 
Dachler, H. P., \& Wilpert, B. (1978). Conceptual dimensions and boundaries of participation in organizations: A critical evaluation. Administrative Science Quarterly, 23(1), 1-39.

Darling-Hammond, L. (2003). Keeping good teachers. Educational Leadership, 60(8), 713.

Deutsch, M. (1973). The Resolution of Conflict: Constructive and Destructive Processes. New Haven, CT: Yale University Press.

Donaldson, L. (1990). A rational basis for criticisms of organizational economics: A reply to Barney. Academy of Management Review, 15(3), 394-401.

Duignan, P. (1990). School-based decision making and management: Retrospect and prospect. In J. Chapman (Ed.), School-Based Decision Making and Management. London: Falmer.

Duke, D. L., \& Gansneder, B. (1990). Teacher empowerment: The view from the classroom. Educational Policy, 4(2), 145-156.

Duke, D. L., Showers, B. K., \& Imber, M. (1980). Teachers and shared decision making: The costs and benefits of involvement. Educational Administration Quarterly, 16(1), 93-106.

Durham, C. C., Knight, D., \& Locke, E. A. (1997). Effects of leader role, team-set goal difficulty, efficacy, and tactics on team effectiveness. Organizational Behavior and Human Decision Process, 72, 203-231.

Eberlin, R. J., \& Tatum, B. C. (2008). Making just decisions: Organizational justice, decision making, and leadership. Management Decision, 46(2), 310-329.

Estler, S. E. (1988). Decision making. In N. J. Boyan (Ed.), Handbook of research on educational administration (305-319). New York: Longman.

Evans, L. (1998). Teacher morale, job satisfaction, and motivation. Thousand Oaks, CA: SAGE.

Fan, X. \& Konold, T.R. (2010). Statistical significance versus effect size. In: Peterson, P., Baker, E., \& McGaw, B. (Eds.) International Encyclopedia of Education, 7, 444450.

Fenstermacher, G.D. (1979). A philosophical consideration of recent research on teacher effectiveness. In L. S. Shulman (Ed.), Review of Research in Education (vol. 6, 157-185). Itaska, Illinois: F.E. Peacock. 
Ferrara, D. L., \& Repa, J. T. (1993). Measuring shared decision making. Educational Leadership, 51(2), 71.

Ferrin, D. L., Bligh, M. C., \& Kohles, J. C. (2008). It Takes Two to Tango: An Interdependence Analysis of the Spiraling of Perceived Trustworthiness and Cooperation in Interpersonal and Intergroup Relationships. Organizational Behavior and Human Decision Processes, 107, 161-178.

Ferris, J. M. (1992). School-based decision making: A principal-agent perspective. Educational Evaluation and Policy Analysis, 14(4), 333-346.

Fiedler, F. E. (1989). The effective utilization of intellectual abilities and job-relevant knowledge in group performance: Cognitive resource theory and an agenda for the future. Applied Psychology: An International Review, 38, 289-304.

Fiedler, F. E. (1995). Cognitive resources and leadership performance. Applied Psychology: An International Review, 44, 5-28.

Fullan, M. (2003). The moral imperative of school leadership. Thousand Oaks, CA: Corwin Press.

Gamage, D., Sipple, P. and Partridge, P. (1996). Research on school-based management in Victoria. Journal of Educational Administration, 34(1), 24-40.

Gibson, S., \& Dembo, M. H. (1984). Teacher efficacy: A construct validation. Journal of Educational Psychology, 76(4), 569-582.

Gigante, N. A., \& Firestone, W. A. (2008). Administrative support and teacher leadership in schools implementing reform. Journal of Educational Administration, 46(3), 302-331.

Goddard, R. D. (2001). Collective efficacy: A neglected construct in the study of schools and student achievement. Journal of Educational Psychology. 93(3), 467-476.

Goddard, R. D. (2002). A theoretical and empirical analysis of the measurement of collective efficacy: The development of a short form. Educational and Psychological Measurement, 62(1), 97-110.

Goddard, R. D., Hoy, W. K., \& Hoy, A. W. (2000). Collective teacher efficacy: Its meaning, measure, and impact on student achievement. American Educational Research Journal, 37(2), 479-507.

Goldstein, J. (2004). Making sense of distributed leadership: The case of peer assistance and review. Educational Evaluation and Policy Analysis, 26(2), 173-197. 
Gorton, R., \& Alston, J. A. (2012). School leadership and administration: Important concepts, case studies, and simulations, (9th ed.). New York: McGraw-Hill.

Graen, G., \& Cashman, J. (1975). A role making model of leadership in formal organizations: A developmental approach. In J. G. Hunt \& L. L. Larson (Eds.), Leadership frontiers (143-165). Kent, OH: Kent State University Press.

Graen, G., Novak, M., \& Sommerkamp, P. (1982). The effects of leader-member exchange and job design on productivity and satisfaction: Testing a dual attachment model. Organizational Behavior and Human Performance, 30, 109131.

Hackman, J. R. (2005). Rethinking team leadership or teams leaders are not music directors. In D. M. Messick \& R. M. Kramer (eds.), The Psychology of Leadership: New Perspectives and Leadership (115-142). Mahwah, NJ: Lawrence Erlbaum.

Hackman, J. R., \& Oldham, G. R. (1980). Work redesign. Reading, MA: AddisonWesley.

Hallinger, P. (2011). Leadership for learning: Lessons from 40 years of empirical research. Journal of Educational Administration, 49(2), 125-142.

Heck, R. H., Hallinger, P. (2010). Testing a longitudinal model of distributed leadership effects on school improvement. The Leadership Quarterly, 21, 867-885.

Herriott, R.E., \& Firestone, W.A. (1984). Two images of schools as organizations: A refinement and elaboration. Educational Administration Quarterly, 20(4) 41-57.

Hoy, W. K., \& Miskel, C. G. (1996). Educational administration: Theory, research, and practice (5th ed.). New York: McGraw-Hill.

Hoy, W. K., \& Sweetland, S. R. (2000). School characteristics and educational outcomes: Toward an organizational model of student achievement in middle schools. Educational Administration Quarterly, 36(5), 703-729.

Hulpia, H., Devos, G., \& Van Keer, H. (2011). The relation between school leadership from a distributed perspective and teachers' organizational commitment: Examining the source of the leadership function. Educational Administration Quarterly, 47(5) 728-771.

Jackson, K. M., \& Marriott, C. (2012). The interaction of principal and teacher instructional influence as a measure of leadership as an organizational quality. Educational Administration Quarterly, 48(2), 230-258. 
Kozlowski, S. W. J., \& Ilgen, D. R. (2006) Enhancing the effectiveness of work groups and teams. Psychological Science in the Public Interest, 7(3), 77-124.

Latham, G. P., Winters, D. C., \& Locke, E. A. (1994). Cognitive and motivational effects of participation: a mediator study. Journal of Organizational Behavior, 15, 49-63.

Leech, W. L. (1999). Faculty perceptions of shared decision making and the principal's leadership behaviors in Duval County secondary schools. (Doctoral Dissertation). Retrieved from UNF Digital Commons. (http://digitalcommons.unf.edu/etd/253).

Leithwood, K., \& Mascall, B. (2008). Collective leadership effects on student achievement. Education Administration Quarterly, 44(4), 529-561.

Lester, P.E., \& Bishop, L.K. (Eds.) (2000). Handbook of tests and measurements in education and the social sciences (2nd ed.). Lanham: Scarecrow Press.

Lewicki, R. J., \& Bunker, B. B. (1996). Developing and maintaining trust in work relationships. In R. Kramer \& T. Tyler (Eds.), Trust in organizations (114-139). Thousand Oaks, CA: Sage.

Lewis, J. D., \& Weigert, A. (1985). Trust as a social reality. Social Forces, 63(4), $967-$ 985.

Locke, E. A., \& Schweiger, D. M. (1979). Participation in decision-making: One more look. In B. M. Staw (Ed.), New directions in organizational behavior, (265-339). Greenwich, CT: JAI Press.

Luhmann, N. (1979), Trust and Power. New York: John Wiley.

Lumpkin, G. T., \& Lichtenstein, B. B. (2005). The role of organizational learning in the opportunity-recognition process. Entrepreneurship Theory and Practice, 29(4), 451-472.

Kerr, N. L., \& Tindale, R. S. (2004). Group performance and decision making. Annual Review of Psychology, 55, 623-655.

Klimoski, R. J., \& Donahue, L. M. (2001). Person perception in organizations: An overview of the field. In M. London (Ed.), How people evaluate others in organizations, (5-44). Mahwah, NJ: Lawrence Erlbaum.

Kouzes, J. M., \& Posner, B. Z. (2002). The Leadership Challenge. San Francisco: JosseyBass.

Marks, H. M., \& Louis, K. S. (1997). Does teacher empowerment affect the classroom? The implications of teacher empowerment for instructional practice and student 
academic performance. Educational Evaluation and Policy Analysis, 19(3), 245275.

Marks, H. M., \& Louis, K. S. (1999). Teacher empowerment and the capacity for organizational learning. Educational Administration Quarterly, 35(5), 707-750.

Marks, H. M., \& Printy, S. M. (2003). Principal leadership and school performance: An integration of transformational and instructional leadership. Educational Administration Quarterly, 39, 370-397.

Margulies, N., \& Black, S. (1987). Perspectives on the implementation of participative approaches. Human Resource Management, 26(3), 385-412.

Messick, D. M. (2005). On the psychological exchange between leaders and followers. In D. M. Messick \& R. M. Kramer (Eds.), The psychology of leadership: New perspectives and research (81-96). Mahwah, NJ: Lawrence Erlbaum.

Miles, J. \& Shevlin, M. (2001). Applying correlation \& regression: A guide for students and researchers. Thousand Oaks: SAGE.

Mishra, A. K. (1996). Organizational responses to crisis: The centrality of trust. In R. Kramer \& T. Tyler (Eds.), Trust in organizations (261-287). Thousand Oaks, CA: Sage.

Mohrman, A. M., Cooke, R. A., \& Mohrman, S. A. (1978). Participation in decision making: A multidimensional perspective. Educational Administration Quarterly, 14(1), 13-29.

Mohrman, S. A., Lawler, E. E., \& Mohrman, A. M. (1992). Applying employee involvement in schools. Education Evaluation and Policy Analysis, 14, 347-360.

Moorman, C., Zaltman, G., \& Deshpande, R. (1992). Relationships between providers and users of market research: The dynamics of trust within and between organizations. Journal of Marketing Research, 29, 314-328.

Muijs, D., \& Harris, A. (2006). Teacher led school improvement: Teacher leadership in the UK. Teacher and Teacher Education, 22, 961-972.

Murphy, S. E., \& Fiedler, F. E. (1992). Cognitive resource theory and utilization of the leader's and group member's technical competence. Leadership Quarterly, 3, 237-255.

Nanus, B. (1989). The leader's edge: The seven keys to leadership in a turbulent world. Chicago: Contemporary. 
Newcombe, G., \& McCormick, J. (2001). Trust and teacher preparation in school-based financial decision making. Educational Management and Administration, 29(2), 181-195.

Peterson, R. S., \& Behfar, K. J. (2005). Leadership as group regulation. In D. M. Messick \& R. M. Kramer (Eds.), The psychology of leadership: New perspectives and research, (143-162). Mahwah, NJ: Lawrence Erlbaum.

Pounder, D. G. (1998). Restructuring schools for collaboration: Promises and pitfalls. Albany: State University of New York Press.

Powell, W. W. (1990). Neither market nor hierarchy: Network forms of organization. In B. M. Staw \& L. L. Cummings (Eds.), Research in Organizational Behavior, 12, 295-336.

Printy, S. (2010). How principals influence instructional practice: Leadership levers. In W. K. Hoy \& M. DiPaola (Eds.), Analyzing school contexts: Influences of principals and teachers in the service of students, (71-101). Charlotte, NC: Information Age.

Printy, S. M., Marks, H. M., \& Bowers, A. J. (2009). Integrated leadership: How principals and teachers share transformational and instructional influence. Journal of School Leadership, 19, 504-532.

Rice, E. M., \& Schneider G. T. (1994). A decade of teacher empowerment: An empirical analysis of teacher involvement in decision making, 1980-1991. Journal of Educational Administration, 32(1), 43-58.

Rosenblatt, Z. \& Somech, A. (1998). The work behavior of Israeli elementary school principals' expectations versus reality. Educational Administration Quarterly, 34(4), 505-532.

Russell, J. J. (1992). Theory into practice: The realities of shared decision making. (Doctoral Dissertation). Fordham University.

Sagie, A., Zaidman, N., Amichai-Hamburger, Y., Te'eni, D., \& Schwartz, D. G. (2002). An empirical assessment of the loose-tight leadership model: Quantitative and qualitative analyses. Journal of Organizational Behavior, 23, 303-320.

Saunders, C., \& Miranda, S. (1998). Information acquisition in group decision making. Information and Management, 34, 55-74.

Sass, D. A., Seal, A. K., \& Martin, N. K. (2010). Predicting teacher retention using stress and support variables. Journal of Educational Administration, 49(2), 200-215. 
Schwarber, P. D. (2005). Leaders and the decision-making process. Management Decision, 43(7), 1086 - 1092.

Serva, M. A., Fuller, M. A., \& Mayer, R. C. (2005). The reciprocal nature of trust: A longitudinal study of interacting teams. Journal of Organizational Behavior, 26, $625-648$.

Smylie, M. A. (1992). Teacher participation in school decision making: Assessing willingness to participate. Educational Evaluation and Policy Analysis, 14(1), 5367.

Smylie, M. A. (2010). Continuous school improvement. Thousand Oaks, CA: Corwin.

Solomon, R. C., \& Flores, F. (2001). Building trust in business, politics, relationships, and life. New York: Oxford University Press.

Somech, A. (2002). Explicating the complexity of participative management: An investigation of multiple dimensions. Educational Administration Quarterly, 38(3), 341-371.

Somech, A. (2010). Participative decision making in schools: A mediating-moderating analytical framework for understanding school and teacher outcomes.

Educational Administration Quarterly, 46(2), 174-209.

Somech, A. \& Drach-Zahavy, A. (2000). Understanding extra-role behavior in schools: The relationships between job satisfaction, sense of efficacy, and teachers' extrarole behavior. Teaching and Teacher Education, 16, 649-659.

Somech, A., \& Wenderow, M. (2006). The impact of participative and directive leadership on teachers' performance: The intervening effects of job structuring, decision-domain, and leader-member exchange. Educational Administration Quarterly, 42(5), 746-772.

Streck, M. T. (2009). Distributed leadership and shared decision making: leadership practices that promote collaboration. (Doctoral Research Project). The Sage Colleges.

Sue-Chan, C., Au, A. K. C., \& Hackett, R. D. (2012). Trust as a mediator of the relationship between leader/member behavior and leader-member-exchange quality. Journal of World Business, 47, 459-468.

Taylor, D. L., \& Bogotch, I. E. (1994). School-level effects of teachers' participation in decision making. Educational Evaluation and Policy Analysis, 16(3), 302-319.

Taylor, D. L. \& Tashakkori, A. (1997). Toward an understanding of teachers' desire for participation in decision making. Journal of School Leadership, 7, 609-628. 
The Goals 2000: Educate America Act, Pub. L. 103-227, 103d Cong., 2nd Sess. (1994).

The No Child Left Behind Act of 2001, Pub. L. 107-110, 107th Cong., 1st Sess. (2002).

Tschannen-Moran, M. (2001). Collaboration and the need for trust. Journal of Educational Administration, 39(4), 308-331.

Tschannen-Moran, M. (2004). Trust matters. San Francisco, CA: Jossey-Bass.

Tschannen-Moran, M., \& Hoy, A. W. (2007). The differential antecedents of selfefficacy beliefs of novice and experienced teachers. Teaching and Teacher Education, 23, 944-956.

Tschannen-Moran, M., Hoy, A. W., \& Hoy, W. K. (1998). Teacher efficacy: Its meaning and measure. Review of Educational Research, 68(2), 202-248.

Tyack, D., \& Cuban, L. (1995). Tinkering toward utopia: A century of public school reform. Cambridge, MA: Harvard University Press.

Viadero, D. (2006). Race report's influence felt 40 years later. Education Week, 25(41), $1-24$.

Vroom, V. H., \& Jago, A. G. (1998). Situation effects and levels of analysis in the study of leader participation. In F. Dansereau \& F. J. Yammarino (Eds.), Leadership: The multiple level approaches (145-159). London: JAI.

Wahlstrom, K. L., \& Louis, K. S. (2008). How teachers experience principal leadership: The roles of professional community, trust, efficacy, and shared responsibility. Educational Administration Quarterly, 44(4), 458-495.

Walker, K., Kutsyuruba, B., \& Noonan, B. (2011). The fragility of trust in the world of school principals. Journal of Educational Administration, 49(5), 471-494.

Wayne, S. J., Shore, L. M., Bommer, W. H., \& Tetrick, L. E. (2002). The role of fair treatment and rewards in perceptions of organizational support and leadermember exchange. Journal of Applied Psychology, 87, 590-598.

Weiner, J. M. (2011). Finding common ground: Teacher leaders and principals speak out about teacher leadership. Journal of School Leadership, 21, 7-41.

Whitaker, T., Whitaker, B., \& Lumpa, D. (2009). Motivating and inspiring teachers: The educational leaders' guide for building staff morale (2nd ed.). Larchmont, NY: Eye on Education.

Yukl, G., \& Fu, P. P. (1999). Determinants of delegation and consultation by managers. Journal of Organizational Behavior, 20, 219-232. 
Yukl, G. A. (2002). Leadership in organizations (5th ed.). Upper Saddle River, NJ: Prentice Hall.

Zand, D. E. (1997). The leadership triad: Knowledge, trust, and power. New York: Oxford University Press. 


\section{Appendix A}

\section{Principal Survey}

Thank you for your participation in this survey. Please answer the following questions honestly. Your participation is anonymous.

How many total years of experience do you have as a principal at your current school?

How many total students are enrolled at your school?

Please indicate your level of agreement with each of the following statements about your school from strongly disagree to strongly agree.

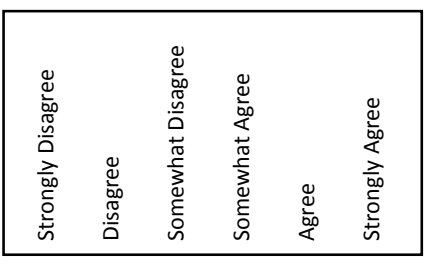

Teachers in the school are able to get through to the most difficult

$$
\begin{array}{llllll}
1 & 2 & 3 & 4 & 5 & 6
\end{array}
$$
students.

Teachers here are confident they will be able to motivate their students. $\quad \begin{array}{llllll}1 & 2 & 3 & 4 & 5 & 6\end{array}$

If a child doesn't want to learn teachers here give up.

$\begin{array}{llllll}1 & 2 & 3 & 4 & 5 & 6\end{array}$

Teachers here don't have the skills needed to produce meaningful $\begin{array}{llllll}1 & 2 & 3 & 4 & 5 & 6\end{array}$ student learning.

Teachers in this school believe that every child can learn.

These students come to school ready to learn.

Home life provides so many advantages that students here are bound

$\begin{array}{llllll}1 & 2 & 3 & 4 & 5 & 6\end{array}$

$\begin{array}{llllll}1 & 2 & 3 & 4 & 5 & 6\end{array}$

$\begin{array}{llllll}1 & 2 & 3 & 4 & 5 & 6\end{array}$ to learn.

Students here just aren't motivated to learn.

$\begin{array}{llllll}1 & 2 & 3 & 4 & 5 & 6\end{array}$

Teachers in this school do not have the skills to deal with student

$\begin{array}{llllll}1 & 2 & 3 & 4 & 5 & 6\end{array}$ disciplinary problems. 
The opportunities in this community help ensure that these students will learn.

Learning is more difficult at this school because students are worried about their safety.

Drug and alcohol abuse in the community make learning difficult for students here. $\begin{array}{llllll}1 & 2 & 3 & 4 & 5 & 6\end{array}$

$\begin{array}{llllll}1 & 2 & 3 & 4 & 5 & 6\end{array}$

$\begin{array}{llllll}1 & 2 & 3 & 4 & 5 & 6\end{array}$

$\begin{array}{llllll}1 & 2 & 3 & 4 & 5 & 6\end{array}$ 


\title{
Appendix B
}

\section{Teacher Survey}

Thank you for your participation in the survey. Please answer the following questions honestly. Your participation is anonymous. This instrument is designed to measure the extent to which you perceive your principal provides the teachers at your school with opportunities for involvement in decision making. It is not meant to measure your actual involvement or influence in decision making.

How many total years of experience do you have as a teacher at your current school?

\begin{abstract}
Please read each statement carefully. A $\underline{5}$ represents "Almost Always," a $\underline{4}$ represents "Frequently," a $\underline{3}$ represents "Sometimes," a $\underline{2}$ represents "Seldom," and a $\underline{1}$ represents "Almost Never." Circle the number that best indicates the degree to which you perceive that in this past school year your principal provided teachers at your school with opportunities to:
\end{abstract}

\section{Goals/Vision/Mission}

Share a vision for the school

Participate in the goal setting process for the school

Establish school priorities

Contribute to the development of a plan to meet the school's goals

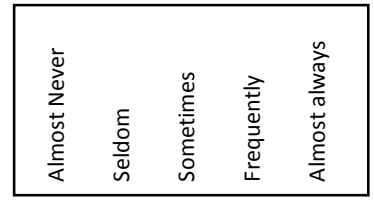

$\begin{array}{lllll}1 & 2 & 3 & 4 & 5 \\ 1 & 2 & 3 & 4 & 5 \\ 1 & 2 & 3 & 4 & 5 \\ 1 & 2 & 3 & 4 & 5\end{array}$




\section{Standards}

Work together to set their own work standards

$\begin{array}{lllll}1 & 2 & 3 & 4 & 5\end{array}$

Contribute to the standards set for discipline in the school

$\begin{array}{lllll}1 & 2 & 3 & 4 & 5\end{array}$

Set standards for their students' work

$\begin{array}{lllll}1 & 2 & 3 & 4 & 5\end{array}$

Set standards for student promotion and/or retention

$\begin{array}{lllll}1 & 2 & 3 & 4 & 5\end{array}$

\section{Curriculum/Instruction}

Adjust the school's curriculum

$\begin{array}{lllll}1 & 2 & 3 & 4 & 5\end{array}$

Determine the pace for instruction for students

$\begin{array}{lllll}1 & 2 & 3 & 4 & 5\end{array}$

Initiate changes in the curriculum

$\begin{array}{lllll}1 & 2 & 3 & 4 & 5\end{array}$

Participate in the selection of textbooks

$\begin{array}{lllll}1 & 2 & 3 & 4 & 5\end{array}$

Participate in district-wide committees to coordinate curricula

$\begin{array}{lllll}1 & 2 & 3 & 4 & 5\end{array}$

Participate in curricula development

$\begin{array}{lllll}1 & 2 & 3 & 4 & 5\end{array}$

Determine grouping for the purpose of instruction

$\begin{array}{lllll}1 & 2 & 3 & 4 & 5\end{array}$

\section{Budget}

Contribute to the development of the school budget

Decide how they will spend their allotted funds

$\begin{array}{lllll}1 & 2 & 3 & 4 & 5\end{array}$

Manage their own budgets

$\begin{array}{lllll}1 & 2 & 3 & 4 & 5\end{array}$

Establish priorities when the school budget has to be cut

$\begin{array}{lllll}1 & 2 & 3 & 4 & 5\end{array}$

$\begin{array}{lllll}1 & 2 & 3 & 4 & 5\end{array}$

\section{Staffing}

Have a voice in the recruiting and selecting of teachers

$\begin{array}{lllll}1 & 2 & 3 & 4 & 5\end{array}$

Help decide teaching assignments of staff members

$\begin{array}{lllll}1 & 2 & 3 & 4 & 5\end{array}$

Take part in staffing decisions including such trade-offs as using instructional

$\begin{array}{lllll}1 & 2 & 3 & 4 & 5\end{array}$ aids or hiring vice-principals, counselors, and other special area staff

Participate in the recruiting and selecting of administrators

$\begin{array}{lllll}1 & 2 & 3 & 4 & 5\end{array}$




\section{Operations}

Develop the schedule for the school

Determine how the school building is utilized

Develop plans to improve building facilities

Determine how the school's technology is utilized

Develop plans to improve building technology

\section{Staff Development}

Review current research on effective programs and practices

Determine the staff development that they will receive

Share their expert knowledge

Participate in staff development activities $\begin{array}{lllll}1 & 2 & 3 & 4 & 5\end{array}$

$\begin{array}{lllll}1 & 2 & 3 & 4 & 5\end{array}$

$\begin{array}{lllll}1 & 2 & 3 & 4 & 5\end{array}$

$\begin{array}{lllll}1 & 2 & 3 & 4 & 5\end{array}$

$\begin{array}{lllll}1 & 2 & 3 & 4 & 5\end{array}$

$\begin{array}{lllll}1 & 2 & 3 & 4 & 5 \\ 1 & 2 & 3 & 4 & 5 \\ 1 & 2 & 3 & 4 & 5 \\ 1 & 2 & 3 & 4 & 5\end{array}$


Appendix C

UVa IRB Approval Letter

May 21, 2013

Ilon Weeldreyer and James Esposito

Leadership, Foundations \& Policy

2021 Ivy Rd., Apt. B9

Charlottesville, VA 22903

Dear llon Weeldreyer and James Esposito:

Thank you for submitting your project entitled: "Principals' Collective Efficacy Beliefs and Teachers' Perceived Opportunities for Involvement in Decision Making" for review by the Institutional Review Board for the Social \& Behavioral Sciences. The Board reviewed your Protocol on May 21, 2013.

The first action that the Board takes with a new project is to decide whether the project is exempt from a more detailed review by the Board because the project may fall into one of the categories of research described as "exempt" in the Code of Federal Regulations. Since the Board, and not individual researchers, is authorized to classify a project as exempt, we requested that you submit the materials describing your project so that we could make this initial decision.

As a result of this request, we have reviewed your project and classified it as exempt from further review by the Board for a period of four years. This means that you may conduct the study as planned and you are not required to submit requests for continuation until the end of the fourth year.

This project \# 2013-0198-00 has been exempted for the period May 21, 2013 to May 20, 2017. If the study continues beyond the approval period, you will need to submit a continuation request to the Board. If you make changes in the study, you will need to notify the Board of the changes.

Sincerely,

Tonya R. Moon, Ph.D.

Chair, Institutional Review Board for the Social and Behavioral Sciences 


\begin{abstract}
Appendix D
Cover Letter for Superintendents

Survey Introduction/Recruitment for Superintendent \& District Administrators
\end{abstract}

\title{
Dear XXXXXXXXXX,
}

A doctoral candidate at the University of Virginia would like to conduct research at XXXXXXXXXX elementary schools. The study focuses on principals' collective efficacy beliefs and teachers' perceived opportunities for involvement in decision making.

The principal who was on staff for the 2012-2013 school year will be asked to participate. The principal survey takes approximately 2 to 3 minutes to complete. Teachers who were on staff for the 2012-2013 school year will be asked to participate. The teacher survey takes approximately 4 to 5 minutes to complete. Participation is voluntary. Responses will be stripped of any identifiers, making them anonymous.

There are no risks or benefits associated with this survey for anyone who participates; however, the researcher will provide a copy of the findings of the study. All information contained therein is aggregated. No individual information will be reported.

Please feel free to contact the researcher with any questions at (540) 421-5418 or by e-mail at ibw2t@virginia.edu.

If you have questions about your rights in the study, contact:

Tonya R. Moon, Ph.D.

Chair, Institutional Review Board for the Social and Behavioral Sciences

One Morton Dr Suite 500

University of Virginia, P.O. Box 800392

Charlottesville, VA 22908-0392

Telephone: (434) 924-5999

Email: irbsbshelp@virginia.edu

Website: www.virginia.edu/vpr/irb/sbs

Please use IRB-SBS number 2013-0198-00 in correspondence.

Your consideration for participation in this study is greatly appreciated.

Thank you,

Ilon Weeldreyer

Doctoral Candidate

University of Virginia 


\author{
Appendix E \\ Cover Letter for Principals \\ Survey Introduction and Instructions for Principals
}

\title{
Dear XXXXXXXXXX,
}

A doctoral candidate at the University of Virginia is conducting research at XXXXXXXXXX schools. The study focuses on principals' collective efficacy beliefs and teachers' perceived opportunities for involvement in decision making.

The principal who was on staff for the 2012-2013 school year will be asked to participate. Only the principal who was on staff at the school during that year should participate.

Your participation is voluntary. Responses will be stripped of any identifiers, making them anonymous. The survey takes approximately 2 to 3 minutes to complete.

There are no risks or benefits associated with this survey for anyone who participates; however, the researcher will provide a copy of the findings of the study. All information contained therein is aggregated. No individual information will be reported.

A completed survey constitutes consent.

Please follow the instructions included via e-mail to complete the survey. Your participation in this study is greatly appreciated.

If you have questions about your rights in the study, contact:

Tonya R. Moon, Ph.D.

Chair, Institutional Review Board for the Social and Behavioral Sciences

One Morton Dr Suite 500

University of Virginia, P.O. Box 800392

Charlottesville, VA 22908-0392

Telephone: (434) 924-5999

Email: irbsbshelp@virginia.edu

Website: www.virginia.edu/vpr/irb/sbs

Please use IRB-SBS number 2013-0198-00 in correspondence.

Thank you,

Ilon Weeldreyer

Doctoral Candidate

University of Virginia 